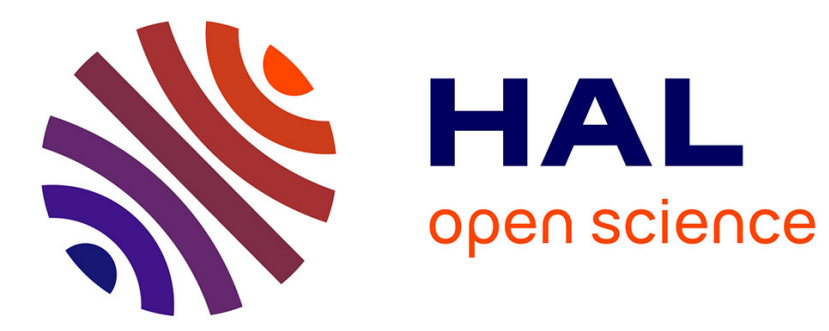

\title{
The Effect of Antimalarial Campaigns on Child Mortality and Fertility in Sub-Saharan Africa
}

Joshua Wilde, Bénédicte Apouey, Joseph Coleman, Gabriel Picone

\section{To cite this version:}

Joshua Wilde, Bénédicte Apouey, Joseph Coleman, Gabriel Picone. The Effect of Antimalarial Campaigns on Child Mortality and Fertility in Sub-Saharan Africa. 2019. halshs-02285933

\section{HAL Id: halshs-02285933 \\ https://shs.hal.science/halshs-02285933}

Preprint submitted on 13 Sep 2019

HAL is a multi-disciplinary open access archive for the deposit and dissemination of scientific research documents, whether they are published or not. The documents may come from teaching and research institutions in France or abroad, or from public or private research centers.
L'archive ouverte pluridisciplinaire HAL, est destinée au dépôt et à la diffusion de documents scientifiques de niveau recherche, publiés ou non, émanant des établissements d'enseignement et de recherche français ou étrangers, des laboratoires publics ou privés. 


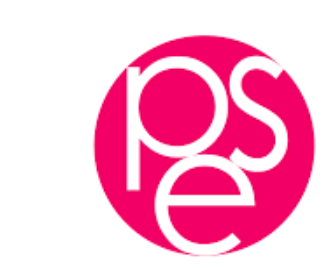

PARISSCHOOLOFECONOMICS
ECOLED'ECONOMIEDE PARIS

WORKING PAPER N 2019 - 49

The Effect of Antimalarial Campaigns on Child Mortality and Fertility in Sub-Saharan Africa

Joshua Wilde

Bénédicte Apouey

Joseph Coleman

Gabriel Picone

JEL Codes: I15, J13, 010, 015

Keywords: Malaria, Bed nets, Child mortality, Fertility, Sub-Saharan Africa 


\title{
The Effect of Antimalarial Campaigns on Child Mortality and Fertility in Sub-Saharan Africa
}

\author{
Joshua Wilde \\ Bénédicte Apouey \\ Joseph Coleman \\ Gabriel Picone *
}

September 9, 2019

*Joshua Wilde: Corresponding Author. Max Planck Institute for Demographic Research. Konrad-Zuse-Straße 1, 18057 Rostock, Germany. E-mail: wilde@demogr.mpg.de. Bénédicte Apouey: Paris School of Economics - CNRS. 48, Boulevard Jourdan, 75014 Paris, France. E-mail: benedicte.apouey@psemail.eu. Joseph Coleman: University of South Florida. 4202 E. Fowler Ave. CMC 342, Tampa, FL 33620, USA. E-mail: jscoleman@mail.usf.edu. Gabriel Picone: University of South Florida. 4202 E. Fowler Ave. CMC 342, Tampa, FL 33620, USA. E-mail: gpicone@usf.edu. The authors thank Martine Audibert, David Canning, Denis Cogneau, Pascaline Dupas, Andrew Foster, Marlène Guillon, Allan Hill, Patricia Jones, Maria Kuecken, Giulia La Mattina, David Lam, T. Paul Schultz, Josselin Thuilliez, Marie-Anne Valfort, David Weil, and participants at the CSAE 2014 conference, the 2014 "Journées de Microéconomie Appliquée," the 2014 PopPov Research Network conference, the 2014 Congress of the European Economic Association, the 2017 PAA annual meeting, the 2017 IUSSP International Population Conference, WATE 2018, the Third Annual Population Health Science Research Workshop 2018, as well as seminar participants at the University of South Florida, the University of North Dakota, and the Max Planck Institute for Demographic Research for helpful comments and encouragement. The authors are also grateful to Stacey Gelsheimer, Robyn Kibler, and Arseniy Yashkin for their research assistance. The authors thank the support of Grant Number R03TW009108 from the Fogarty International Center. The content is solely the responsibility of the authors and does not necessarily represent the official views of the Fogarty International Center or the National Institute of Health. 


\begin{abstract}
We examine the extent to which recent declines in child mortality and fertility in SubSaharan Africa can be attributed to insecticide-treated bed nets (ITNs). Exploiting the rapid increase in ITNs since the mid-2000s, we employ a difference-in-differences estimation strategy to identify the causal effect of ITNs on mortality and fertility. We show that the ITN distribution campaigns reduced all-cause child mortality, but surprisingly increased total fertility rates in the short run in spite of reduced desire for children and increased contraceptive use. We explain this paradox in two ways. First, we show evidence for an unexpected increase in fecundity and sexual activity due to the better health environment after the ITN distribution. Second, we show evidence that the effect on fertility is positive only temporarily - lasting only 1-3 years after the beginning of the ITN distribution programs - and then becomes negative. Taken together, these results suggest the ITN distribution campaigns may have caused fertility to increase unexpectedly and temporarily, or that these increases may just be a tempo effect - changes in fertility timing which do not lead to increased completed fertility.
\end{abstract}

Keywords: Malaria, Bed nets, Child mortality, Fertility, Sub-Saharan Africa.

JEL codes: I15, J13, O10, O15. 


\section{Introduction}

Understanding the complex relationship between child mortality and fertility has been a major subject of investigation within the social sciences for at least the last century. However, even after decades of study, there is still debate over both the theoretical and empirical relationships between these two variables, and the relative importance of the various mechanisms which link them. Theoretically, child mortality and fertility should be negatively related: reductions in child mortality should not only reduce the demand for replacement children, but also reduce the demand for precautionary childbearing, implying a more than one-for-one reduction in fertility. As a result, many believe that reducing child mortality will lead to smaller populations. Others go one step further, believing that reducing child mortality is actually a necessary condition for population slowing. For example, Hans Rosling of the Gapminder Foundation claimed in his 2010 Ted Talk that "It's only by [improving] child survival that we will stop population growth" (Rosling, 2010). In addition, the Gates Foundation listed "Saving lives leads to over-population" - with an emphasis on child survival - as one of the three main myths that block progress for the poor in their 2014 annual letter (Gates Foundation, 2014). With the advent of the Millennium Development Goals in 2000, there has been a massive increase in funding and support for programs to reduce infant and child mortality in the developing world.

However, if the improvements to the health environment which cause the reductions in mortality also affect the costs and benefits of childbearing, the relationship between child mortality and fertility becomes less clear. For example, such a cost reduction from a better health environment should lead women to choose higher fertility (Barro and Becker, 1989; Doepke 2005, 2015). Improvements in health may also increase fecundity directly, or influence women to modify the timing of their births to correspond with the improved health environment. All of these mechanisms could lead to increases in fertility when child mortality falls. If so, health interventions to reduce child mortality may not reduce population sizes, but rather increase them, necessitating additional investments in health and education to meet the needs of these larger cohorts.

In this paper, we contribute to the empirical literature on the linkages between child mortality, health interventions to reduce child mortality, and fertility by analyzing the effect of an international health program intended to reduce child mortality - but not fertility - on fertility itself. Specifically, we identify the causal effect of the large and rapid increase in the distribution of insecticide-treated bed nets (ITNs) in sub-Saharan Africa in the 2000s on child mortality and fertility rates. To overcome identification concerns, we employ multiple discrete and continuous difference-in-differences estimation methodologies, some of which exploit differences in pre-intervention malaria prevalence rates and the timing of the ITN roll-out at the regional level, while others include variation in the intensity of the ITN distribution campaigns. Our models are estimated using a unique data set that merges information on child mortality and fertility outcomes from the Demographic and Health Surveys (DHS) with a panel of malaria prevalence and antimalarial interventions from the Malaria Atlas Project (MAP) for 35 sub-Saharan countries between 2000 and 2014. 
We find that the introduction of ITNs significantly reduces child mortality for children under three years of age. For older children, the effect is still significant in magnitude, but statistically insignificant. Specifically, for the mean region in our sample we find a 23.4 percent reduction in mortality for children aged 13-24 months, and a 47.3 percent reduction in mortality for children aged 25-36 months as a result of the ITN distribution campaigns. We find a statistically insignificant 4.7 percent reduction in infant (0-12 months of age) mortality, which is consistent with the biological literature showing that in addition to receiving malaria antibodies from their mothers through breastmilk, all children within the first six months of life retain partial malarial immunity gained in utero from their mothers. However, this result masks significant heterogeneity by socioeconomic status: infant mortality among children born to women who did not complete primary eduction fell by a statistically significant 10.7 percent as a result of the ITN distribution, while mortality for children of women with a primary education did not fall. Taken together, our results imply that the average cumulative probability of death before age five fell by 11.5 percent as a result of the ITN intervention. Comparing this with an overall decrease in child mortality of 47.4 percent between 2000-2015 (World Bank, 2019), our results imply that about onefourth of the decline in child mortality in sub-Saharan Africa over this period was due to the ITN distribution campaigns.

We also find that the effect of the ITN distribution on fertility is positive for all age groups. Specifically, we find that the distribution of ITNs in the average region increased the annual probability of having a child by between 11 and 15 percent for women below the age of 39 , and by 31.8 percent for women 40-44. However, this result also masks significant heterogeneity in the effect of the ITN distribution campaign by socioeconomic status: the effects are highly concentrated among women with at least a primary education, with no statistically significant positive effect for women without a primary education except for those over the age of 40. Overall, our estimates imply that the ITN campaigns raised the total fertility rate by 0.71 children in the overall sample (an increase of 13.8 percent), but by 0.99 and 0.34 children for the educated and uneducated respectively. However, when we add a dynamic component to our model, we find that this large positive effect only lasts for 1-3 years before turning negative, implying that these results should only be interpreted as immediate, short-run fertility effects, which may not lead to increases in completed lifetime fertility.

This paper also contains two online appendices. Appendix A details a theoretical model that outlines under which conditions an improvement in the health and mortality environment will cause individuals to increase their fertility rates, and serves as the conceptual framework for our empirical results. In Appendix B, we provide additional robustness checks, evidence on the mechanisms behind the results presented in the main text, and further discussion. We analyze the effect of the distribution campaigns on all of the proximate determinants of fertility proposed by Bongaarts (1978) for which we have data, along with the effect on birth intervals, desires for additional children, and heterogeneity of the mortality effects by gender. We find that while women reported wanting fewer children and 
increased their contraceptive usage after the intervention, the extensive margin of sexual activity rose as well. In addition, indicators of health related to fecundity also improved. This suggests that women may have wanted less children, but unexpectedly had more since they were more sexually active and more fertile. We further explore the possibility by hypothesizing two mechanisms by which women may have been unable to perfectly control their fertility: low levels of empowerment and an unmet need for contraception. Our results suggest the opposite - women with less decision making power or an unmet need for contraception actually experienced smaller increases in fertility.

Our paper is related to the literature on malaria eradication and human capital outcomes generally. Barreca (2010) estimates the effect of malaria eradication in the United States, and finds that in utero exposure to malaria leads to lower levels of educational attainment. Bleakley (2010) studies the same eradication campaign in the United States as Barreca, and finds a positive effect on labor productivity later in life. Lucas (2010) identifies the effect of malaria eradication in Sri Lanka and Paraguay on years of schooling and literacy rates, and finds that after eradication there is an improvement in these variables for females. Cutler et al. (2010) finds similar results to Lucas (2010) in India, while Venkataramani (2012) explores the effects of declining malaria in Mexico. In sub-Saharan Africa, Barofsky et al. (2015) find that a malaria control program in Uganda increased years of schooling by 0.5 years, while Kuecken et al. (2016) find that country-level malaria distributions from the Roll Back Malaria Partnership increased educational attainment across the continent.

Our study is most closely related to three papers in particular. First, Lucas (2013) studies the effect of malaria eradication in Sri Lanka in the 1950s on fertility directly. Her results mirror our own, in that she finds an increase in fertility rather than a decrease as most theoretical models would predict. Cogneau and Rossi (2016) find an association between bed net distribution and child survival in a large set of sub-Saharan African countries from 2000-2015. Similar to our results, they find that the preponderance of reduction in child mortality is concentrated among lower socioeconomic status households. Finally, Pathania (2014) uses the scale up of ITNs in Kenya to causally identify a 33 percent reduction in post-neonatal mortality due to the ITN distribution program in that country.

Our paper provides several important contributions to the existing literature. The first few are of policy interest: we provide the first causal, reduced form estimate of the efficacy of a large and visible international health intervention that attracts billions of dollars of funding on one of its main outcomes of interest: child mortality. Of particular importance is that this paper derives its estimates using extensive population data from almost all countries in sub-Saharan Africa, rather than smaller, localized randomized control trials which may not be externally valid at scale, and may not capture spillover or general equilibrium effects. In addition, we provide a reduced form estimate of a major unintended consequence of that program: fertility change. Importantly, we find that while the program achieved its main focus in significantly reducing child deaths by malaria, the positive effect on fertility - at least in the short run - is the opposite of the prevailing belief among many aid and advocacy organizations. Our results suggest that the program's effect of re- 
duced mortality and increased fertility will cause a temporary rise in the dependency ratio, possibly impeding economic growth (Ashraf et al., 2009; Ashraf et al., 2013; Canning et al., 2017). It also provides a cautionary tale for other large scale health interventions, in that it suggests additional investments in education and family planning may be needed to offset temporary or unintended fertility effects. It should be stressed, however, that our results must necessarily be interpreted as short-run effects. Our dynamic results suggest that the long-run effect of child mortality on fertility may in fact be negative, and will only be known after the women in our sample fully complete their childbearing.

The next major contribution of our paper is that it pushes the boundary of the literature on the specific mechanisms by which a change in the health and mortality environment affects fertility. Our paper tests over ten different mechanisms and determinants of fertility change hypothesized in the literature, allowing us to provide evidence for the importance of some channels, while minimizing the importance of others.

\section{Background}

Worldwide, malaria is the second leading cause of death by infectious disease after pneumonia, responsible for 8 percent of all child deaths globally. Africa is especially hard hit - of the 415,000 annual deaths from malaria, 93 percent occurred in Africa (RBM 2018). In addition, malaria is the leading cause of death among children in Africa, causing 16 percent of all deaths (RBM, 2018). The disease is especially dangerous for young children who have not yet developed partial immunity against the disease. Particularly tragic is that using available technologies, malaria can be prevented, diagnosed, and cured quite easily (Apouey et al., 2018). As a result, malaria was specifically targeted in the sixth Millennium Development Goal. Between 2000 and 2015, the substantial expansion of malaria interventions - primarily the distribution of ITNs, but also indoor residual spraying (IRS) and the use of artemisinin-based combination therapies (ACT) - led to a 60 percent decline in malaria mortality rates globally, and 66 percent decline in Africa alone (UN 2019). Since 2000, over 6.2 million deaths from malaria have been averted, primarily in children under five years of age in sub-Saharan Africa (UN 2019).

Malaria is caused by the bite of a female anopheline mosquito that is infected with protozoan parasites. Although there are several species of the parasite, the Plasmodium falciparum strain is the most common in Africa, responsible for $99.7 \%$ of infections and the deadliest in Africa (RBM, 2018). ${ }^{1}$ Following the bite by an infected mosquito, the parasites migrate to the liver where they penetrate red blood cells, causing an infection. An infected individual with no previous immunity is almost certain to develop severe flulike symptoms that may lead to death, depending on the age and general health of the individual. Over years of exposure, individuals develop partial immunity to the infection. Children under 5 and pregnant women are at higher risk of contracting and dying from the

\footnotetext{
${ }^{1}$ In this study, we refer to "malaria episodes" and "malaria prevalence" as those caused by the P. falciparum parasite.
} 
disease (Crawley and Nahlen, 2004), while mortality rates for healthy adults are relatively low. Importantly, while young children have not yet developed immunity, pregnant women also temporarily lose their immunity.

Because of the high morbidity and mortality associated with the infection, the Roll Back Malaria Partnership was launched in 1998 to coordinate action against malaria. Preventive interventions against malaria include ITN coverage, IRS, intermittent preventive treatment uptake during pregnancy (IPTp), use of mosquito repellants, cleaning of drains, and treatment of standing water with larvicidal chemicals. ${ }^{2}$ Most of these interventions work by reducing the number of mosquitoes or preventing bites. Sleeping under an ITN is considered the most cost-effective intervention to prevent malaria (Lengeler, 2004).

Among these vector control measures, RBM recommends two core interventions: ITN usage and IRS. In parallel, the 2008 Millennium Development Goals Malaria Summit of the United Nations set a target of universal coverage with ITNs for all endemic areas in Africa (RBM, 2018). International donors such as the Global Fund, the President's Malaria Initiative, and the World Bank provide ITNs and funding to perform IRS in each country. Then, the National Malaria Control Program (NMCP) for each country is responsible for the distribution of nets and the implementation of IRS with the help of non-governmental organizations.

\section{Data}

We derive household- and individual-level information on mortality, fertility, and sociodemographic characteristics from a set of surveys produced by the DHS Program between 2000 and 2014 for 35 countries in sub-Saharan Africa. The list of surveys used can be found in Table B.1 in Online Appendix B. Information on malaria prevalence and preventive behaviors are from the Malaria Atlas Project (MAP). Both of these data sets are described separately below.

\section{A The DHS Program}

The DHS Program assists hundreds of national survey programs to collect globally standardized data on population and health in low- and middle-income countries. Within this program, we use the standard Demographic Health Surveys (DHS), the Interim Demographic Health Survey (DHS-I), the Malaria Indicator Surveys (MIS), and the AIDS Indicator Surveys (AIS) to compile a detailed data set of birth histories for 833,246 women and $1,147,543$ children. $^{3}$

Information on child mortality and fertility are derived from these birth histories. In the DHS, and DHS-I surveys, the women's questionnaire provides birth histories for all children born to women in the sample, including the date of birth for all children ever born

\footnotetext{
${ }^{2}$ Larval source management only plays a minor role in malaria control in Africa.

${ }^{3}$ We also include one survey of the Multiple Indicator Cluster Surveys (MICS). MICS questionnaires contain comparable information on individual and household sociodemographic characteristics as the DHS questionnaires.
} 
and the date of death for deceased children. The MIS and AIS usually include a shorter birth history module that contains the date of birth for the last five children and data on whether the children are alive at the interview date. ${ }^{4}$ Because malaria eradication was not a health policy priority before the creation of the Roll Back Malaria Partnership, we restrict our sample to surveys and births which occurred beginning in 1999. Overall, the data set includes 91 surveys from 35 countries and 365 sub-national regions.

\section{B The Malaria Atlas Project (MAP)}

Information on malaria prevalence and preventive behaviors come from MAP. Using the region of residence of households, we are able to merge the birth histories with data on malaria prevalence rates, ITN usage, and IRS coverage. ${ }^{5}$ MAP uses parasite surveys as well as environmental data to calculate annual malaria prevalence rates on a $5 \times 5 \mathrm{~km}$ grid using a geostatistical model. ${ }^{6}$ With shape files for each sub-national region given by the DHS program, we use GIS software to calculate a panel of malaria prevalence rates for each region in our survey. In instances where regional boundaries in the birth history data have changed between surveys, we combine regions using maps provided in the public report of each survey to get consistent regions over time.

We measure malaria prevalence as the Plasmodium falciparum parasite rate (PfPR). Specifically, our measure of PfPR is $\mathrm{PfPR}_{2-10}$, which represents the percentage of children between the ages of two and 10 who have measurable levels of the P. falciparum parasite in their peripheral blood (Gething et al., 2011). ${ }^{7}$ Figure 1 Panel A shows the parasite rate in the set of countries used in our sample in the year 2000 using the raw MAP data at the $5 \times 5 \mathrm{~km}$ resolution. One striking feature of this figure is that there are large variations in PfPR across space - even in areas where malaria is considered endemic.

In addition to prevalence data, MAP also provides data on ITN usage at the $5 \times 5 \mathrm{~km}$ resolution. We calculate average ITN usage as we did malaria prevalence rates. It also provides information on IRS and ACT uptake for each country-year. Figure 2 represents the evolution of ITN usage, IRS, and ACT uptake for the set of countries used in our

\footnotetext{
${ }^{4}$ The only exception is the last two MIS surveys in Malawi (2012 and 2014) which only have data on the last four births.

${ }^{5} \mathrm{~A}$ region in our data is a sub-national geographic unit as defined by the DHS. Generally they correspond to the GEOLEV1 GIS regions of a country, which are usually the first-level administrative region. For example, the first-level administrative region in the United States is the state, while the second-level is the county. However, since these sub-Saharan African countries are generally much smaller than the US, the average region size in our sample is approximately the same size as a US county.

${ }^{6}$ For Africa, MAP uses total of 27,573 geo-referenced points from literature searches, personal communications, and household surveys across 43 African countries spanning a time range from 1995 to 2014. Useful pieces of parasite survey information are the location-time of each survey, the number of individuals tested for the parasite, and the number of individuals infected with the parasite. The environmental data include rainfall, temperature, land cover, and urban/rural status. In the geostatistical model, the imputed value of PfPR for a particular target location is a weighted average of the observed values of PfPR (from the nearby parasite surveys) and the predicted values of PfPR (computed using the environmental factors). The weights reflect the spatial and temporal proximity between the target location and the location of the parasite surveys. See Bhatt et al. (2015) and its supplemental material for more details about the MAP data.

${ }^{7}$ This is the age group for which the parasite is most easily detected.
} 
analysis between 2000 and 2014. The figure shows a rapid scale-up of access to ITNs and ACT starting around 2005. IRS rates also increased between 2000 and 2010, but declined slightly more recently.

Not only is there temporal variation in the scale-up of the ITN distribution campaigns demonstrated in Figure 2, but there is also spatial variation. Figure 1 Panel B shows the geographic distribution of ITN usage across the countries in our sample in 2014 from the MAP data. We do not show the distribution of ITN usage in 2000 because it was zero everywhere. Therefore, the change in the ITN usage rates from 2000-2014 can be seen by simply looking at the 2014 usage rates. Evident from the figure, there is a large variation in the intensity by which regions received ITNs - variation which does not generally correlate with underlying malaria prevalence. It is this variation - both spatially in Figure 1 and temporally in Figure 2 - from which our identification strategy is derived.

\section{Empirical Specification}

\section{A Statistical Models}

We estimate the effect of antimalarial campaigns on child mortality and fertility in two ways. First, we use a continuous difference-in-differences model that exploits the regional variation in the timing and intensity of the campaigns, along with variation in precampaign malaria prevalence. This estimation strategy is broadly similar to that used in Bleakley (2010), Barofsky et al. (2015), Lucas (2010), Cutler et al. (2010), and Venkataramani (2012), among others. The second estimation strategy is a discrete difference-indifferences model, where instead of using a continuous measure of campaign intensity as a treatment variable, we simply use a dichotomous variable to indicate whether the malaria campaign had begun in a given region.

Each method has advantages and drawbacks. As we argue in Section 4.B, the variation in campaign intensity appears to be a supply shock which is uncorrelated with regional characteristics such as underlying malaria prevalence or the level of development. If so, the large increase in regional ITN usage rates can be seen as exogenous, and the continuous difference-in-differences model takes into account this variation in campaign intensity across regions and over time. This variation is important, since there were considerable regional differences in ITN distribution intensity. For example, in some regions initial distributions were followed by a reduction in campaign intensity, whereas in others the distribution efforts continued to scale up dramatically over time. Using this variation yields a more precise picture of the effect of ITNs on our outcomes of interest.

However, in spite of the evidence we show in Section 4.B, it may still be difficult for some to believe that the ITN campaign intensity was truly exogenous to time-variant regional characteristics. Therefore, we also use a discrete difference-in-differences model, which replaces our continuous ITN intensity variable with a dichotomous variable for whether the campaign had already started in that region. The advantage to this method is 
that the campaign variable is now exogenous to time-variant regional characteristics, and thus potentially better identified. However, since there were large variations in how the treatment occurred in each region, a major disadvantage of moving to this simple beforeand-after methodology is a loss of precision. In addition, if the effect of the intervention changed over time, our estimated effect would only yield the average effect of the distribution over all time periods after the intervention began.

Specifically, we estimate the following mortality and fertility equations for both the continuous and discrete difference-in-difference models:

$$
M_{i r t}^{a}=\gamma_{1}^{m a} I T N_{r t}+\gamma_{2}^{m a} \overline{P_{r}} \times I T N_{r t}+\Pi^{m a} X_{i r t}^{m}+\alpha_{r}^{m a}+\theta_{t}^{m a}+\psi_{r}^{m a} t+\epsilon_{i r t}^{m a}
$$

and

$$
F_{j r t}^{b}=\gamma_{1}^{f b} I T N_{r t-1}+\gamma_{2}^{f b} \overline{P_{r}} \times I T N_{r t-1}+\Pi^{f b} X_{j r t}^{f}+\alpha_{r}^{f b}+\theta_{t}^{f b}+\psi_{r}^{f b} t+\epsilon_{j r t}^{f b}
$$

where $M_{i r t}^{a}$ is a dummy variable for whether child $i$ in age group $a$ who lived in region $r$ in year $t$ died during her $a$ th year of life. Similarly $F_{j r t}^{b}$ is an indicator for whether a woman $j$ in age group $b$ who lives in region $r$ in year $t$ had a child within the last 12 months. We estimate five mortality equations, one corresponding to each child's first five years of life. Similarly, we estimate four fertility equations corresponding with different phases of a woman's fertile years. It should be noted that since we have a yearly panel, our estimates imply annual hazards of birth or death. Therefore, in our fertility equation a single woman can enter an age group sample multiple times, one for each year she is in that age group, before moving on to the next age group sample.

$I T N_{r t}$ is calculated differently for each of the two types of models we use. For the continuous difference-in-differences model, it is the fraction of individuals in region $r$ at time $t$ who report sleeping under an ITN, given in the MAP data. For the discrete model, it is merely an indicator variable which takes the value of 1 if the campaign was operative in a region $r$ at time $t$. We determine the timing of whether a campaign was operative in a region from country-specific Roll Back Malaria reports, following Apouey et al (2017). For the fertility equation in both models, we lag the ITN variable by one year, since the conception of children born this year occurred around nine months earlier.

Also notice that the ITN variable is calculated at the region level. Therefore, we are not measuring whether the specific child $i$ or woman $j$ slept under an ITN: the interpretation of this variable should be as the intensity of the ITN distribution campaign in the region, not the effect of whether the individual actually slept under a bed net. This is intentional: our intent is to identify the effect of the campaign - including spillover effects - on mortality and fertility in a region, using average ITN usage as a proxy for campaign intensity. Since the main effect of the campaigns was to reduce malaria, this is likely a somewhat tedious distinction, but important to make since we cannot rule out additional effects of the campaigns on mortality and fertility through other channels. ${ }^{8}$ However, since the purpose of

\footnotetext{
${ }^{8}$ For example, if the bed nets also prevented bites from the Tse-Tse fly, interpreting our results as solely
} 
this paper is to estimate the aggregate mortality effects of campaigns - including general equilibrium and spillover effects - this is precisely the methodology one should employ. ${ }^{9}$

$\overline{P_{r}}$ is our measure of pre-intervention malaria prevalence: $\mathrm{PfPR}_{2-10}$ in the year 2000 . The main parameters of interest in these specifications are on the interaction between $I T N_{r t}$ and $\overline{P_{r}}$, or $\gamma_{2}^{m a}$ and $\gamma_{2}^{f b}$. If antimalarial campaigns are effective in reducing malaria mortality among children of age $a$, then we expect $\gamma_{2}^{m a}<0$. The sign on $\gamma_{2}^{f b}$ is ambiguous, since - as shown in our conceptual framework in the online appendix A - the theoretical effect of antimalarial campaigns on fertility is itself ambiguous.

The control variables in the mortality equation, $X_{i r t}^{m}$, include fixed effects for the mother's age at birth, birth order fixed effects, and controls for mother's education, child gender, urban/rural status, and the number of months in the year before the interview took place. ${ }^{10}$ The control variables in the fertility equation, $X_{i r t}^{f}$, include fixed effects for the mother's age, and controls for education and urban/rural status. All regressions also control for two other malaria reduction interventions - anti-malarial drugs (Artemisinin-based Combination Therapy or ACT) and indoor residual spraying (IRS), which are given in the MAP data at the country-year level. Finally, we also control for region and year fixed effects $\left(\alpha_{r}^{m a}, \alpha_{r}^{f b}, \theta_{t}^{m a}\right.$, and $\left.\theta_{t}^{f b}\right)$ and region specific time trends $\left(\psi_{r}^{m a} t\right.$ and $\left.\psi_{r}^{f b} t\right)$.

\section{B Identification Assumptions}

The main econometric concern of our study is the endogeneity of our interaction term. Notice that it is not necessary for our identification strategy that the intensity of the campaigns themselves be exogenous to the average levels of mortality, fertility, or even pre-existing levels of malaria prevalence in each region, because we have a region fixed effect. This effect controls for any time-invariant characteristic of a region, including it's overall level of development, malaria ecology, whether they generally receive more aid from international organizations, etc.

In addition to including regional fixed effects, we additionally provide evidence in Figure 3, Figure 4, and Table B.3 that the ITN distribution was relatively haphazard in three ways. Specifically, we show that (1) the timing of the ITN distribution campaigns at the country level was uncorrelated with any observable country characteristics, such as the

the effect of malaria reduction would be incorrect since reductions in mortality from both sleeping sickness and malaria would be included in our estimates.

${ }^{9}$ Even if one wanted to estimate the effect of whether a specific individual slept under an ITN, they would not be able to do so with our data. While the DHS does contain data on whether an individual respondent slept under a bed net the night before the survey, we do not have an annual panel of such responses, and therefore would not be able to identify how this variable changed over time. In addition, the individual decision to sleep under an ITN is highly endogenous, since it is likely correlated with any number of other unobserved individual-level characteristics which may also explain mortality or fertility.

${ }^{10}$ Controlling for the number of months this way allowed the estimates to be considered annual hazards based on the calendar year, in spite of differing numbers of months of mortality "exposure". For example, a child born in January and interviewed in January would only have had one possible month in which to die in a given year, while a the same child interviewed the following December would have had twelve. Without this control is would appear that children born in months far away from the interview date would have higher mortality rates than those born in months just before the interview month. 
level of development or pre-intervention malaria prevalence; (2) once the campaigns began at the country level, the ITN distribution began in every region in that country simultaneously, independent of observable characteristics; and (3) the amount of ITNs eventually received by each region is uncorrelated with the region's pre-intervention malaria prevalence or any other observable characteristic. Beyond establishing the quasi-exogeneity of the ITN distribution to support our econometric methodology, our finding that the ITN distribution was so haphazard is interesting by itself.

The two panels in Figure 3 plot ITN usage rates - our measure of campaign intensity - over time for different regional subsets, relative to the intervention year. Panel A divides regions in our sample into quartiles of pre-intervention malaria prevalence. This figure is notable for two reasons. First, if the intensity of the ITN distribution was higher for areas with more underlying malaria, we should see areas in higher malaria prevalence quartiles should have received more ITNs, and sooner. We do not. Specifically, the highest three quartiles groups are essentially identical - each one rising from $0 \%$ usage to $16-17 \%$ usage in the intervention year, and evolving almost identically over time. The only quartile group for which there is a difference is the lowest malaria prevalence quartile, but the difference is slight - rising to $13 \%$ ITN usage from $0 \%$ in the first year, and trailing by only a few percentage points thereafter.

The second notable feature of this figure is how sharp the intervention was. Regions went from no ITN usage to usage in the mid-teens within one year. It is difficult to image that such sharp increases were the result of anything but a supply shock, especially given the fact that these increases coincided exactly with the year of intervention as outlined in the Roll Back Malaria documents. As a result, we can rule out changes in ITN usage from demand-side forces, or other slowly evolving region-specific time-variant mechanisms such as changes in regional income or development.

Panel B of Figure 3 is similar to Panel A, but in this case singles out a single country Nigeria - for closer inspection. ${ }^{11}$ Time is measured according to the calendar year instead of years since the intervention. Each line in the figure represents one of 37 different subnational regions in Nigeria.

As before, there are several notable features of this figure. First, as in Panel A it is remarkable how sharp the intervention was - all regions in the country simultaneously went from no ITN usage to between $10 \%$ and $30 \%$ usage within one year. Second, although each region in Nigeria began receiving ITNs in the same year, there is considerable heterogeneity between regions in campaign intensity. This is a general trend across our sample - each country began receiving ITNs in all regions in the same year, but once a country's distribution program began, there was significant regional variation in how the distribution unfolded. This is consistent with conversations we had with one of the government ministers in charge of the distribution campaign in Cote D'Ivorie, who said that once the

\footnotetext{
${ }^{11}$ We chose Nigeria since it is the country with the highest aggregate malaria burden worldwide, both due to its high population and high malaria prevalence. Twenty-five percent of all malaria cases worldwide occur within Nigeria, which is more than twice as much as the next highest country, the Democratic Republic of the Congo with 11\% (RBM 2018). However, each country in our sample generally shows a similar evolution of ITN usage.
} 
resources for malaria abatement were received at the national level, they came so quickly that the NMCP sent them wherever they could be received, without much overall strategy.

Third, the subsequent evolution of the campaign over time strengthens our conclusion that usage was driven almost exclusively by supply-side effects. For example, ITN usage peaks one year after the beginning of the national campaign, then begins to decline to about one-third to one-half of its original level by year three. This is consistent with two supplyside effects which are well documented in the literature: first, that ITNs usually wear out or lose their insecticide after about three years, and second, donor fatigue after an initial push. Once this decline in usage happens, there is usually a second donor infusion which replaces the worn-out nets, and sometimes expands the program further, as was the case in Nigeria. This pattern of initial investment, depreciation, and re-investment by international donors is a well-documented supply-side effect, and happens in approximately half of our sample countries. The other half experienced consistent and explosive growth in ITNs over the sample period, leading to the overall pattern found in Figure 3.

Figure 4 shows evidence that the timing and regional variation in campaign intensity within a country was uncorrelated with malaria prevalence, further demonstrating that the distribution campaigns were not targeting regions or countries based on their observable characteristics. Panel A plots regional malaria prevalence in the year 2000 against the year of intervention. There is no correlation between the timing of the distribution campaigns and the pre-intervention level of malaria. Panel B is similar, except instead of looking at the timing of the campaigns, it looks at intensity. The vertical axis measures the regional level of ITN usage in 2015, plotted against regional malaria prevalence in 2000. As before, there is no correlation between campaign intensity and malaria prevalence.

Table B.3 presents evidence that the ITN distribution campaigns were also uncorrelated with other observable characteristics related to economic development. Using our DHS data, we aggregated nine variables related to economic development to the region level, and regressed the intervention year on these variables to determine whether regions which were less developed received ITNs sooner. We find no systematic evidence that regional development mattered for the timing of the ITN distribution. ${ }^{12}$

One identification issue for the continuous difference-in-differences model is if policy makers systematically assigned more nets to regions where mortality or fertility were already changing faster - violating the parallel trends assumption. This is difficult to test directly in the continuous model. We address this concern in three ways. First, we include region-specific time trends in all our specifications. Second, we show the discrete difference-in-differences model results as robustness. Third, using the discrete model, we run a modified "Autor test" based on Autor (2003) to formally test for parallel trends in the pre-period. ${ }^{13}$ We present these results in Section 5.B, which find evidence for parallel

\footnotetext{
${ }^{12}$ We performed a similar regression at the country level and also found no effect. However, that regression only had 35 observations, so finding no effect is perhaps unsurprising.

${ }^{13}$ To do this, note that traditionally to test for parallel trends one would visually compare the pre-intervention trends between regions which eventually received the intervention and those which did not. However, that requires a discrete treatment and a single control group, whereas in our analysis both the treatment and control groups are
} 
trends.

A final concern is whether the ITNs were distributed in conjunction with other interventions which reduced mortality. This is especially important, since bed nets are often distributed during antenatal or other health clinic visits. To test for this, we run our main specification using vaccinations and antenatal care visits as the dependent variable to test whether the ITN distribution led to higher takeup for these other interventions. As discussed in the results below, we find no correlation between ITN distribution intensity and usage of these other preventive health interventions, which is consistent with the fact that only $8 \%$ of ITNs are distributed at antenatal care facilities (RBM 2019). ${ }^{14}$

\section{Results}

\section{A The Effect of Campaigns on Mortality and Fertility}

Table 1, Panel A reports our estimates of the effect of the campaigns on child mortality using our continuous difference-in-differences model. The columns contain results for different age groups: children born 0-12, 13-24, 25-36, 37-48, and 49-60 months before the interview. The interaction term between malaria prevalence and ITN usage is our coefficient of interest.

Our raw regression coefficients are difficult to interpret directly. For example, the coefficient on the interaction term shows the percentage point increase in the annual hazard of death if ITN coverage was $100 \%$, and malaria prevalence was also $100 \%$. Neither are true for any region in our sample. In order to aid in interpreting our raw regression coefficients for a more realistic scenario, at the bottom of each table we report a row entitled "Intervention Effect", which converts our regression coefficient on the interaction term into a percentage change from the mean, under the assumption of the mean level of malaria prevalence in a region (approximately $40 \%)^{15}$, and a change in ITN usage from 0 to $50 \%$ (similar to the mean increase in ITN usage over the sample period, as given in Figure 2). Therefore, we reduce the size of the coefficient by a factor of approximately $0.4 * 0.5=$ 0.2 , and then divide that percentage point change by the mean level of mortality in that age group to get the estimated effect of the entire ITN distribution campaign as a percent

continuous variables for our continuous model, while only the control group is continuous in the discrete model. There is no formal test of parallel trends for the continuous model. However, for the discrete model a commonly used technique is to allow triple interactions with the leads and lags of the treatment in the regression equation. If the regression coefficients on the triple interactions are zero for periods before the intervention, then the parallel trends assumption is satisfied. In addition, the coefficients on the post-periods show how the treatment phases in over time. See Autor (2003) for an example.

${ }^{14}$ While this may seem to indicate there is in fact no bundling of services, it is more likely that it is a zero net effect of bundling and crowding out - ITNs may be bundled with other interventions when they are received, but health clinics which receive more ITNs may receive less vaccines and other resources as policy makers try to distribute resources across clinics.

${ }^{15}$ The average prevalence is not precisely $40 \%$ for all regressions: it is calculated separately for each different regression, based on the subset of observations used for that regression. However, it is never more than 1 or 2 percentage points different from $40 \%$. 
change from the mean. For example, in Column (1), the coefficient on the interaction term is -0.016 , the mean malaria prevalence in this subset was $41.32 \%$, and the overall mortality hazard for this age group is $7.1 \%$. Therefore, we calculate $-0.016 * 0.5 * 0.4136 / 0.071=$ -0.04656 , meaning the ITN distribution campaign in the average region reduced infant mortality by 4.656 percent, as reported at the bottom of Column (1). Similarly converted standard errors are reported in parentheses under each interpreted coefficient.

The 4.656 percent decline in infant mortality is not statistically significant. However, for children 13-24 and 25-36 months, there is a strong negative impact of ITN distribution on mortality $-23.35 \%$ and $47.27 \%$ respectively. These results are consistent with evidence from the biological literature which shows that children in their second and third year are most at risk for malaria. ${ }^{16}$ For children 37-48 and 49-60 months, the effects are less negative ( $16.25 \%$ and $7.38 \%$ respectively), however they are no longer statistically significant, also consistent with the biological literature as children of this age begin to acquire partial immunity. Using these interpreted changes in the annual hazard of death, we can calculate the effect of the ITN campaigns on the probability of surviving to age five. According to our estimates, the probability of dying from any cause before age 5 fell from $10.5 \%$ to 9.3\% solely as a result of the ITN campaigns, a decline of $11.5 \%$.

Table 1, Panel B reports our estimates of the effect of the ITN distribution on fertility. In the columns, we report the results by mother age groups, allowing us to interpret our results as changes in the age-specific fertility rate. As before, our coefficient of interest is on the interaction term between malaria prevalence and ITN usage. This coefficient is positive and significant at the one percent level for every age group except 15-19, where it is significant at the 5 percent level. Looking at our interpreted results at the bottom of the table, we find that the ITN distribution campaigns increased age-specific fertility rates by between $11-15 \%$ for all age groups except for the oldest women, where they increased by over $30 \%$. Overall, this implies an increase in the total fertility rate of 0.71 children per woman, an increase of 13.8 percent on a base of 5.12 children.

Table 2 reports similar results to Table 1, except this time we allow heterogeneous effects for socioeconomic status. Specifically, we now include a triple-interaction between our original interaction term and a dummy variable for whether a woman has not received a primary school education. This table yields two interesting findings. First, it shows that the majority of the reduction in child mortality occurred among children of uneducated mothers. For example, while we previously calculated the ITN distribution led to an overall reduction in the probability of death before age five of $11.5 \%$, this masks a decline of $16.6 \%$ for children of women without a primary education, compared with a decline of just $4.5 \%$ for those with. Second, it shows that the increase in fertility was concentrated among women with higher socioeconomic status: the 0.71 increase in the total fertility rate can be decomposed into a 0.34 increase for women without a primary education and 0.99

\footnotetext{
${ }^{16}$ Children gain partial malaria immunity from the disease for approximately the first 6 months of life via maternal immunoglobulin $\mathrm{G}(\mathrm{IgG})$ antibodies acquired in utero. In addition, partial immunity during the first year may be gained through parasite growth-inhibitory factors such as lactoferrin and secretory $\operatorname{IgA}$ found in breast milk (Doolan et al., 2009).
} 
for those with. In fact, the only age group of women which shows a statistically significant increase in fertility as a result of the intervention is the oldest group, aged 40-44.

Tables 3 and 4 repeat the analysis of Tables 1 and 2, but for our discrete difference-indifferences model. Since we do not use variation in ITN usage in this model, we expect the estimated coefficients to be only a fraction of the continuous difference-in-differences model for two main reasons: first, the ITN campaigns didn't achieve 50\% coverage immediately, but rather on average between 15-20\%; and second because ITN usage faded over the first several years after the initial intervention in half of the regions. Our results bear out this prediction. However, all our major findings in Tables 1 and 2 are also found in Tables 3 and 4: we find that the intervention had a significant negative effect on child mortality, particularly among children ages $13-24$, and that there was a positive effect on fertility. ${ }^{17}$ In addition, the negative mortality effects are more pronounced among children of women without a primary education, whereas the positive fertility effects are more pronounced among women who do. However, the magnitudes are much smaller - the mortality effects are $-1.4 \%$ and $-8.1 \%$ for the educated and uneducated respectively, compared with $-4.5 \%$ and $-16.6 \%$ in the continuous model. Similarly, total fertility rates increase by 0.23 for the educated and actually decline by 0.2 for the uneducated, compared with increases of 0.99 and 0.34 in the continuous model.

\section{B Identification, Dynamic Effects, and the Autor Test}

As noted in Section 4.B, there are several threats to the credibility of our estimates. One concern was that regions which received more ITNs also received more of other interventions which affected infant mortality or fertility directly, such as vaccines or antenatal care. To test this, we re-estimate our main specification using several health behaviors not directly affected by bed net usage as our new dependent variables. Specifically, we use a dummy for whether the child has received a visit from a health care worker in the last 12 months, whether the child has been given full vaccination of BCG for tuberculosis, DPT (for diphtheria, pertussis, or tetanus), or either of those two vaccines. The results of the falsification test are given in Appendix Table B.4. We find no effect on the interaction term in any of our regressions. This suggests that instead of being complements, ITNs and other health interventions are either uncorrelated.

Another concern mentioned in Section 4.B was the assumption of parallel trends. We presented several possible checks for this assumption, one of which we called an "Autor Test" based on Autor (2003). The idea behind this test is to allow triple interactions with the leads and lags of the treatment in the discrete regression equation model, and if the regression coefficients on the triple interactions are zero before the intervention, then the parallel trends assumption is satisfied. However, an additional benefit of this test is that it allows us to show how the treatment effect phases in over time by looking at the coefficients

\footnotetext{
${ }^{17}$ The only notable difference between the results of the two models is that although both find overall increases in fertility, the discrete model finds significant increases for two of the four age subgroups, whereas there is an increase for all groups using the continuous model.
} 
on the triple interaction in the post-period.

We show the results of the Autor test both for our mortality and fertility regressions using the discrete model in Figures 5 and 6 respectively. ${ }^{18}$ The triple interaction corresponding with the year just preceding the intervention is omitted to serve as a reference. As we see in the infant mortality (0-12 months) Autor test in Figure 5, the trend in the years preceding the intervention are flat and insignificant. However, in the intervention year the effect turns negative, and is significant at the 5\% level. The effect remains negative in the year after the intervention (albeit only at the 10\% level), and in insignificant thereafter. There are several possible interpretations of this finding. The first is a reverse harvesting effect - the intervention happens, saving lives. However, a fraction of those children end up dying from other causes later, mitigating the effect. The second interpretation is that after the initial distribution, the number of ITNs depreciated (as shown above), and the mortality effects were thereby mitigated. In this case, one would prefer the continuous difference-in-differences model since that variation would have been used to inform the estimate, whereas here they are not.

The Autor test for fertility among the educated shown in Figure 6 is even more stark than Figure 5. As before, the pre-trend is insignificant, while the effect on fertility in the intervention year is very positive and significant. ${ }^{19}$ As with the mortality results, the effect goes away after 1 year, but interestingly become negative 3 years after the intervention. In this case, there are three interpretations. The first two are the same as for mortality: a harvesting effect, and as a consequence of the depreciation of initial infusion of ITNs. However, the third interpretation is a tempo vs. quantum effect: perhaps the ITN distribution induced women to have more births now, but did not change the number of overall births they intended to have. In this case, women simply shifted the same number of births forward, leading to more births today and less in the future. Therefore, it is important to view our positive fertility results as short run, one year effects, rather than the effect on completed fertility.

\section{Summary of Additional Appendix Results and Dis- cussion}

\section{A Additional Appendix Results}

Online Appendix B contains information on our sample, multiple robustness and falsification checks of our results, as well as testing for heterogeneous effects on different subpopulations. More importantly, however, are ten tables which report results attempting to explain our previously-reported findings.

In the appendix, we rerun our continuous difference in differences model on variables

\footnotetext{
${ }^{18}$ The Autor test for additional groups are found in Figures B.2-4 in the Online Appendix B

${ }^{19}$ Remember that in reality this is one year after the intervention, because these variables are lagged one year in order to account for a 9-month gestation period.
} 
describing as many of Bongaarts' proximate fertility determinants as possible (Bongaarts, 1978). In this way, we hope to see how the ITN distribution affected important determinants of fertility, which could inform our interpretation. Specifically, we estimate the effect of the campaigns on the number of women reporting to be sexually active, contraceptive use, and terminations. ${ }^{20}$ We then estimate the effect on fertility preferences (whether a woman wants more children), birth intervals, and sex ratios at birth (an indicator for spontaneous terminations).

In Appendix B, we find that the number of women who reported being sexually active increased, along with contraceptive usage, while the number of women reporting wanting more children decreased. All other variables did not see any statistically significant effects. ${ }^{21}$ It is important to note that many of these variables were measured at the time of the survey, not the time of the intervention. ${ }^{22}$ As a result, these findings can be interpreted in multiple ways. For example, consider the finding that women were less likely to reported wanting additional children after the intervention. First, one may assume that the ITN distribution lowered fertility preferences, and therefore the increase in fertility was not intended. However, it could also be the case that the ITN distribution induced women to have children earlier, who then later reported that they wanted no more children, because they already had them as a result of the ITN distribution.

\section{B Potential Explanations of our Results}

Given our findings in this article, we identify four possible theoretical explanations for our results. These explanations are not mutually exclusive. Distinguishing between them is an important topic for future research, but difficult to do in this analysis given the limitations and structure of our data. Below we discuss each one, and discuss the strengths and weaknesses of each theory.

The first theory is that the ITN distribution campaigns lowered the cost of childbearing, inducing them to choose higher fertility as a result of a standard Beckerian fertility model shown in Online Appendix A. Although possible, this answer is somewhat problematic since it predicts an increase in completed fertility, in contrast with our finding of a reduced desire for additional children after the ITN campaigns. In addition, our Autor test indicates that the change in fertility may be the result of a temporary tempo effect. Therefore, this explanation seems less likely.

A second hypothesis is a pure tempo effect - women may chose to have children sooner

\footnotetext{
${ }^{20}$ Bongaarts used marriage rates as a proxy for the extensive margin of sexual activity. We do not have information on post-partum infecundity.

${ }^{21}$ Many of the dependent variables produced sizable results, but unfortunately these estimates were very noisy. For just one of many examples, we found that the fraction of males born increased by 0.158 percentage points, which indicates a drop in spontaneous terminations, and could suggest that fertility rose due to lower rates of miscarriage and improved fecundity. However, this effect is quite large relative to the literature (Bruckner and Catalano, 2007; Catalano et al., 2009; Wilde et al. 2017; McLaren et al. 2019; Wilde 2019) - the standard error surrounding this estimate is just very large.

${ }^{22}$ We have a panel of ITN usage, mortality, and fertility, but not a panel of responses to all the supplementary questions by individual.
} 
due to the better health environment from the ITN distribution. This is consistent with the results from the Autor test. This could also be consistent with our results on desired fertility, if women reported not wanting more children because they had them earlier as a result of the ITN distribution.

A third explanation is an unexpected increase in fecundity due to the improved health environment from the ITN campaigns. We find suggestive evidence in Appendix B that fecundity improved. For example, Table B.15 demonstrates that the increases in fertility were concentrated among underweight (i.e. less healthy) women. However, Table B.14 shows that increases in fertility were larger for women who were not anemic (i.e healthy), which is the opposite of the general result from Table B.15. These results could be reconciled by noting that Apouey et al (2017) found that anemia rates fell as a result of the campaigns, which means more there were less women with anemia, who were then more able to have children. However, the evidence for the fecundity channel using our data is not fully conclusive. If women wanted to become pregnant and were now more physically able to do so, then this could lead to higher fertility. Lucas (2013) also finds a positive effect of malaria eradication on fertility in Sri Lanka, and suggests that the fecundity effect is a primary mechanism through which this occurs. ${ }^{23}$

However, the explanation presents a puzzle since we find that preferences for more childbearing fell as a result of the campaigns. If women can take action to prevent pregnancy, then increased fecundity may not translate to higher fertility. This suggests that if fertility rose because of increased fecundity, it may have been unintentional. One mechanism by which this could occur is if women lack information about the improved health environment and its effect on their fecundity. This hypothesis could also explain why fertility rose only for the educated group: if all women experience a positive fecundity shock, yet that same health shock reduced child mortality predominantly among women with no education, the negative fertility effect of reduced child mortality could blunt or even dominate the positive fecundity effect, leading to an increase in fertility for the educated but not the uneducated.

Another variation on this hypothesis is that women experienced a positive fecundity shock, but were not able to fully control their fertility due to a lack of empowerment, unmet need for contraception, or other social considerations. However, these explanations are less salient since we test for heterogeneity for these groups in Appendix Tables B.12 and B.13, and find that the increases in fertility are concentrated among women with high levels of empowerment and without an unmet need for contraception - also consistent with our finding that fertility is higher for the educated.

The fourth explanation is an increase in sexual activity after the ITN distribution campaigns. There are two possibilities as to why this occurred. First, as mentioned previously there may have been an increase in the number of women who wanted to have children

\footnotetext{
${ }^{23}$ As evidence for her claim, she draws from the epidemiological literature on malaria which demonstrates the effects of malaria on stillborn births and miscarriage are higher for women experiencing their first pregnancy than higher order pregnancies. In her paper, she finds that malaria eradication increased survival among first-born children, suggesting malaria infections are an important channel by which reductions in malaria increases fertility.
} 
immediately after the beginning of the campaigns, which led women to increase their sexual activity. The other explanation is that the reduction in malaria after the campaigns led more individuals to engage in sexual activity simply because they felt less sick and had higher libido, and not because they were intending to have more children.

\section{Conclusion}

Using a large data set of birth histories combined with information on ITN usage and malaria prevalence, we estimate the effect of the rapid increase in ITN usage in sub-Saharan Africa on child mortality and fertility. We find that bed nets have been effective in their goal of reducing child mortality for children ages 1 to 3 . We also find that the introduction of ITNs has a positive impact on fertility for educated women in the short run.

Although our paper explores the reduced-form effect of bed nets on mortality and fertility, we cannot causally determine the effect of the reduction on child mortality on fertility directly since the ITN distribution campaigns also affected general health, which could affect fertility directly. This relationship forms an integral part of many theories of fertility decline. We explore the mechanisms which drove the fertility increase by looking at proximate determinants of fertility change, and the heterogeneity of the positive fertility effects among subgroups.

Our explanations for why this may have happened fall into two groups: first, that the increases in fertility were intentional, but that these changes were temporary and only induced a tempo effect; and second, that the increases in fertility were unintentional and a result of increased fecundity and sexual activity due to the better health environment.

Our findings on child mortality strengthen the arguments made by the WHO for an increase in funding for disbursements for malaria control. After rising from $\$ 100$ million in 2000 to $\$ 3.1$ billion in 2017 , international donations for malaria control have stagnated over the past several years (RBM 2018). There is a sense that donor fatigue may threaten the funding for the continued distribution of malaria control commodities. According to the Roll Back Malaria Partnership, an estimated US\$ 6.6 billion is needed every year by 2020 to achieve only the first two Global Technical Strategy (GTS) milestones set by the WHO (RBM 2019). Current funding is less than half of this level, and progress in the fight against malaria seems to have stalled: after sustained decreases in malaria incidence from 2000 and 2015, from 2015-2018 the incidence rate has remained flat (RBM 2018).

In contrast, our findings do not support the contention that erosion of international funding for malaria control, specifically of ITNs, would lead to higher fertility rates in the short-run. While our results are suggestive that this may be the case for long-run fertility, we show the exact opposite for the short-run. Inasmuch as higher fertility rates are associated with lower educational achievement, higher maternal mortality, and lower income per capita, our results suggest that programs which aim to reduce child mortality be coupled with health, education, and family planning services in order to blunt the possible deleterious effects of increased population growth in the short run. 


\section{References}

[1] Apouey, Bénédicte H., Gabriel Picone, Joshua Wilde, Joseph Coleman, and Robyn Kibler. 2017. "Malaria and Anemia Among Children in Sub-Saharan Africa: The Effect of Mosquito Net Distribution." Revue Economique, 68(2), 163-197.

[2] Apouey, Bénédicte, Gabriel Picone, and Joshua Wilde. 2018. "The Economics of Malaria Prevention." Oxford Research Encyclopedia of Economics and Finance. New York: Oxford University Press.

[3] Ashraf, Quamrul, Ashley Lester, and David Weil. 2009. "When Does Improving Health Raise GDP?" NBER Macroeconomics Annual 2008, University of Chicago Press.

[4] Ashraf, Quamrul, David Weil, and Joshua Wilde. 2013. "The Effect of Fertility Reduction on Economic Growth." Population and Development Review, 39(1): 97-130.

[5] Autor, David. 2003. "Outsourcing at Will: The Contribution of Unjust Dismissal Doctrine to the Growth of Employment Outsourcing," Journal of Labor Economics, 21(1): 1-32.

[6] Barofsky, Jeremy, Claire Chase, and Tobenna Anekwe. 2010. "Malaria Eradication and Economic Outcomes in Sub-Saharan Africa: Evidence from Uganda." Journal of Health Economics, 44:118-136.

[7] Barreca, Alan. 2010. "The Long-Term Economic Impact of In Utero and Postnatal Exposure to Malaria." Journal of Human Resources, 45(4): 865-892.

[8] Barro, Robert, and Gary Becker. 1989. "Fertility Choice in a Model of Economic Growth.” Econometrica 57(2):481-501.

[9] Bhatt, S., D. J. Weiss, E. Cameron, D. Bisanzio, B. Mappin, U. Dalrymple, K. E. Battle, et al. 2015. "The effect of malaria control on Plasmodium falciparum in Africa between 2000 and 2015." Nature, 526, 207-211.

[10] Bleakley, Hoyt. 2010. "Malaria Eradication in the Americas: a Retrospective Analysis of Childhood Exposure." American Economic Journal: Applied Economics 2(2):1-45.

[11] Bongaarts, John. 1978. "A Framework for Analyzing the Proximate Determinants of Fertility." Population and Development Review 4(1):105-132.

[12] Bruckner, Tim Allen, and Ralph Catalano. 2007. "The secondary sex ratio and agespecific male mortality: evidence for culling in utero." American Journal of Human Biology, 19(6):763-73.

[13] Canning, David, Mahesh Karra, and Joshua Wilde. 2017. "The Effect of Fertility Decline on Economic Growth in Africa: A Macrosimulation Model." Population and Development Review, 43(S1): 237-263.

[14] Catalano, Ralph, Tim Allen Bruckner, and Kirk Smith. 2008. "Ambient temperature affects sex ratios and male longevity through selection in utero." Proceedings of the National Academy of Sciences, 105(6): 2244-7.

[15] Cogneau, Denis and Pauline Rossi. 2016. "Malaria Control and Infant Mortality in Africa.” PSE Working Paper 2017-02.

[16] Crawley, Jane, and Bernard Nahlen. 2004. "Prevention and Treatment of Malaria in Young African Children.” Seminars in Pediatric Infectious Diseases 15(3):169-80.

[17] Cutler, David, Winnie Fung, Michael Kremer, Monica Singhal, and Tom Vogl. 2010. "Early-life Malaria Exposure and Adult Outcomes: Evidence from Malaria Eradication in India." American Economic Journal: Applied Economics, 2(2):72-94. 
[18] Doepke, Matthias. 2005. "Child Mortality and Fertility Decline: Does the BarroBecker Model Fit the Facts?" Journal of Population Economics, 18(2):337-366.

[19] Doepke, Matthias. 2015. "Gary Becker on the Quantity and Quality of Children." Journal of Demographic Economics. 81(1):59-66.

[20] Doolan, Denise, Carlota Dobano, and J. Kevin Baird. 2009. "Acquired Immunity to Malaria." Clinical Microbiology Reviews 22(1):13-36.

[21] Gates Foundation. 2014. Annual Letter 2014. Available at: http://www.gatesfoundation.org/Who-We-Are/Resources-and-Media/AnnualLetters-List/Annual-Letter-2014. Accessed August 15, 2016.

[22] Gething, Peter, Anand Patil, David Smith, Carlos Guerra, Iqbal Elyazar, Geoffrey Johnston, Andrew Tatem, et al. 2011. "A new world malaria map: Plasmodium falciparum endemicity in 2010.” Malaria Journal 10:378.

[23] Kuecken, Maria, Josselin Thuilliez, and Marie-Anne Valfort. 2016. "Disease and Human Capital Accumulation: Evidence from the Roll Back Malaria Partnership in Africa." Mimeo.

[24] Lengeler, Christian. 2004. "Insecticide-treated bed nets and curtains for preventing malaria." Cochrane Database of Systematic Reviews 2.

[25] Lucas, Adrienne. 2010. "Malaria Eradication and Educational Attainment: Evidence from Paraguay and Sri Lanka." American Economic Journal: Applied Economics, 2:46-71.

[26] Lucas, Adrienne. 2013. "The Impact of Malaria Eradication on Fertility.” Economic Development and Cultural Change, 61(3):607-631.

[27] McLaren, Zoe, Leah Bevis, and Joshua Wilde. 2019. "The Effect of Ambient Temperature During Preganacy on Human Sex Ratios at Birth," Unpublished Manuscript.

[28] Pathania, Vikram. 2014. "The Impact of Malaria Control on Infant Mortality in Kenya." Economic Development and Cultural Change, 62(3):459-487.

[29] Roll Back Malaria Partnership (RBM). 2018. "World Malaria Report 2018," Available at: https://endmalaria.org/about-malaria/key-facts. Accessed August 23, 2019.

[30] Roll Back Malaria Partnership (RBM). 2019. "Key Facts about Malaria," Available at: https://endmalaria.org/about-malaria/key-facts. Accessed August 23, 2019.

[31] Rosling, Hans. 2010, June. Hans Rosling: Global population growth, box by box. [Video file]. Retrieved from https://www.ted.com/talks/hans_rosling_on_global_population_growth/transcript/a?language=en

[32] United Nations (UN). 2019. "Goal 6: Combat HIV/AIDS, Malaria and Other Diseases.” Retrieved from http://www.un.org/millenniumgoals/aids.shtml. Accessed on Aug 23, 2019.

[33] Venkataramani, Atheendar. 2012. "Early Life Exposure to Malaria and Cognition in Adulthood: Evidence from Mexico." Journal of Health Economics 31(5):767-780.

[34] Wilde, Joshua, Bénédicte H. Apouey, and Toni Jung. 2017. "The Effect of Ambient Temperature Shocks During Conception and Early Pregnancy on Later Life Outcomes." European Economic Review, 97C: 87-107.

[35] Wilde, Joshua. 2019. "Missing women, sex-ratios at birth, and the demographic transition," Unpublished Manuscript.

[36] World Bank. 2019. "Mortality rate, under-5 (per 1,000 live births)," World Development Indicators, The World Bank Group, https://data.worldbank.org/indicator/SH.DYN.MORT?locations=ZG. Accessed Aug 20, 2019. 
Table 1: Malaria Control Effects on Mortality and Fertility

\begin{tabular}{|c|c|c|c|c|c|}
\hline & (1) & (2) & (3) & $(4)$ & (5) \\
\hline \multicolumn{6}{|l|}{ Panel A. Child Mortality } \\
\hline Months Since Birth & $0-12$ & $13-24$ & $25-36$ & $37-48$ & $49-60$ \\
\hline Dependent Variable & Death & Death & Death & Death & Death \\
\hline Mean of Dependent Variable & 0.0714 & 0.0224 & 0.0076 & 0.0041 & 0.0029 \\
\hline ITN & $\begin{array}{c}-0.0309 * * * \\
(0.0090)\end{array}$ & $\begin{array}{l}-0.0026 \\
(0.0051)\end{array}$ & $\begin{array}{l}0.0099 * * * \\
(0.0028)\end{array}$ & $\begin{array}{c}0.0023 \\
(0.0022)\end{array}$ & $\begin{array}{l}-0.0009 \\
(0.0024)\end{array}$ \\
\hline Malaria Prev. in $2000 *$ ITN & $\begin{array}{l}-0.0160 \\
(0.0183)\end{array}$ & $\begin{array}{c}-0.0252 * * \\
(0.0111)\end{array}$ & $\begin{array}{c}-0.0173^{* * * *} \\
(0.0050)\end{array}$ & $\begin{array}{l}-0.0032 \\
(0.0036)\end{array}$ & $\begin{array}{l}-0.0010 \\
(0.0041)\end{array}$ \\
\hline $\begin{array}{l}\text { Observations } \\
\text { R-Squared }\end{array}$ & $\begin{array}{c}1,147,542 \\
0.014\end{array}$ & $\begin{array}{c}1,021,288 \\
0.013\end{array}$ & $\begin{array}{c}868,009 \\
0.004\end{array}$ & $\begin{array}{c}736,594 \\
0.002\end{array}$ & $\begin{array}{c}611,217 \\
0.002\end{array}$ \\
\hline Intervention Effect ( $\% \Delta$ from Mean) & $\begin{array}{l}-4.656 \\
(5.334) \\
\end{array}$ & $\begin{array}{l}-23.35 * * \\
(10.23)\end{array}$ & $\begin{array}{l}-47.27 * * * \\
(13.62)\end{array}$ & $\begin{array}{l}-16.25 \\
(18.28)\end{array}$ & $\begin{array}{l}-7.376 \\
(29.96)\end{array}$ \\
\hline \multicolumn{6}{|l|}{ Panel B. Fertility } \\
\hline Woman's Age & All & $15-19$ & $20-29$ & $30-39$ & $40-44$ \\
\hline $\begin{array}{l}\text { Dependent Variable } \\
\text { Mean of Dependent Variable }\end{array}$ & $\begin{array}{l}\text { Birth } \\
0.184\end{array}$ & $\begin{array}{l}\text { Birth } \\
0.121\end{array}$ & $\begin{array}{l}\text { Birth } \\
0.235\end{array}$ & $\begin{array}{l}\text { Birth } \\
0.188\end{array}$ & $\begin{array}{c}\text { Birth } \\
0.0856\end{array}$ \\
\hline ITN & $\begin{array}{l}-0.0057 \\
(0.0170)\end{array}$ & $\begin{array}{l}-0.0112 \\
(0.0169)\end{array}$ & $\begin{array}{c}-0.0503 * \\
(0.0260)\end{array}$ & $\begin{array}{l}-0.0451^{*} \\
(0.0239)\end{array}$ & $\begin{array}{c}-0.0501 * * \\
(0.0206)\end{array}$ \\
\hline Malaria Prev. in $2000 *$ ITN & $\begin{array}{l}0.1155^{* * *} \\
(0.0299)\end{array}$ & $\begin{array}{l}0.0701 * * \\
(0.0345)\end{array}$ & $\begin{array}{c}0.1383 * * * \\
(0.0515)\end{array}$ & $\begin{array}{c}0.1351 * * * \\
(0.0478)\end{array}$ & $\begin{array}{c}0.1366^{* * * *} \\
(0.0441)\end{array}$ \\
\hline Observations & $5,904,107$ & $1,362,706$ & $2,438,572$ & $1,632,916$ & 469,913 \\
\hline R-Squared & 0.0497 & 0.0834 & 0.0279 & 0.0269 & 0.0249 \\
\hline Intervention Effect ( $\% \Delta$ from Mean) & $\begin{array}{l}12.56^{* * * *} \\
(3.251)\end{array}$ & $\begin{array}{l}11.50 * * \\
(5.664)\end{array}$ & $\begin{array}{l}11.76 * * * \\
(4.378)\end{array}$ & $\begin{array}{l}14.50^{* * * *} \\
(5.131)\end{array}$ & $\begin{array}{l}31.77 * * * \\
(10.25)\end{array}$ \\
\hline
\end{tabular}

Notes: In Panel A, the dependent variable is an indicator for whether a child ever born was alive in a given age range based on the DHS birth histories. In Panel B, the dependent variable is an indicator for whether the woman had a live birth within the last 12 months for a given woman-year, for each age group. All regressions include year fixed effects, region fixed effects, region time trends, and a set of individual controls as outlined in Section III. ITN refers to the fraction of individuals in a region which reported sleeping under an ITN. "Intervention Effect" is the percentage effect from the mean of the dependent variable of an increase in ITNs of 50 percentage points (the average increase between 2000 and 2015 in our data) evaluated at the mean level of malaria prevalence (approximately 40 percent). Standard errors clustered at the region level in parentheses. $* * * \mathrm{p}<0.01, * * \mathrm{p}<0.05, * \mathrm{p}<0.1$. 
Table 2: Heterogeneous Mortality and Fertility Effects by Education

\begin{tabular}{|c|c|c|c|c|c|}
\hline & $(1)$ & $(2)$ & (3) & $(4)$ & $(5)$ \\
\hline \multicolumn{6}{|l|}{ Panel A. Child Mortality } \\
\hline Months Since Birth & $0-12$ & $13-24$ & $25-36$ & $37-48$ & $49-60$ \\
\hline Dependent Variable & Death & Death & Death & Death & Death \\
\hline Mean of Dependent Variable & 0.0714 & 0.0224 & 0.0076 & 0.0041 & 0.0029 \\
\hline ITN & $\begin{array}{c}-0.0304 * * * \\
(0.0092)\end{array}$ & $\begin{array}{l}-0.0004 \\
(0.0049)\end{array}$ & $\begin{array}{c}0.0114 * * * \\
(0.0029)\end{array}$ & $\begin{array}{c}0.0020 \\
(0.0021)\end{array}$ & $\begin{array}{l}-0.0002 \\
(0.0022)\end{array}$ \\
\hline Malaria Prev. in $2000 *$ ITN & $\begin{array}{c}0.0085 \\
(0.0188)\end{array}$ & $\begin{array}{c}-0.0175 * \\
(0.0102)\end{array}$ & $\begin{array}{c}-0.0146 * * * \\
(0.0054)\end{array}$ & $\begin{array}{l}-0.0022 \\
(0.0040)\end{array}$ & $\begin{array}{c}0.0002 \\
(0.0039)\end{array}$ \\
\hline No Education & $\begin{array}{l}0.0048 * \\
(0.0024)\end{array}$ & $\begin{array}{c}0.0032 * * \\
(0.0014)\end{array}$ & $\begin{array}{l}0.0016 * \\
(0.0009)\end{array}$ & $\begin{array}{c}0.0009 \\
(0.0007)\end{array}$ & $\begin{array}{c}0.0005 \\
(0.0007)\end{array}$ \\
\hline Malaria Prev. in $2000 *$ No Education & $\begin{array}{c}0.0127 * * \\
(0.0052)\end{array}$ & $\begin{array}{c}0.0041 \\
(0.0032)\end{array}$ & $\begin{array}{c}0.0027 \\
(0.0020)\end{array}$ & $\begin{array}{c}-0.0010 \\
(0.0015)\end{array}$ & $\begin{array}{c}0.0010 \\
(0.0016)\end{array}$ \\
\hline ITN $*$ No Education & $\begin{array}{l}-0.0032 \\
(0.0087)\end{array}$ & $\begin{array}{l}-0.0063 \\
(0.0050)\end{array}$ & $\begin{array}{l}-0.0041 \\
(0.0032)\end{array}$ & $\begin{array}{c}0.0006 \\
(0.0027)\end{array}$ & $\begin{array}{l}-0.0018 \\
(0.0024)\end{array}$ \\
\hline Malaria Prev. in $2000 *$ ITN * No Edu & $\begin{array}{c}-0.0451 * * \\
(0.0184)\end{array}$ & $\begin{array}{l}-0.0120 \\
(0.0107)\end{array}$ & $\begin{array}{l}-0.0031 \\
(0.0070)\end{array}$ & $\begin{array}{l}-0.0022 \\
(0.0053)\end{array}$ & $\begin{array}{l}-0.0016 \\
(0.0048)\end{array}$ \\
\hline Observations & $1,147,542$ & $1,021,288$ & 868,009 & 736,594 & 611,217 \\
\hline R-Squared & 0.015 & 0.013 & 0.005 & 0.003 & 0.002 \\
\hline Educated Intervention Effect ( $\% \Delta$ from Mean) & $\begin{array}{c}2.474 \\
(5.469)\end{array}$ & $\begin{array}{c}-16.20^{*} \\
(9.424)\end{array}$ & $\begin{array}{c}-39.97 * * * \\
(14.72)\end{array}$ & $\begin{array}{l}-11.30 \\
(20.16)\end{array}$ & $\begin{array}{c}1.268 \\
(28.73)\end{array}$ \\
\hline Uneducated Intervention Effect ( $\% \Delta$ from Mean) & $\begin{array}{c}-10.67 * \\
(6.478) \\
\end{array}$ & $\begin{array}{c}-27.32 * * \\
(13.12)\end{array}$ & $\begin{array}{c}-48.55^{* * * *} \\
(18.72) \\
\end{array}$ & $\begin{array}{l}-22.51 \\
(25.92) \\
\end{array}$ & $\begin{array}{l}-10.13 \\
(40.89) \\
\end{array}$ \\
\hline \multicolumn{6}{|l|}{ Panel B. Fertility } \\
\hline Woman's Age & All & $15-19$ & $20-29$ & $30-39$ & $40-44$ \\
\hline Dependent Variable & Birth & Birth & Birth & Birth & Birth \\
\hline Mean of Dependent Variable & 0.184 & 0.121 & 0.235 & 0.188 & 0.0856 \\
\hline 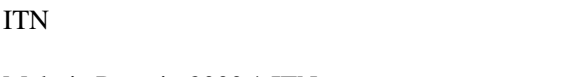 & $\begin{array}{l}-0.0161 \\
(0.0176)\end{array}$ & $\begin{array}{l}-0.0124 \\
(0.0168)\end{array}$ & $\begin{array}{c}-0.0772 * * * \\
(0.0266)\end{array}$ & $\begin{array}{c}-0.0612 * * * \\
(0.0234)\end{array}$ & $\begin{array}{c}-0.0457 * * \\
(0.0200)\end{array}$ \\
\hline Malaria Prev. in $2000 *$ ITN & $\begin{array}{c}0.1739 * * \\
(0.0301)\end{array}$ & $\begin{array}{c}0.1104 * * * \\
(0.0334)\end{array}$ & $\begin{array}{c}0.2144 * * * \\
(0.0511)\end{array}$ & $\begin{array}{c}0.1868 * * * \\
(0.0465)\end{array}$ & $\begin{array}{c}0.1201 * * * \\
(0.0427)\end{array}$ \\
\hline No Education & $\begin{array}{c}0.0451 * * * \\
(0.0045)\end{array}$ & $\begin{array}{c}0.0809 * * * \\
(0.0072)\end{array}$ & $\begin{array}{c}0.0398 * * * \\
(0.0052)\end{array}$ & $\begin{array}{c}0.0204 * * * \\
(0.0051)\end{array}$ & $\begin{array}{c}0.0150 * * * \\
(0.0035)\end{array}$ \\
\hline Malaria Prev. in $2000 *$ No Education & $\begin{array}{c}-0.0001 \\
(0.0094)\end{array}$ & $\begin{array}{c}0.0079 \\
(0.0148)\end{array}$ & $\begin{array}{c}0.0109 \\
(0.0110)\end{array}$ & $\begin{array}{c}0.0052 \\
(0.0106)\end{array}$ & $\begin{array}{l}-0.0010 \\
(0.0081)\end{array}$ \\
\hline ITN $*$ No Education & $\begin{array}{c}0.0317 * * \\
(0.0142)\end{array}$ & $\begin{array}{l}-0.0213 \\
(0.0175)\end{array}$ & $\begin{array}{c}0.0725 * * * \\
(0.0183)\end{array}$ & $\begin{array}{c}0.0346 * * \\
(0.0176)\end{array}$ & $\begin{array}{l}-0.0076 \\
(0.0176)\end{array}$ \\
\hline Malaria Prev. in $2000 *$ ITN $*$ No Edu & $\begin{array}{c}-0.1400 * * * \\
(0.0279)\end{array}$ & $\begin{array}{c}-0.0940 * * \\
(0.0374)\end{array}$ & $\begin{array}{c}-0.1869 * * * \\
(0.0355)\end{array}$ & $\begin{array}{c}-0.1025^{* * * *} \\
(0.0342)\end{array}$ & $\begin{array}{c}0.0285 \\
(0.0362)\end{array}$ \\
\hline Observations & $5,904,107$ & $1,362,706$ & $2,438,572$ & $1,632,916$ & 469,913 \\
\hline R-Squared & 0.0497 & 0.0835 & 0.0280 & 0.0269 & 0.0249 \\
\hline Educated Intervention Effect ( $\% \Delta$ from Mean) & $\begin{array}{c}18.90 * * * \\
(3.277)\end{array}$ & $\begin{array}{c}18.11 * * * \\
(5.478)\end{array}$ & $\begin{array}{c}18.22 * * * \\
(4.343)\end{array}$ & $\begin{array}{c}20.05 * * * \\
(4.994)\end{array}$ & $\begin{array}{c}27.93 * * * \\
(9.936)\end{array}$ \\
\hline Uneducated Intervention Effect ( $\% \Delta$ from Mean) & $\begin{array}{c}3.68 \\
(3.998)\end{array}$ & $\begin{array}{c}2.69 \\
(8.123)\end{array}$ & $\begin{array}{c}2.34 \\
(5.047)\end{array}$ & $\begin{array}{c}9.04 \\
(5.998)\end{array}$ & $\begin{array}{c}34.55^{* * * *} \\
(12.06)\end{array}$ \\
\hline
\end{tabular}

Notes: In Panel A, the dependent variable is an indicator for whether a child ever born was alive in a given age range based on the DHS birth histories. In Panel B, the dependent variable is an indicator for whether the woman had a live birth within the last 12 months for a given woman-year, for each age group. All regressions include year fixed effects, region fixed effects, region time trends, and a set of individual controls as outlined in Section III. ITN refers to the fraction of individuals in a region which reported sleeping under an ITN. "No Educ" or "Uneducated" refers to women who have not completed primary school, while "Educated" refers to women who have. "Intervention Effect" is the percentage effect from the mean of the dependent variable of an increase in ITNs of 50 percentage points (the average increase between 2000 and 2015 in our data) evaluated at the mean level of malaria prevalence (approximately 40 percent). Standard errors clustered at the region level in parentheses. $* * * \mathrm{p}<0.01, * * \mathrm{p}<0.05, * \mathrm{p}<0.1$. 
Table 3: Malaria Control Effects on Mortality and Fertility: Indicator

\begin{tabular}{|c|c|c|c|c|c|}
\hline & (1) & (2) & (3) & (4) & $(5)$ \\
\hline \multicolumn{6}{|l|}{ Panel A. Child Mortality } \\
\hline Months Since Birth & $0-12$ & $13-24$ & $25-36$ & $37-48$ & $49-60$ \\
\hline Dependent Variable & Death & Death & Death & Death & Death \\
\hline Mean of Dependent Variable & 0.0714 & 0.0224 & 0.0076 & 0.0041 & 0.0029 \\
\hline ITN & $\begin{array}{l}-0.0019 \\
(0.0024)\end{array}$ & $\begin{array}{c}0.0006 \\
(0.0016)\end{array}$ & $\begin{array}{c}0.0009 \\
(0.0007)\end{array}$ & $\begin{array}{l}-0.0004 \\
(0.0005)\end{array}$ & $\begin{array}{c}-0.0007 \\
(0.0005)\end{array}$ \\
\hline Malaria Prev. in $2000 *$ ITN & $\begin{array}{l}-0.0071 \\
(0.0051)\end{array}$ & $\begin{array}{c}-0.0075^{* *} \\
(0.0035)\end{array}$ & $\begin{array}{l}-0.0019 \\
(0.0016)\end{array}$ & $\begin{array}{c}0.0012 \\
(0.0011)\end{array}$ & $\begin{array}{c}0.0011 \\
(0.0011)\end{array}$ \\
\hline Observations & $1,147,542$ & $1,021,288$ & 868,009 & 736,594 & 611,217 \\
\hline R-Squared & 0.014 & 0.013 & 0.004 & 0.002 & 0.002 \\
\hline Intervention Effect ( $\% \Delta$ from Mean) & $\begin{array}{l}-4.147 \\
(2.994)\end{array}$ & $\begin{array}{c}-13.96^{* * *} \\
(6.443)\end{array}$ & $\begin{array}{c}-10.23 \\
(8.688)\end{array}$ & $\begin{array}{c}12.53 \\
(10.73)\end{array}$ & $\begin{array}{c}16.51 \\
(15.49)\end{array}$ \\
\hline \multicolumn{6}{|l|}{ Panel B. Fertility } \\
\hline Woman's Age & All & $15-19$ & $20-29$ & $30-39$ & $40-44$ \\
\hline Dependent Variable & Birth & Birth & Birth & Birth & Birth \\
\hline Mean of Dependent Variable & 0.184 & 0.122 & 0.235 & 0.187 & 0.0854 \\
\hline ITN & $\begin{array}{c}0.0024 \\
(0.0048)\end{array}$ & $\begin{array}{c}0.0057 \\
(0.0042)\end{array}$ & $\begin{array}{l}-0.0037 \\
(0.0067)\end{array}$ & $\begin{array}{c}0.0032 \\
(0.0056)\end{array}$ & $\begin{array}{c}0.0003 \\
(0.0047)\end{array}$ \\
\hline Malaria Prev. in $2000 *$ ITN & $\begin{array}{l}0.0073^{*} \\
(0.0044)\end{array}$ & $\begin{array}{c}-0.0096^{* *} \\
(0.0044)\end{array}$ & $\begin{array}{c}0.0185 * * * \\
(0.067)\end{array}$ & $\begin{array}{c}0.0043 \\
(0.0054)\end{array}$ & $\begin{array}{l}0.0082 * \\
(0.0047)\end{array}$ \\
\hline Observations & $5,813,609$ & $1,340,270$ & $2,399,614$ & $1,609,224$ & 464,501 \\
\hline R-Squared & 0.0496 & 0.0832 & 0.0279 & 0.0269 & 0.0249 \\
\hline Intervention Effect ( $\% \Delta$ from Mean) & $\begin{array}{c}1.580^{*} \\
0.957\end{array}$ & $\begin{array}{c}-3.166^{* *} \\
1.462\end{array}$ & $\begin{array}{c}3.162 * * * \\
1.141\end{array}$ & $\begin{array}{l}0.933 \\
1.159\end{array}$ & $\begin{array}{c}3.836^{*} \\
2.231\end{array}$ \\
\hline
\end{tabular}

Notes: In Panel A, the dependent variable is an indicator for whether a child ever born was alive in a given age range based on the DHS birth histories. In Panel B, the dependent variable is an indicator for whether the woman had a live birth within the last 12 months for a given woman-year, for each age group. All regressions include year fixed effects, region fixed effects, region time trends, and a set of individual controls as outlined in Section III. ITN is a dichotomous variable which indicates whether the ITN distribution campaign had begun in the region. "Intervention Effect" is the percentage effect from the mean of the dependent variable of the intervention evaluated at the mean level of malaria prevalence (approximately 40 percent). Standard errors clustered at the region level in parentheses. $* * * \mathrm{p}<0.01, * * \mathrm{p}<0.05, * \mathrm{p}<0.1$. 
Table 4: Heterogeneous Mortality and Fertility Effects by Education: Indicator

\begin{tabular}{|c|c|c|c|c|c|}
\hline & $(1)$ & $(2)$ & (3) & (4) & $(5)$ \\
\hline \multicolumn{6}{|l|}{ Panel A. Child Mortality } \\
\hline Months Since Birth & $0-12$ & $13-24$ & $25-36$ & $37-48$ & $49-60$ \\
\hline Dependent Variable & Death & Death & Death & Death & Death \\
\hline Mean of Dependent Variable & 0.0714 & 0.0224 & 0.0076 & 0.0041 & 0.0029 \\
\hline ITN & $\begin{array}{l}-0.0010 \\
(0.0026)\end{array}$ & $\begin{array}{c}0.0018 \\
(0.0015)\end{array}$ & $\begin{array}{c}0.0012 \\
(0.0007)\end{array}$ & $\begin{array}{l}-0.0003 \\
(0.0005)\end{array}$ & $\begin{array}{l}-0.0002 \\
(0.0005)\end{array}$ \\
\hline Malaria Prev. in $2000 *$ ITN & $\begin{array}{c}-8.63 e-05 \\
(0.0055)\end{array}$ & $\begin{array}{l}-0.0052 \\
(0.0033)\end{array}$ & $\begin{array}{l}-0.0009 \\
(0.0017)\end{array}$ & $\begin{array}{c}0.0016 \\
(0.0012)\end{array}$ & $\begin{array}{c}0.0008 \\
(0.0011)\end{array}$ \\
\hline No Education & $\begin{array}{c}0.0054 * * \\
(0.0024)\end{array}$ & $\begin{array}{c}0.0036 * * \\
(0.0014)\end{array}$ & $\begin{array}{c}0.0013 \\
(0.0009)\end{array}$ & $\begin{array}{l}0.0011 * \\
(0.0006)\end{array}$ & $\begin{array}{c}0.0009 \\
(0.0007)\end{array}$ \\
\hline Malaria Prev. in $2000 *$ No Education & $\begin{array}{c}0.0117 * * \\
(0.0050)\end{array}$ & $\begin{array}{c}0.0039 \\
(0.0032)\end{array}$ & $\begin{array}{c}0.0028 \\
(0.0020)\end{array}$ & $\begin{array}{l}-0.0009 \\
(0.0014)\end{array}$ & $\begin{array}{l}5.11 \mathrm{e}-05 \\
(0.0017)\end{array}$ \\
\hline ITN $*$ No Education & $\begin{array}{l}-0.0027 \\
(0.0030)\end{array}$ & $\begin{array}{c}-0.0033^{*} \\
(0.0018)\end{array}$ & $\begin{array}{l}-0.0007 \\
(0.0011)\end{array}$ & $\begin{array}{l}-0.0002 \\
(0.0008)\end{array}$ & $\begin{array}{l}-0.0013 \\
(0.0008)\end{array}$ \\
\hline Malaria Prev. in $2000 *$ ITN * No Edu & $\begin{array}{c}-0.0133^{* *} * \\
(0.0063)\end{array}$ & $\begin{array}{l}-0.0033 \\
(0.0039)\end{array}$ & $\begin{array}{l}-0.0017 \\
(0.0025)\end{array}$ & $\begin{array}{l}-0.0007 \\
(0.0017)\end{array}$ & $\begin{array}{c}0.0010 \\
(0.0019)\end{array}$ \\
\hline Observations & $1,147,542$ & $1,021,288$ & 868,009 & 736,594 & 611,217 \\
\hline R-Squared & 0.014 & 0.013 & 0.004 & 0.002 & 0.002 \\
\hline Educated Intervention Effect ( $\% \Delta$ from Mean) & $\begin{array}{c}-0.0503 \\
(3.220)\end{array}$ & $\begin{array}{l}-9.712 \\
(6.022)\end{array}$ & $\begin{array}{l}-4.925 \\
(9.385)\end{array}$ & $\begin{array}{c}16.16 \\
(11.83)\end{array}$ & $\begin{array}{c}11.43 \\
(16.39)\end{array}$ \\
\hline Uneducated Intervention Effect ( $\% \Delta$ from Mean) & $\begin{array}{c}-7.796^{* * *} \\
(3.834) \\
\end{array}$ & $\begin{array}{c}-15.79 * \\
(8.809) \\
\end{array}$ & $\begin{array}{l}-14.01 \\
(12.95) \\
\end{array}$ & $\begin{array}{c}9.201 \\
(15.96) \\
\end{array}$ & $\begin{array}{c}26.36 \\
(25.32) \\
\end{array}$ \\
\hline \multicolumn{6}{|l|}{ Panel B. Fertility } \\
\hline Woman's Age & All & $15-19$ & $20-29$ & $30-39$ & $40-44$ \\
\hline Dependent Variable & Birth & Birth & Birth & Birth & Birth \\
\hline Mean of Dependent Variable & 0.184 & 0.122 & 0.235 & 0.187 & 0.0854 \\
\hline ITN & $\begin{array}{l}-0.0021 \\
(0.0055)\end{array}$ & $\begin{array}{c}0.0043 \\
(0.0047)\end{array}$ & $\begin{array}{l}-0.0111 \\
(0.0077)\end{array}$ & $\begin{array}{l}-0.0023 \\
(0.0064)\end{array}$ & $\begin{array}{c}0.0007 \\
(0.0055)\end{array}$ \\
\hline Malaria Prev. in $2000 *$ ITN & $\begin{array}{l}0.0185^{*} \\
(0.0092)\end{array}$ & $\begin{array}{c}0.0035 \\
(0.0096)\end{array}$ & $\begin{array}{c}0.0353 * * \\
(0.0152)\end{array}$ & $\begin{array}{c}0.0179 \\
(0.0122)\end{array}$ & $\begin{array}{c}0.0051 \\
(0.0112)\end{array}$ \\
\hline No Education & $\begin{array}{c}0.0426 * * * \\
(0.0044)\end{array}$ & $\begin{array}{c}0.0751^{* * *} \\
(0.0065)\end{array}$ & $\begin{array}{c}0.0396 * * * \\
(0.0053)\end{array}$ & $\begin{array}{c}0.0192 * * * \\
(0.0051)\end{array}$ & $\begin{array}{c}0.0148 * * * \\
(0.0033)\end{array}$ \\
\hline Malaria Prev. in $2000 *$ No Education & $\begin{array}{c}0.0035 \\
(0.0094)\end{array}$ & $\begin{array}{c}0.0170 \\
(0.0138)\end{array}$ & $\begin{array}{c}0.0072 \\
(0.0112)\end{array}$ & $\begin{array}{c}0.0052 \\
(0.0106)\end{array}$ & $\begin{array}{l}-0.0005 \\
(0.0079)\end{array}$ \\
\hline ITN $*$ No Education & $\begin{array}{c}0.0153 * * * \\
(0.0057)\end{array}$ & $\begin{array}{c}0.0043 \\
(0.0068)\end{array}$ & $\begin{array}{c}0.0235 * * * \\
(0.0073)\end{array}$ & $\begin{array}{c}0.0151 * * \\
(0.0069)\end{array}$ & $\begin{array}{l}-0.0009 \\
(0.0072)\end{array}$ \\
\hline Malaria Prev. in $2000 *$ ITN * No Edu & $\begin{array}{c}-0.0464 * * * \\
(0.0106)\end{array}$ & $\begin{array}{c}-0.0474 * * * \\
(0.0135)\end{array}$ & $\begin{array}{c}-0.0507 * * * \\
(0.0137)\end{array}$ & $\begin{array}{c}-0.0349 * * * \\
(0.0133)\end{array}$ & $\begin{array}{c}0.0061 \\
(0.0143)\end{array}$ \\
\hline Observations & $5,813,609$ & $1,340,270$ & $2,399,614$ & $1,609,224$ & 464,501 \\
\hline R-Squared & 0.0497 & 0.0833 & 0.0279 & 0.0269 & 0.0249 \\
\hline Educated Intervention Effect ( $\% \Delta$ from Mean) & $\begin{array}{c}4.012 * * \\
(1.998)\end{array}$ & $\begin{array}{c}1.144 \\
(3.144)\end{array}$ & $\begin{array}{l}6.032 * * \\
(2.606)\end{array}$ & $\begin{array}{c}3.856 \\
(2.638)\end{array}$ & $\begin{array}{c}2.394 \\
(5.244)\end{array}$ \\
\hline Uneducated Intervention Effect ( $\% \Delta$ from Mean) & $\begin{array}{c}-5.017 * * \\
(2.304)\end{array}$ & $\begin{array}{c}-14.434 * * * \\
(4.400)\end{array}$ & $\begin{array}{l}-2.630 \\
(2.200)\end{array}$ & $\begin{array}{l}-3.672 \\
(2.680)\end{array}$ & $\begin{array}{c}5.234 \\
(5.958)\end{array}$ \\
\hline
\end{tabular}

Notes: In Panel A, the dependent variable is an indicator for whether a child ever born was alive in a given age range based on the DHS birth histories. In Panel B, the dependent variable is an indicator for whether the woman had a live birth within the last 12 months for a given woman-year, for each age group. All regressions include year fixed effects, region fixed effects, region time trends, and a set of individual controls as outlined in Section III. ITN is a dichotomous variable which indicates whether the ITN distribution campaign had begun in the region. "No Educ" or "Uneducated" refers to women who have not completed primary school, while "Educated" refers to women who have. "Intervention Effect" is the percentage effect from the mean of the dependent variable of the intervention evaluated at the mean level of malaria prevalence (approximately 40 percent). Standard errors clustered at the region level in parentheses. $* * * \mathrm{p}<0.01, * * \mathrm{p}<0.05, * \mathrm{p}<0.1$. 
Figure 1: Malaria Prevalence Rates (PFPR) and ITN Usage

Panel A: Malaria Prevalence (2000)

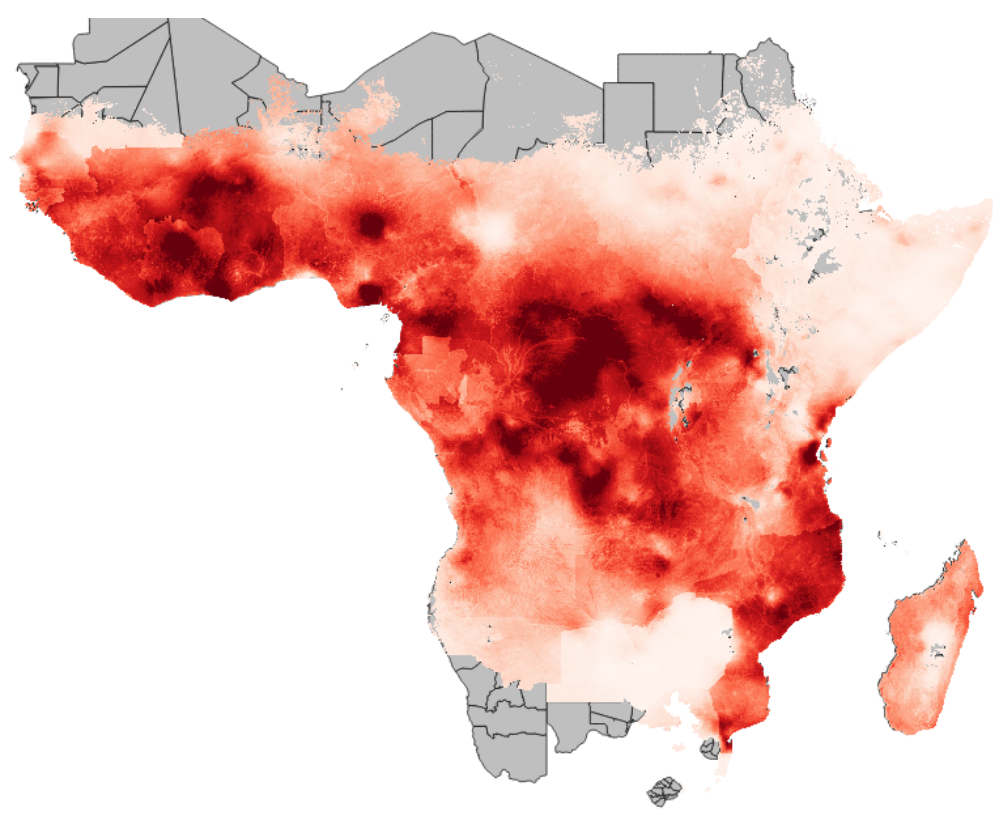

Panel B: ITN Usage (2014)

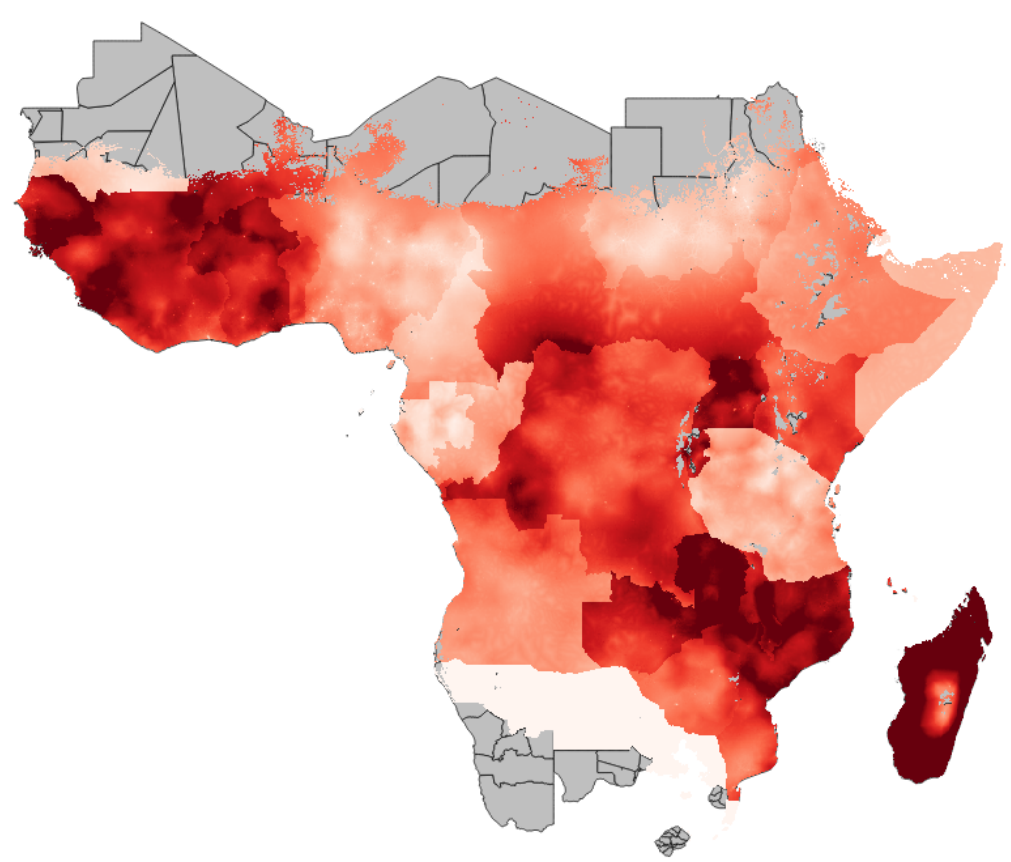

Notes: In both panels, darker colors indicate higher values of the respective variable, ranging from 0 to $100 \%$. In Panel A, Malaria Prevalence is measured as $\mathrm{PfPR}_{2-10}$, which represents the percentage of children between the ages of two and 10 who have measurable levels of the $\mathrm{P}$. falciparum parasite in their peripheral blood. In Panel B, ITN Usage represents the imputed fraction of individuals sleeping under an ITN from the Malaria Atlas Project (MAP). 
Figure 2: Evolution of ITN Usage, IRS, and ACT Uptake Since 2000

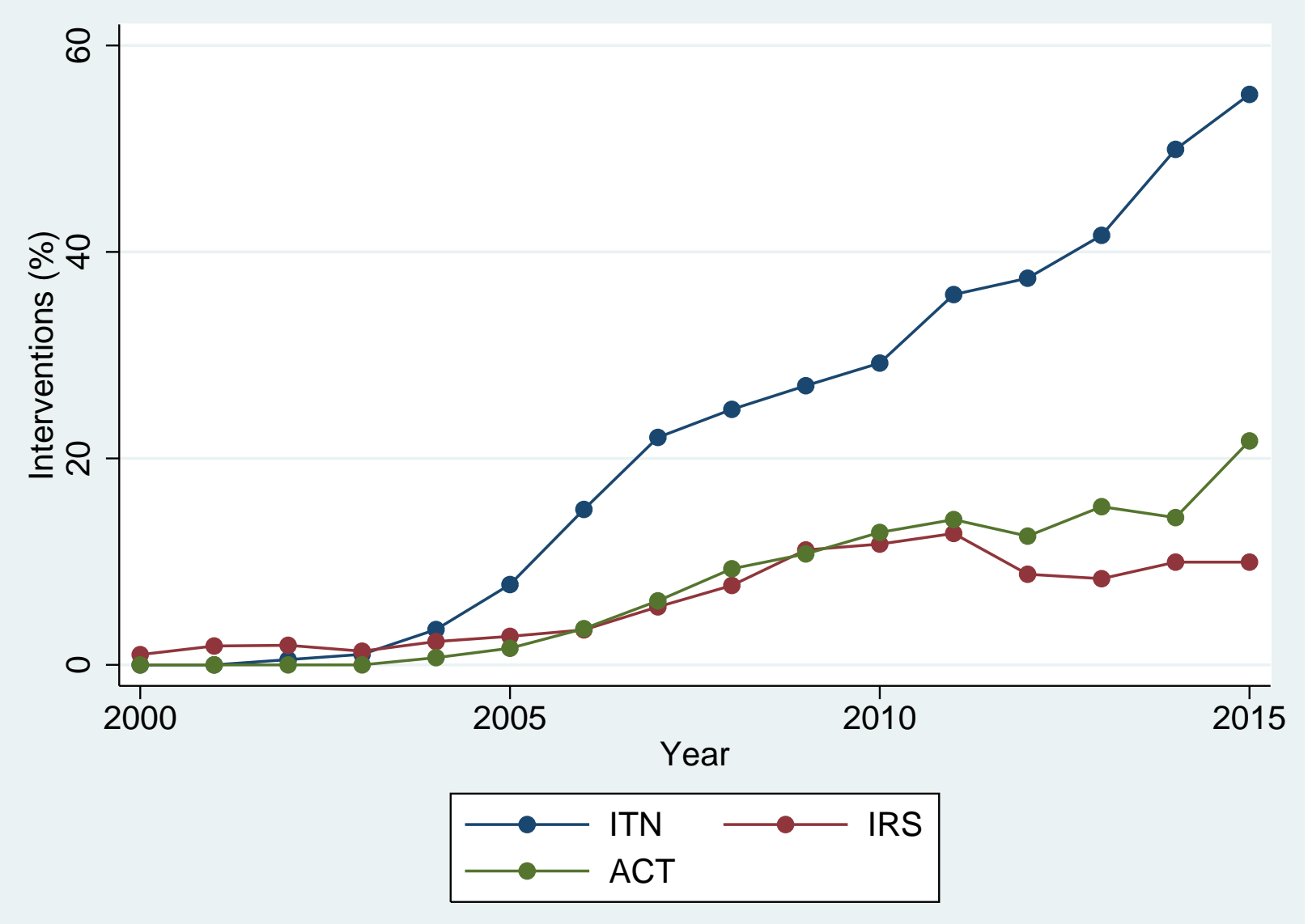

Notes: Using MAP data, we compute the level of each intervention type in each region as the fraction of individuals who report having received the respective intervention. Using these regional-level data, we then calculate the average level per year across all regions. Since IRS and ACT only given at the country level, we report the save value of IRS and ACT for each region in a country. 
Figure 3: ITN Usage Across Regions (2000-2015)

Panel A: Entire Sample - Normalized by Intervention Year, by Quartile of PfPR in Year 2000

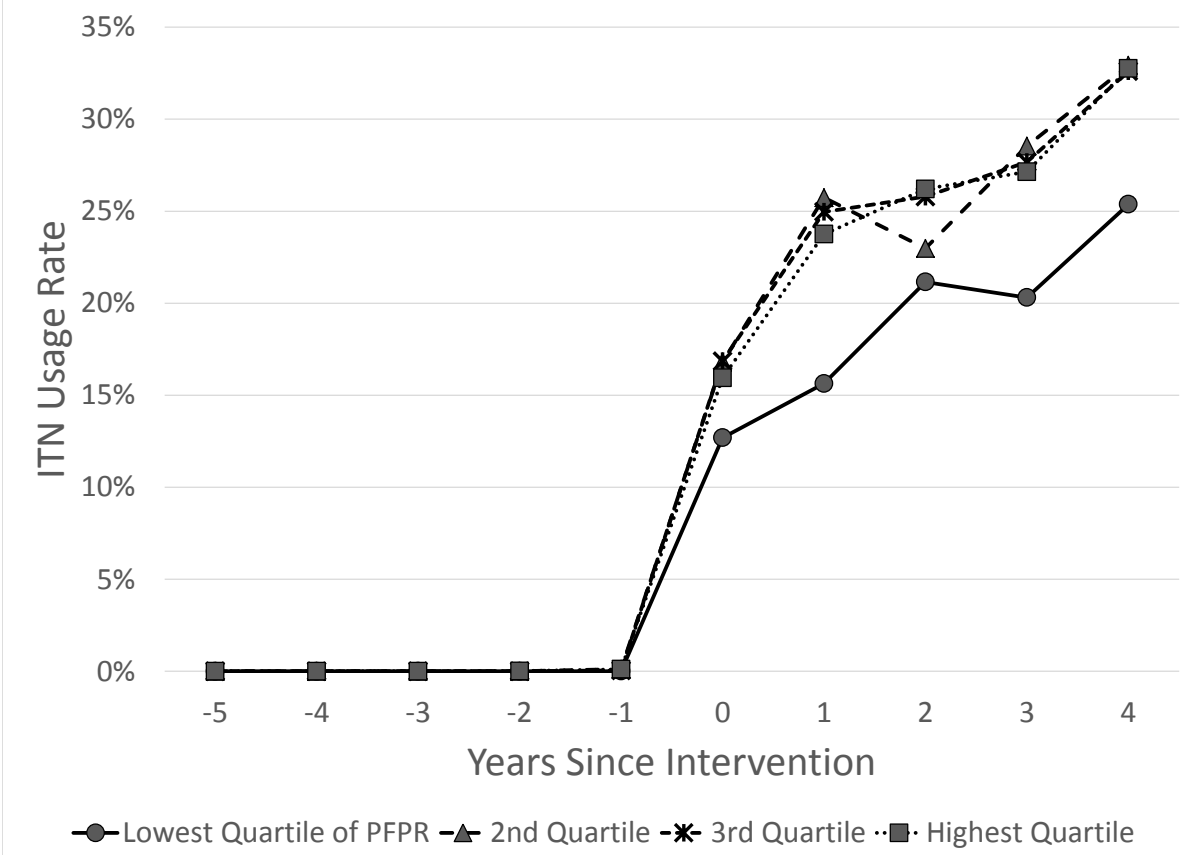

Panel B: Nigeria Only

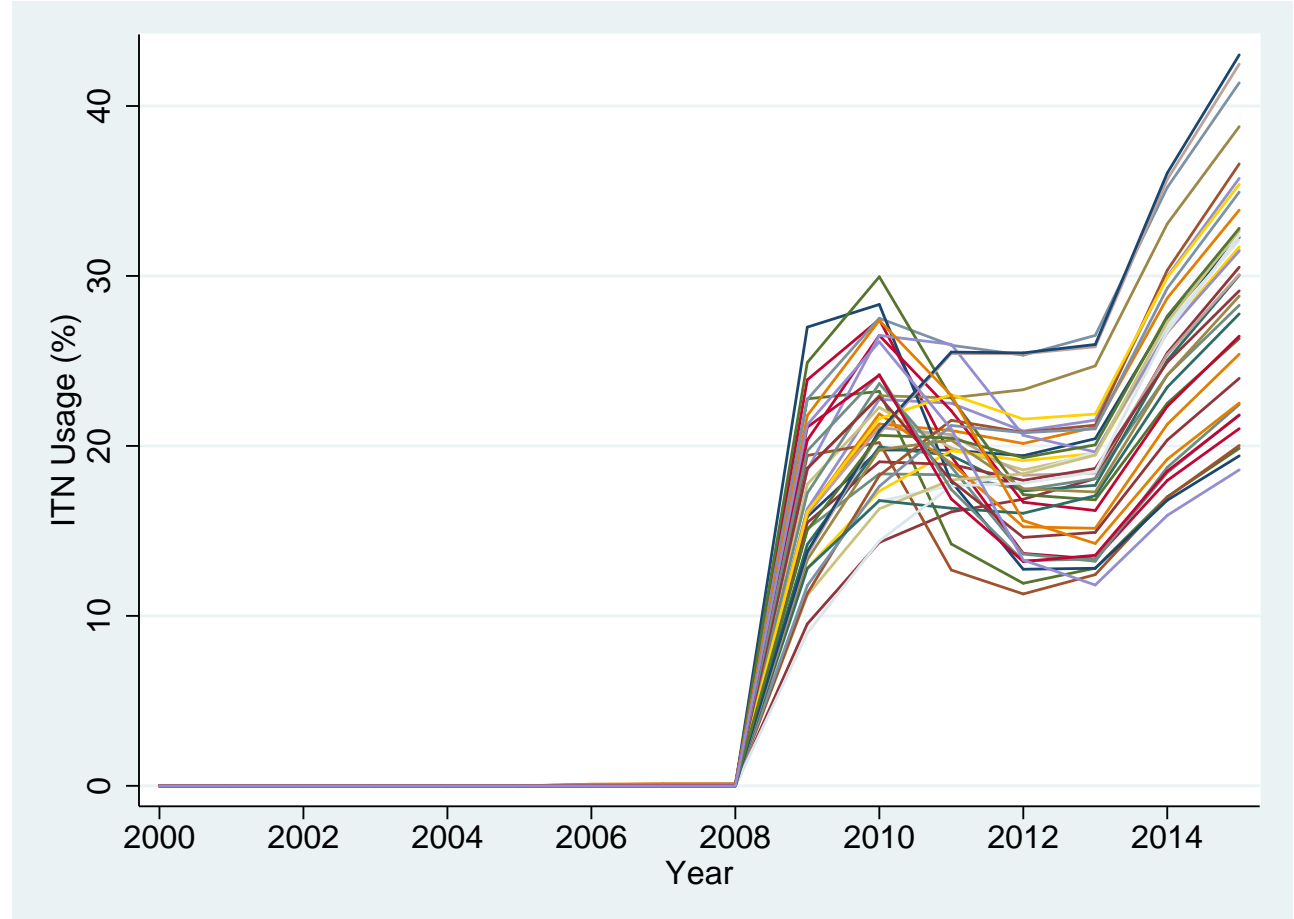

Notes: Both panels report the fraction of individuals who report sleeping under an ITN by year from the MAP data. Panel A aggregates the entire sample into four quartiles by malaria prevalence, and plots it against the years since the intervention took place. Panel B plots ITN usage for each of Nigeria's 37 regions for each year between 2000-2015. 
Figure 4: Pre-Intervention Malaria Prevalence, and Intervention Timing and Intensity

Panel A: Intervention Timing

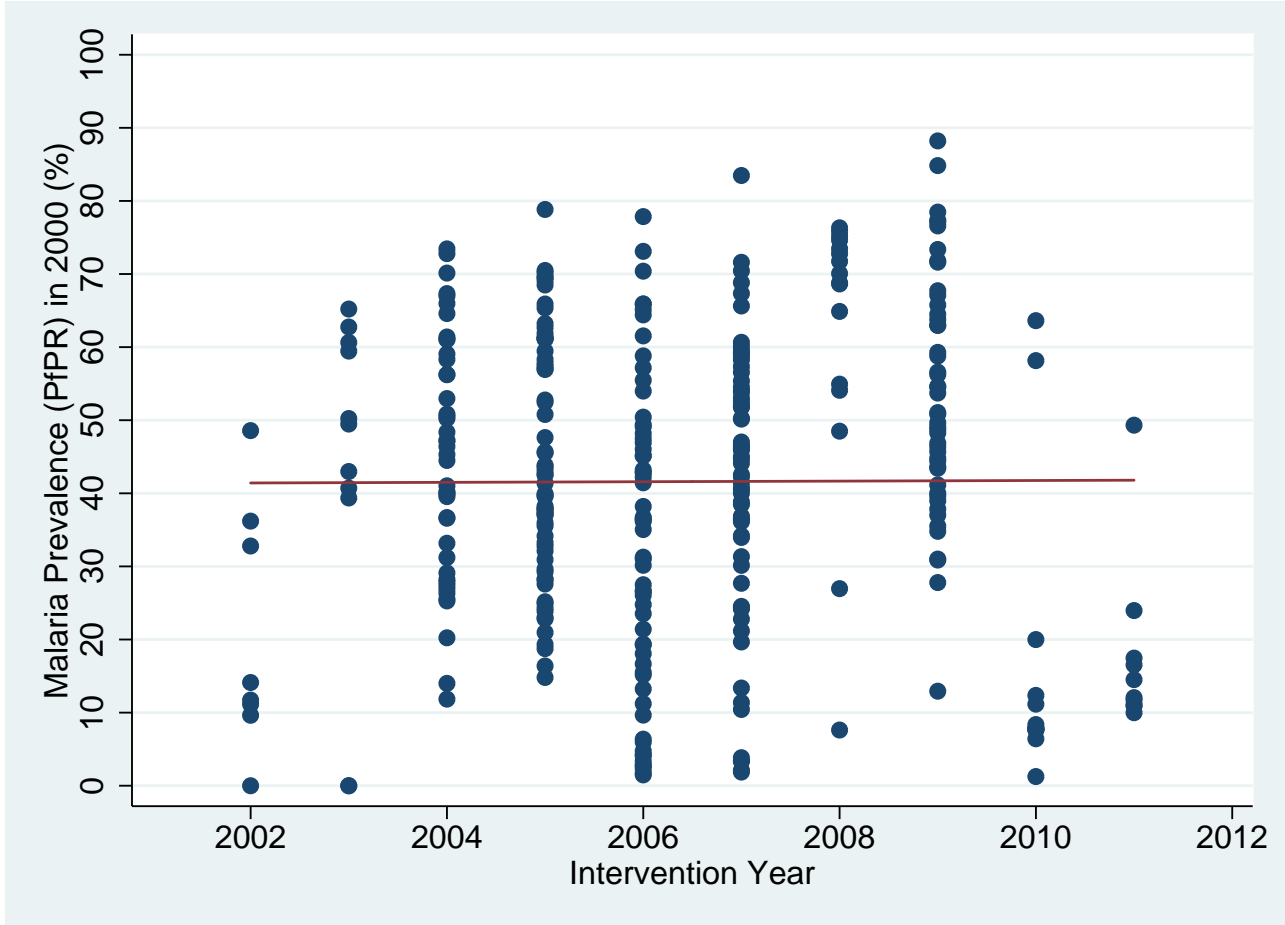

Panel B: Intervention Intensity

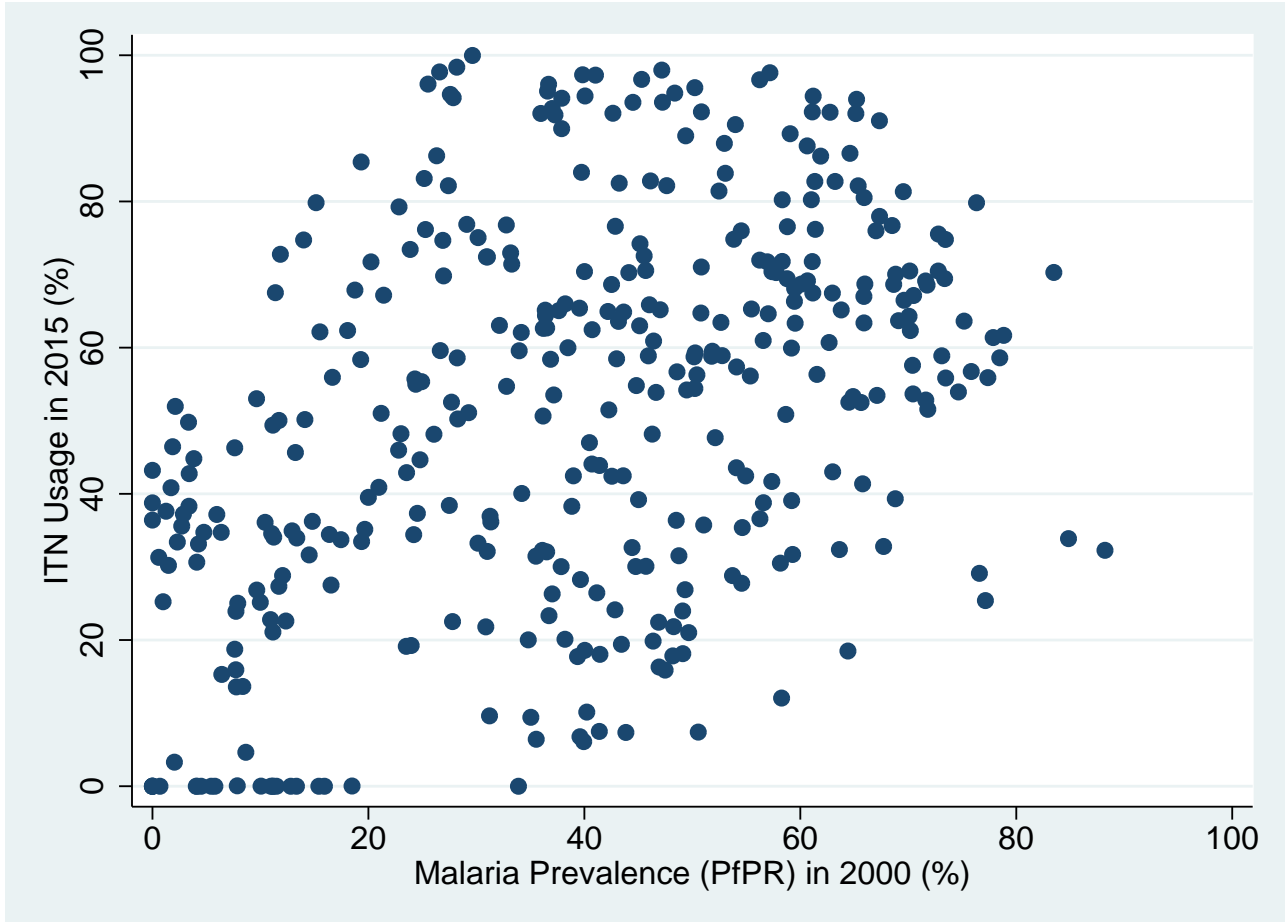

Notes: Both panels show correlations with the pre-intervention (2000) malaria prevalence in a region. Panel A plots regional malaria prevalence in 2000 against the timing of the intervention year, while Panel B plots it against ITN usage in 2015. 
Figure 5: Mortality Autor: Infant

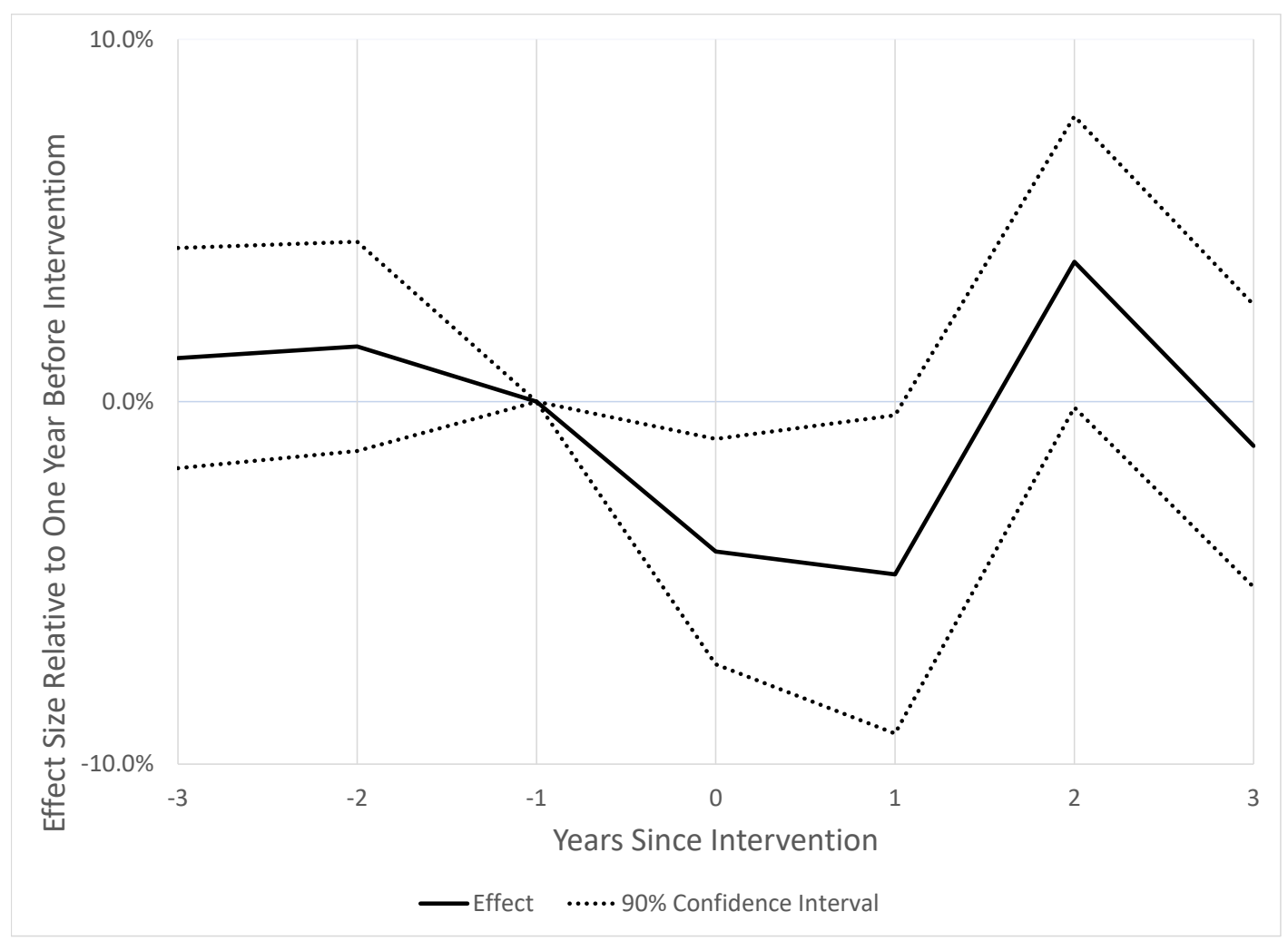

Notes: The figure shows the triple interaction coefficients from a regression which re-estimates the infant mortality regression reported in Table 3, Panel A, Column 1, but instead of using regional time trends, includes triple interactions with leads and lags of the ITN variable. 
Figure 6: Fertility Autor: Educated

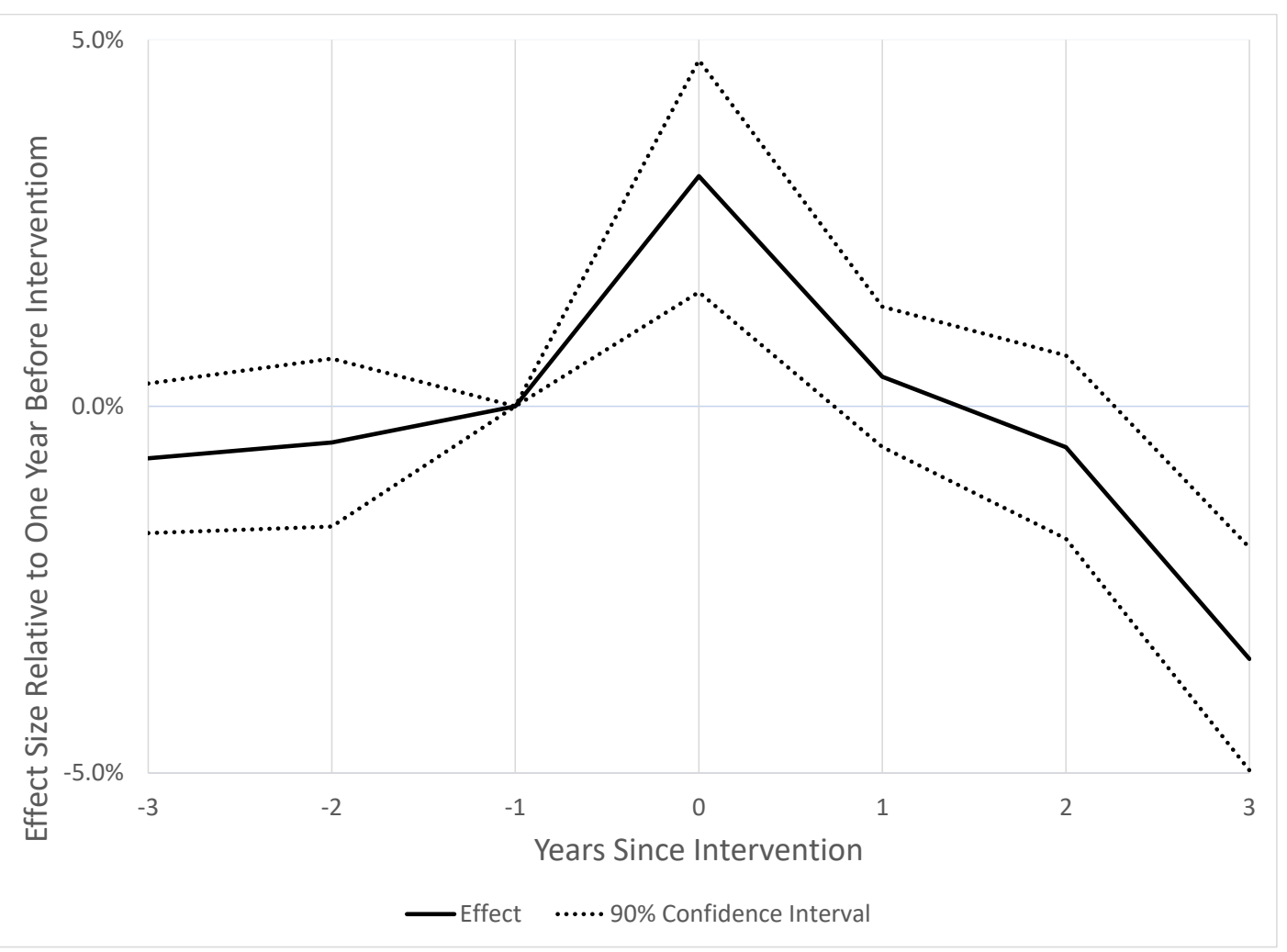

Notes: The figure plots the triple interaction coefficients from a regression which re-estimates the fertility regression reported in Table 3, Panel $\mathrm{B}$, Column 1, but instead of using regional time trends, includes triple interactions with leads and lags of the ITN variable. The regression only includes women who have at least a primary education. 


\section{Online Appendix A: Conceptual Framework}

That an increase in bed net usage should reduce child mortality is rather straightforward. In contrast, the channels through which net usage could affect fertility are less intuitive. There are several channels identified in the literature through which child mortality may influence fertility - all of which show that reductions in mortality should reduce fertility.

Most straightforward is the replacement child effect. If women target a certain number of surviving offspring, then each child who dies before reaching adulthood will be replaced, leading to a higher number of births. Related to this effect is the precautionary childbearing effect, which states than the reduction in mortality should be met with a larger than onefor-one fall in fertility as predicted by the replacement children effect. This is due to risk aversion - if a woman wants three surviving children and the mortality rate is 50 percent, she will need to have six children to get three in expectation, so will likely have more than six children to ensure she has at least three children survive. As child mortality approaches zero, the uncertainty concerning the number of surviving children falls, and therefore precautionary children are unnecessary.

Third, parents may not only derive utility from the number of surviving children they have, but also from their "quality". If the fraction of children which will die before reaching adulthood is high, then incentives to invest in those children is low, and therefore the parents are more likely to increase quantity of their children as opposed to their "quality". As mortality is reduced, investment in children is relatively more attractive, as is the incentive to have a large quantity of children. This is generally referred to as moving along the quality-quantity frontier.

There is one theoretical channel proposed in the literature by which there could be reverse causality between mortality and fertility. If higher fertility is associated with shorter birth intervals, and shorter birth intervals are associated with higher infant mortality, then reducing fertility may lead to healthier children who are less likely to die.

So far, we see that there is no theoretical reason to believe that decreases in mortality should increase fertility directly. However, in the context of the introduction of malaria control policies, not only would this affect child mortality, but also the health environment and thereby the cost of childbearing. This assumption can be justified in several ways. First, more incidents of malaria will directly increase the amount of time parents need to care for children while they are sick (e.g. through increased visits to a clinic, caring for sick children at home, etc.). Second, since time and income are substitutes, if parents spend a portion of their income on remedies for malaria, this can be modeled as an increase in the time cost of raising children. Third, since malaria increases the probability of a miscarriage, higher malaria incidence increases the number of pregnancies needed to produce a live birth. Inasmuch as pregnancy is time intensive, this should lead to a higher time cost per child. Finally, there may be direct utility costs of higher malaria on bearing or raising children. For example, since maternal mortality is higher if there is more malaria, a woman may choose not to have an additional child if she values her own life. 


\section{Theoretical Model on Bed Nets and Fertility}

Our model is a static model which incorporates all of the channels described above. It is mostly borrowed from Kalemi-Ozcan (2003) with a few slight modifications. Specifically, we strip out the education component from her model, and add a variable cost of childbearing which depends on the mortality environment. In this model, the prevalence of malaria affects a woman's fertility choice through three channels. The first three run directly through reductions in infant mortality - a higher probability of child survival to adulthood will reduce the need for both precautionary child-bearing and replacement children, as well as move the mother along the quantity-quality frontier. The fourth channel is that malaria increases the cost of having children, causing a reduction in malaria to have a positive effect on fertility since children are now less costly. ${ }^{24}$ Consider a woman who derives utility from consumption and children in the following manner:

$$
U=\gamma \ln (C)+(1-\gamma) \ln (w N)
$$

where $C$ is consumption, $N$ is the number of surviving adult children, and $w$ is the prevailing wage rate. She optimizes over the number of children $n$ she wishes to have, subject to a unit time constraint which is divided between raising children and working. The time cost of raising one child is $v(m)$, where $m$ is the prevalence rate of malaria. We assume that $v^{\prime}(m)>0$, meaning that more malaria increases the time cost of raising children. As a result, the woman's budget constraint is

$$
C=w[1-v(m) n]
$$

Let $q(m)$ be the probability of survival of each child, where $q^{\prime}(m)<0$. The number of survivors $N$ will be a random variable with a binomial distribution, meaning that the probability that $N$ out of $n$ children will live to adulthood is

$$
f(N ; n, q)=\left(\begin{array}{c}
n \\
N
\end{array}\right) q(m)^{N}[1-q(m)]^{n-N}
$$

for each integer $N$ between 0 and $n$. Combining (3) and (4) and introducing this uncertainty into the model, the woman maximizes her expected utility

$$
E(U)=\{\gamma \ln (w[1-v(m) n])+(1-\gamma) \ln (w N)\} f(N ; n, q(m))
$$

Since the mean of the binomial is $n q$,

\footnotetext{
${ }^{24}$ As noted before, some of the additional costs to the mother may affect utility directly rather than increase the time cost of childbearing. While these utility costs are not time per se, modeling them as a time cost is functionally equivalent to introducing a direct disutility measure into the utility function since in our model time is traded for utility.
} 


$$
\begin{array}{r}
U(N)=U[n q(m)]+[N-n q(m)] U_{N}[n q(m)]+\frac{[N-n q(m)]^{2}}{2 !} U_{N N}[n q(m)] \\
+\frac{[N-n q(m)]^{3}}{3 !} U_{N N N}[n q(m)]
\end{array}
$$

From log utility, the partial derivatives are:

$$
U_{N}=\frac{(1-\gamma)}{N}, U_{N N}=-\frac{(1-\gamma)}{N^{2}}, U_{N N N}=\frac{2(1-\gamma)}{N^{3}}
$$

Substituting back into the above $U(N)$ equation and taking expectations we have:

$$
\begin{array}{r}
E(U)=U[n q(m)]+E\left\{[N-n q(m)] \frac{(1-\gamma)}{n q(m)}\right\}-E\left\{\frac{[N-n q(m)]^{2}}{2 !} \frac{(1-\gamma)}{[n q(m)]^{2}}\right\} \\
+E\left\{\frac{[N-n q(m)]^{3}}{3 !} \frac{2(1-\gamma)}{[n q(m)]^{3}}\right\}
\end{array}
$$

The second and fourth terms are zero since the first and third central moments of the binomial distribution are zero. The third term contains the second central moment of the binomial, which is $E[N-n q(m)]^{2}=n q(m)[1-q(m)]$. Therefore, (10) can be rewritten as

$$
E(U)=U[n q(m)]-n q(m)(1-q) \frac{(1-\gamma)}{2[n q(m)]^{2}},
$$

which can also be rewritten as

$$
E(U)=\gamma \ln (w(1-v(m) n))+(1-\gamma) \ln [w n q(m)]-\frac{(1-\gamma)[1-q(m)]}{2 n q(m)} .
$$

Therefore, we simplify this utility function by using a third-order Taylor expansion around the mean of $N$ to get:

$$
E(U)=\gamma \ln (w(1-v(m) n))+(1-\gamma) \ln [w n q(m)]-\frac{(1-\gamma)[1-q(m)]}{2 n q(m)}
$$

Taking the first order condition of (9) with respect to $n$ and multiplying by $n^{2}$ for simplicity yields

$$
G[n, m]=\frac{-\gamma v(m) n^{2}}{1-v(m) n}+(1-\gamma) n+\frac{(1-\gamma)[1-q(m)]}{2 q(m)}=0
$$

This defines an implicit function from which we can calculate the effect of an increase in malaria prevalence $m$ on fertility $n$, where 


$$
\frac{d n}{d m}=-\frac{G_{m}}{G_{n}}
$$

In order to understand the mechanisms driving the results of our model, we now consider two cases: one where $\frac{d v}{d m}=0$, and another where $\frac{d v}{d m}>0$. First, consider the case where $\frac{d v}{d m}=0$. In this case:

$$
\begin{aligned}
G_{m} & =\frac{\gamma-1}{2 q(m)^{2}} \cdot \frac{d q}{d m}>0 \text { since } \gamma \in(0,1) \text { and } \frac{d q}{d m}<0 \\
G_{n} & =\frac{-\gamma v n(2(1-v n)+v n)}{(1-v n)^{2}}<0 \text { since } 1-v n>0
\end{aligned}
$$

Since $G_{m}$ is positive and $G_{n}$ is negative, it follows that $\frac{d n}{d m}>0$, implying that a reduction in malaria due to the introduction of bed nets should lead to a reduction in fertility. As mentioned previously, this is working through two channels. First, a decrease in malaria increases child survival to adulthood, meaning it will take less children born to reach a woman's target number of surviving children. This is the case even if there is no uncertainty in the model over how many of her children will die. This is known as the replacement child effect, and is one-to-one with the reduction in child mortality. However, the second channel - a reduction in precautionary child-bearing - is a direct result of the uncertainty in the model. A risk averse woman who faces a greater probability of losing children will opt to have more children than she otherwise would, simply to insure against the catastrophic case where most or all of her children die before reaching adulthood. If the probability of death falls due to a reduction in malaria, this case becomes less likely, meaning she will have less "safety" children.

Now consider the case where $\frac{d v}{d m}>0$. In this case, $G_{n}$ remains unchanged. However, an additional term is added to $G_{m}$ to become

$$
G_{m}=\frac{\gamma-1}{2 q(m)^{2}} \cdot \frac{d q}{d m}-\frac{\gamma n^{2}}{[1-v(q)]^{2}} \cdot \frac{d v}{d m}
$$

Since $\frac{d v}{d m}$ is positive, the second term will be positive. Therefore the sign of $G_{m}$ now becomes ambiguous. As a result, the sign of $\frac{d n}{d m}$ becomes ambiguous as well. The intuition here is that if eliminating malaria causes children to be less costly to raise, women will choose to have more of them. This channel runs in the opposite direction as the two channels which run directly through decreases in mortality.

\section{Bed Nets and Fertility in Sub-Saharan Africa}

Which of these channels will dominate in the context of a real-world child mortality intervention is an empirical question that only few studies have examined. The most notable among them is Lucas (2013) who focuses on the eradication of malaria in Sri Lanka and Paraguay in the 1950s, and finds that the elimination of malaria led to an increase in fertility. She hypothesizes that malaria posed a biological constraint on women's ability to conceive and carry children to full term, and that absent this constraint, more children were born. However, Sri Lanka in the 1950s is very different from Africa in the 2000s. For 
example, it is unlikely that women in Sri Lanka in the 1950s had much access to contraception. Therefore they had a limited ability to actually choose the number of children they had and fertility was mainly a byproduct of sexual activity. The total fertility rate in Sri Lanka before 1950 was consistently high at approximately six children per women, and did not begin to decline until the mid 1960s (World Bank, 2019a). As a result, Lucas' interpretation of malaria being a biological constraint on fertility is appropriate, and corresponds to the case in our model where the only channel which is operative is the (biological) cost of children, which implies that when malaria incidence is reduced, fertility increases.

In contrast, although contraception was far from universal in Africa in the 2000s, fertility rates had already begun to fall. Fertility in sub-Saharan Africa was constant at approximately 6.7 children per woman from 1950 to 1985, after which it fell by approximately 0.1 child per woman every year on average (World Bank, 2019b). Therefore, the technology for fertility reduction seems to have been in place in the 2000s, suggesting that the relationship between malaria and fertility in Africa in the 2000s could be substantially different from that in Sri Lanka in the 1950s. However, there are still many reasons to believe that women in sub-Saharan Africa do not fully have the ability to independently choose their own fertility, such as social and cultural considerations, lower levels of empowerment, and continued lack of access to contraception. 


\section{References}

[1] Kalemli-Ozcan, Sebnem. 2003. "A Stochastic Model of Mortality, Fertility, and Human Capital Investment." Journal of Development Economics, 70(1):103-118.

[2] Lucas, Adrienne. 2013. "The Impact of Malaria Eradication on Fertility." Economic Development and Cultural Change, 61(3):607-631.

[3] World Bank. 2019a. "Fertility rate, total (births per woman)," World Development Indicators, The World Bank Group, https://data.worldbank.org/indicator/SP.DYN.TFRT.IN?locations=LK. Accessed Aug 23, 2019.

[4] World Bank. 2019b. "Fertility rate, total (births per woman)," World Development Indicators, The World Bank Group, https://data.worldbank.org/indicator/SP.DYN.TFRT.IN?locations=ZG. Accessed Aug 23, 2019. 


\section{Online Appendix B}

\section{Mechanisms}

In the main article, the analysis was limited to estimating the causal effect of ITN distribution campaigns on mortality and fertility. In this appendix, we attempt to elucidate the reasons why fertility is increasing due to the ITN distribution campaigns. We analyze heterogeneity by gender to see if certain subgroups were more affected by the malaria interventions than others. We also test whether the fertility increases were along the intensive or extensive margins by exploring the effect on birth spacing. We then use Bongaarts' (1978) proximate determinants model to determine the mechanics behind the change in fertility. Finally, we test whether fertility preferences changed, followed by tests for whether the positive fertility increases were heterogenous with respect to the ability of women to control their own fertility.

\section{Heterogeneity Results}

\section{Heterogeneous Effects on Mortality by Gender}

In Table B.5, we divide our sample between female births and male births to see if the ITN distribution had heterogeneous effects on mortality by gender. In the overall sample, ITNs only had a statistically significant effect on mortality in the second and third years of life. We find a similar effect for males - mortality falls for children between 13 and 36 months. However, for females mortality is only significantly reduced for girls aged 13-24 months, and only at the 10 percent level. This is consistent with a number of theories, such as male preference in intra-household ITN allocation, or the male biological fragility. However, it is important to note that the magnitude of the effect for females aged 24-36 months - -30.06\% - is quite large, and comparable to the effect for males. We do not find significance due to very large standard errors. As a result our finding of "no significant effect" may be because the regression is underpowered - not because there actually is no effect.

\section{Heterogeneous ITN Usage by Socioeconomic Status}

One theory as to why we find heterogeneous results for different socioeconomic groups is that ITN takeup rates are different between groups. Unfortunately, MAP data does not include ITN usage rates by education or income level, so we are unable to test this directly. However, we can use the DHS data to estimate group differences in ITN usage, and how those differences evolved over time. In Figure B.1, we plot reported bed net usage rates from the DHS data by education group. ${ }^{25}$ We see that households with women without

\footnotetext{
${ }^{25}$ Since DHS surveys do not exist for every year for every country, we do not have a balanced panel of bed net usage at the region level as in the MAP data. Therefore, we use geometric interpolation between DHS survey years at the country level to derive this figure. Note also that the DHS data ask about any bed net usage - not ITNs specifically - which explains why bed net usage rates in 2000 are approximately 25 percent, even though Figure 2 reports ITN usage to be approximately 0 percent in 2000.
} 
primary education have lower bed net usage rates than households with at least primary education in 2000. However, less-educated households increased their bed net usage at a faster rate and essentially converged to educated households by 2010 , with the largest scale-up in bed net usage beginning in 2005 - corresponding with the main ITN scale-up shown in Figure 2. It is important to note, however, that the differences between the two groups are relatively small - only separated by less than 5 percentage points at the largest gap. Therefore, while there is some evidence suggesting the uneducated disproportionately benefited by the ITN distribution programs, we do not feel comfortable concluding these differences are the main driver of the heterogeneous results between education groups.

\section{Birth Spacing}

Finally, we test how a specific dynamic of fertility - birth spacing - changed after the ITN distribution. Knowing whether women are having more children due to changes in spacing will help elucidate whether fertility increases are along the intensive or extensive margins. For example, if overall fertility rises with no change in birth spacing, this may be because a larger fraction of women are having children. In Table B.6, we run the same regression with triple interactions as in Table 3, except the sample contains women who have had at least previous birth, and the dependent variable is the number of months since a woman had her last child. ${ }^{26}$

We find no statistically significant changes in birth spacing, except for women in the youngest age group (15-19). For example, we find that educated women ages 15-19 in the average region reduced their birth spacing by 3.02 months on a base of 25.68, implying that fertility intensified along the intensive margin by 11.8 percent, as reported in Column (3). We find no statistical difference between educated and uneducated women for this age group. Overall, women intensify their births by a statistically insignificant 0.76 months.

\section{Fertility and Bongaarts' Proximate Determinants}

Bongaarts (1978) posited a proximate determinants model of fertility which famously proposed that irrespective of whether fertility is a choice, it should be directly affected by four different channels. These were later expanded to eight: proportion married, contraception, induced abortion, lactational infecundability, frequency of intercourse, sterility, spontaneous intrauterine mortality, and duration of the fertile period. In this section, we test whether these proximate determinants of fertility changed as a result of the ITN distribution, and thereby better understand what is driving the fertility increase. The DHS data provides direct measures for a number of these proximate determinants. Specifically, the DHS has data on contraception, pregnancy termination, and sexual activity. For other variables, there are indirect tests, such as for induced abortion and spontaneous termination. No comprehensive data exists on sterility, lactation, or duration of the fertile period. ${ }^{27}$

\footnotetext{
${ }^{26}$ This is why there are fewer observations compared to the other fertility tables.

${ }^{27}$ Questions regarding contraception sometimes include responses referring to sterility and lactational infecundability. However, there are no questions directly related to these fertility determinants.
} 
We begin with induced abortion and spontaneous intrauterine mortality. It is difficult to test for fetal loss directly in the DHS data for several reasons. First, pregnancies are particularly fragile during the first two weeks after conception, with approximately 75 percent of conceptions being terminated spontaneously even before the mother knows she is pregnant (Wilcox et al., 1988; Boklage, 1990; Wilde et al., 2017). Since a termination is only counted in the DHS birth history if 1) a woman knows she is pregnant and 2) the pregnancy terminates, the vast majority of fetal loss will not be captured by the data. Second, even if the DHS did contain the true universe of terminations, it does not distinguish between spontaneous and induced abortions.

In spite of these challenges, we conduct two tests. First, due to the fact that males are generally weaker in utero than females, a common indicator for excess intrauterine mortality is the sex ratio at birth. In Table B.7, we run our main specification in equation (1), except that our dependent variable is an indicator for whether the birth is a male. We find there is no detectable effect on the sex ratio due to the ITN distribution campaigns. However, it should be noted that the magnitude of this result - that the fraction of males born increased by 0.158 percentage points - is very large relative to the literature on sex ratios at birth. While not conclusive, this suggests that spontaneous terminations may have fallen as a result of the ITN distributions, and thereby increased the number of conceptions brought to term.

Second, we test whether detected terminations changed in Table B.8. We find no consistent statistically significant evidence for a change in terminations. However, as with the sex ratio results, some estimates are sizable in magnitude in spite of not being statistically significant. As a result, neither Table B.7 nor B.8 provide evidence that fertility increased due to reductions in spontaneous or induced abortion, yet we are hesitant to rule out effects on these mechanisms due to the large uncertainty in the estimates.

Next we look at the extensive margin of sexual activity. In Table B.9, we run our fertility regression where our dependent variable is an indicator variable for whether a woman reports being sexually active in the past four weeks. Overall, we find statistically insignificant yet large effects. However, for women of prime childbearing ages (20-40) we find statistically significant increases of between $15-25 \%$, particularly for educated women, the subgroup for which fertility rose the most. Therefore, one possible explanation for the increase in fertility after the ITN distribution campaigns is that more women became sexually active. This makes sense - if sexual activity or libido is linked with personal comfort, then individuals who are sick with malaria may forgo sexual activity they would have otherwise engaged in in the absence of the disease. Another explanation would be reverse causality - fertility didn't increase because of increased sexual activity, but rather women wanted more children and became sexually active as a result.

Finally we ask whether there were changes in contraceptive usage. ${ }^{28}$ In Table B.10 we use as the dependent variable an indicator for whether women reported not using contraception. We find the ITN distribution campaigns led to higher rates of contraceptive use,

\footnotetext{
${ }^{28}$ We define contraceptive use to include both traditional and modern forms.
} 
both among uneducated and educated women. The estimated effect is about twice as large for uneducated women, and is highly statistically significant for uneducated women between 20-40 years of age. However, the difference between the educated and uneducated is not statistically significant.

\section{Fertility Desires}

While Bongaarts' proximate determinants model is useful to understand the mechanics of fertility decline, it does not address how a woman's fertility choice is determined. For example, a decrease in contraceptive use may be caused by a desire to increase fertility, but it may also be due to contraceptive supply shocks, pressure from intimate partners or extended family, or social norms more broadly. As a result, in order to understand why fertility increased after the ITN interventions, it may be useful to understand the extent to which the better health environment induced changes in fertility intentions rather than the actual number of births.

Using the DHS data, we test whether women desired more children as a result of the ITN distribution programs. Specifically, we analyze the response to a question on whether a woman wants another child. We run the same fertility regression as before and report the results in Table B.11. We observe strong and universal declines in desired children, for all age groups, and both for educated and uneducated women. In addition, there are no detectable differences in the effect of the ITN distribution on fertility preferences between the educated and uneducated. In results not reported (but available upon request), we also run similar regressions for a question asking whether a woman wants an additional child within two years, and find the same result.

One must be careful in interpreting this result, however. For example, the simplest interpretation is that as a result of the improved mortality environment, women believe a higher fraction of their children would survive, and therefore decided not to have more children. However, it should be noted that this question was asked of women at the time of the survey, not the time of the intervention. Therefore, if as a result of the better health environment women decided to have children earlier, they may have completed their childbearing before the survey was taken, and then answered they wanted no more children.

\section{Women's Empowerment, Unmet Need for Contraception, and Unexpected Fecundity}

Many of the theoretical mechanisms presented in the literature linking health, mortality, and fertility take as given that fertility is a choice. For example, the model in Appendix $\mathrm{A}$ is based on a Beckerian rational choice framework, within which agents can choose the optimal number of children to maximize utility under uncertain mortality outcomes. However, many believe that actualized fertility necessarily depends on social and cultural factors outside a woman's immediate control. For example, Bongaarts' (1978) proximate 
determinants model was a direct response to the rational choice model presented by Becker (1960).

In this section, we seek to provide evidence on whether the fertility increases in our main results were intentional. Testing this directly is not possible with our data. Therefore, we seek to provide indirect evidence by testing whether the fertility increases were concentrated among groups which are more likely to not fully achieve their optimal fertility. We consider three broad constraints to fertility choice: first, social constraints; second, imperfect access to contraception; and third, lack of information about the effect of the ITN distribution on fecundity.

To test whether social constraints may play a role, we reestimate our main fertility regression, except we test for heterogeneity by decision making power. We hypothesize that if social constraints are a factor, we would expect to see the increases in fertility concentrated among women with less input in household decisions. We test this hypothesis in Table B.12. In this table, we re-estimate our fertility regression presented in Table 2, except that instead of looking at heterogeneity by education, we look at heterogeneity by an indicator variable for whether a woman reports ever having at least a partial say in any of six household decisions. ${ }^{29}$ We find no increases in fertility among women who report not having any say in household decisions - the opposite of what we would expect to find if the fertility gains were caused by social constraints. All the statistically detectable fertility gains were among women who reported having at least some say.

We next test whether the increases in fertility were primarily among women with an unmet need for contraception. ${ }^{30}$ Our results are presented in Table B.13, and show that the fertility increase was concentrated among those without an unmet need for contraception. Just as our previous result, this is contrary to what one would expect if the fertility increases were driven by women who had less control over their fertility. ${ }^{31}$

Our last hypothesis is unexpected health effects on fecundity. There are several mechanisms by which malaria may affect fecundity. Malaria episodes may affect male fecundity, since sperm quality decreases significantly during malaria episodes, presumably because the resulting fevers increase the temperature in the testes (Singer et al., 1987). When

\footnotetext{
${ }^{29}$ The six decisions are: her own health care, making large household purchases, making household purchases for daily needs, visits to family or relatives, food to be cooked each day, or what to do with money her husband earns. For these variables, the DHS records whether a woman reports having a joint say with a partner, joint say with another person, or complete say. We define our "Ever Say" variable to be one if a woman has at least partial say of any form in any of the six decisions, and zero otherwise. This is an admittedly low bar - however, only about 50 percent of the women in our sample report ever having any say.

${ }^{30} \mathrm{~A}$ woman is broadly defined as having an unmet need for contraception if she is sexually active, is not using contraception, yet doesn't want another child. We use definition two in the DHS for unmet need, which keeps women who never had sex, are infertile, or menopausal in the sample, but records them as not having an unmet need. The other alternative is to set those women equal to missing. Our results are robust to both definitions.

${ }^{31}$ However, an important limitation of our data is that our variables capturing say in decision making and unmet need for contraception are measured at the time of the interview, and not at the time of the intervention. We do not know whether women with low say in household decisions or an unmet need for contraception at the time of the intervention experienced increased fertility. But we can make a retrospective statement: the fertility increases which took place in the past - just after the intervention - were primarily among women who reported having lower say and an unmet contraceptive need at the time of the interview.
} 
malaria is cured, male fecundity rebounds very rapidly. Female fecundity may also be affected during malaria episodes. McReady et al. (2012) find that the probability of miscarriage for a woman with malaria is 50 percent, as opposed to a 20 percent risk for a healthy woman. Similarly, malaria is associated with higher levels of anemia, and anemia may cause anovulation (no eggs being released) or poor egg health.

Unfortunately fecundity cannot be tested directly from our data. However, we use anemia and underweight status as proxies for whether a woman is unhealthy. ${ }^{32}$ As before, we run our main fertility regression but testing for heterogeneous effects by our indicators for poor health.

Beginning with our results on heterogeneity by anemia status, Table B.14 shows that while fertility rose for both anemic and non-anemic women, fertility rose significantly more for those without anemia. For example, overall fertility rates rose by $23.5 \%$ for those without anemia, while they rose only $10.5 \%$ for women with anemia. Both those coefficients are significantly different from zero and each other. For heterogeneity by underweight status in Table B.15, we find that increases in fertility were concentrated in women who were underweight. These two results seem contradictory, since in one the less healthy women experienced smaller increases in fertility, whereas in the other the opposite occurred. As mentioned in the main text, these results could be reconciled by noting that anemia rates fell as a result of the ITN distribution, meaning less women with anemia who were then more able to have children. However, the evidence for the fecundity channel using our data is not fully conclusive.

Taking these three results together, we find little evidence that the increases in fertility induced by the ITN distribution campaigns were concentrated among women who would be expected to have less control over their own fertility.

\section{References}

[1] Becker, Gary. 1960. "An Economic Analysis of Fertility.” Demographic and Economic Change in Developed Countries. Princeton: Princeton University Press

[2] Boklage, Charles. 1990. "Survival Probability of Human Conceptions from Fertilization to Term." International Journal of Fertility, 35(2):75-94.

[3] Bongaarts, John. 1978. "A Framework for Analyzing the Proximate Determinants of Fertility." Population and Development Review 4(1):105-132.

[4] McGready, R., Lee, S.J., Wiladphaingern, J., Ashley, E.A., Rijken, M.J., Boel, M., Simpson, J.A., Paw, M.K., Pimanpanarak, M., Oh Mu, Singhasivanon, P., White, N.J., Nosten, F.H. 2011. "Adverse effects of falciparum and vivax malaria and the safety of antimalarial treatment in early pregnancy: a population-based study." The Lancet Infectious Diseases, 12(5): 388-396.

\footnotetext{
${ }^{32} \mathrm{We}$ define anemia as a dichotomous variable for whether the woman is anemic or not, and underweight as a dummy for whether a woman's BMI is under 18.5, the standard threshold for being underweight. Anemia in this case is whether a woman's iron level was low enough to be considered moderately or severely anemic according to the DHS definitions.
} 
[5] Singer, R., Segenreich, E., Sagiv, M., Shohat, B., Livni, E., Bartoov, B., Zukerman, Z., Leiba, S. and Servadio, C. 1987. "Decreased semen quality in a male infected with malaria." International Journal of Andrology, 10: 685-689.

[6] Wilcox, Allen J., Donna Day Baird, and Clarice R. Weinberg. 1999. "Time of Implantation of the Conceptus and Loss of Pregnancy." New England Journal of Medicine, 340:1796-1799.

[7] Wilde, Joshua, Bénédicte H. Apouey, and Toni Jung. 2017. "The Effect of Ambient Temperature Shocks During Conception and Early Pregnancy on Later Life Outcomes." European Economic Review, 97C: 87-107. 
Table B.1: List of Surveys

\begin{tabular}{|c|c|c|c|}
\hline Country & Years & Regions & Surveys \\
\hline Angola & $2000-2011$ & 18 & MIS06-07, MIS11 \\
\hline Benin & 2000-2012 & 12 & DHS06, DHS11-12 \\
\hline Burkina Faso & $2000-2014$ & 13 & DHS03, DHS10, MIS14 \\
\hline Burundi & 2000-2012 & 17 & DHS10, MIS12 \\
\hline Cameroon & $2000-2011$ & 10 & DHS04, DHS11 \\
\hline Chad & $2000-2004$ & 8 & DHS04 \\
\hline Comoros & $2000-2012$ & 3 & DHS12 \\
\hline Congo (Brazzaville) & 2000-2012 & 11 & DHS05, AIS09, DHS11-12 \\
\hline Congo (DRC) & $2000-2014$ & 9 & DHS07, DHS13-14 \\
\hline Côte d'Ivoire & $2000-2012$ & 11 & AIS05, DHS11-12 \\
\hline Ethiopia & $2000-2003$ & 11 & DHS05, DHS11 \\
\hline Gabon & 2000-2012 & 9 & DHS12 \\
\hline Gambia & $2000-2013$ & 6 & DHS13 \\
\hline Ghana & $2000-2014$ & 10 & DHS03, DHS08, MICS11, DHS14 \\
\hline Guinea & $2000-2012$ & 8 & DHS05, DHS12 \\
\hline Kenya & $2000-2009$ & 8 & DHS03, DHS08-09, DHS14, MIS15 \\
\hline Lesotho & $2000-2009$ & 10 & DHS04-05, DHS09-10 \\
\hline Liberia & $2000-2013$ & 15 & DHS06-07, MIS08-09, MIS11, DHS13 \\
\hline Madagascar & $2000-2013$ & 6 & DHS03-04, DHS08-09, MIS11, MIS13 \\
\hline Malawi & $2000-2014$ & 27 & DHS04, DHS10, MIS12, MIS14 \\
\hline Mali & $2000-2012$ & 9 & DHS01, DHS06, DHS12-13 \\
\hline Mozambique & $2000-2011$ & 11 & DHS03-04, AIS09, DHS11 \\
\hline Namibia & $2000-2013$ & 13 & DHS00, DHS06-07, DHS13 \\
\hline Niger & $2000-2012$ & 8 & DHS06, DHS12 \\
\hline Nigeria & $2000-2013$ & 37 & DHS03, DHS08, MIS10, DHS13 \\
\hline Rwanda & $2000-2013$ & 5 & DHS05, DHS(I)07-08, DHS10, MIS13 \\
\hline Sao Tome & $2000-2008$ & 4 & DHS08-09 \\
\hline Senegal & $2000-2014$ & 11 & DHS05, MIS06, MIS08-09, DHS10-11, DHS12-13, DHS14 \\
\hline Sierra Leone & $2000-2013$ & 4 & DHS08, DHS13 \\
\hline Swaziland & $2000-2010$ & 4 & DHS06-07 \\
\hline Tanzania & $2000-2012$ & 9 & DHS04-05, AIS07-08, DHS09-10, AIS11-12 \\
\hline Togo & $2000-2013$ & 5 & DHS13 \\
\hline Uganda & $2000-2014$ & 4 & DHS06, MIS09-10, DHS11, MIS14-15 \\
\hline Zambia & $2000-2014$ & 9 & DHS01-02, DHS07, DHS13-14 \\
\hline Zimbabwe & $2000-2014$ & 10 & DHS05-06, DHS10-11 \\
\hline
\end{tabular}

Notes: AIS stands for AIDS Indicator Survey, DHS for Demographic and Health Survey, DHS(I) for Interim DHS, MICS for the Multiple Indicator Cluster Survey, and MIS for Malaria Indicator Survey.

Table B.2: Descriptive Statistics

\begin{tabular}{lcccc}
\hline Variable & Mean & S.d. & Min & Max \\
\hline & & & & \\
Child Mortality Equation & & & & \\
Malaria Prevalence in 2000 & 0.4117 & 0.1986 & 0.0059 & 0.8821 \\
ITN at t & 0.1652 & 0.1941 & 0 & 0.9692 \\
IRS at t & 0.0433 & 0.1006 & 0 & 1 \\
ACT at t & 0.0501 & 0.0851 & 0 & 0.5089 \\
Risk Exposure & 0.9510 & 0.1751 & 0 & 1 \\
Male & 0.5069 & 0.5001 & 0 & 9 \\
Urban & 0.2665 & 0.4421 & 0 & 1 \\
Birth Order & 3.4980 & 2.3530 & 1 & 20 \\
Mother's Age at Birth & 26.3231 & 6.6325 & 14 & 50 \\
Mother's Primary Edu & 0.5371 & 0.4986 & 0 & 1 \\
Mother's Primary Edu+ & 0.1803 & 0.3845 & 0 & 1 \\
& & & & \\
Fertility Equation & & & & \\
Malaria Prevalence in 2000 & 0.3977 & 0.2048 & 0.0059 & 0.8821 \\
ITN at t-1 & 0.1447 & 0.1846 & 0 & 0.9692 \\
IRS at t-1 & 0.0389 & 0.0930 & 0 & 0.8059 \\
ACT at t & 0.0491 & 0.0841 & 0 & 0.5089 \\
Urban & 0.3642 & 0.4812 & 0 & 1 \\
Age & 26.6729 & 7.9031 & 15 & 44 \\
Primary Edu & 0.6217 & 0.4849 & 0 & 1 \\
Secondary Edu+ & 0.2910 & 0.4542 & 0 & 1 \\
\hline & & & & \\
\hline
\end{tabular}


Table B.3: Regional Timing of ITN Distribution

\begin{tabular}{|c|c|c|c|c|c|c|c|c|c|c|}
\hline $\begin{array}{l}\text { Dependent } \\
\text { Variable }\end{array}$ & $\begin{array}{l}\text { (1) } \\
\text { Int. } \\
\text { Year }\end{array}$ & $\begin{array}{l}(2) \\
\text { Int. } \\
\text { Year }\end{array}$ & $\begin{array}{l}\text { (3) } \\
\text { Int. } \\
\text { Year }\end{array}$ & $\begin{array}{l}\text { (4) } \\
\text { Int. } \\
\text { Year }\end{array}$ & $\begin{array}{l}\text { (5) } \\
\text { Int. } \\
\text { Year }\end{array}$ & $\begin{array}{c}\text { (6) } \\
\text { Int. } \\
\text { Year }\end{array}$ & $\begin{array}{l}\text { (7) } \\
\text { Int. } \\
\text { Year }\end{array}$ & $\begin{array}{l}\text { (8) } \\
\text { Int. } \\
\text { Year }\end{array}$ & $\begin{array}{l}\text { (9) } \\
\text { Int. } \\
\text { Year }\end{array}$ & $\begin{array}{l}\text { (10) } \\
\text { Int. } \\
\text { Year }\end{array}$ \\
\hline Urban & $\begin{array}{c}0.743 \\
(0.534)\end{array}$ & & & & & & & & & $\begin{array}{c}0.375 \\
(0.592)\end{array}$ \\
\hline Radio & & $\begin{array}{c}0.781 \\
(0.807)\end{array}$ & & & & & & & & $\begin{array}{l}-0.361 \\
(0.758)\end{array}$ \\
\hline TV & & & $\begin{array}{c}1.052 \\
(0.853)\end{array}$ & & & & & & & $\begin{array}{c}3.331 \\
(2.645)\end{array}$ \\
\hline Fridge & & & & $\begin{array}{c}1.681 \\
(1.486)\end{array}$ & & & & & & $\begin{array}{l}-0.403 \\
(2.120)\end{array}$ \\
\hline Car & & & & & $\begin{array}{l}4.489^{*} \\
(2.630)\end{array}$ & & & & & $\begin{array}{c}4.521 \\
(3.678)\end{array}$ \\
\hline Electricity & & & & & & $\begin{array}{c}0.504 \\
(0.760)\end{array}$ & & & & $\begin{array}{c}-3.501 * * \\
(1.577)\end{array}$ \\
\hline Wealth & & & & & & & $\begin{array}{l}0.0856 \\
(0.172)\end{array}$ & & & $\begin{array}{c}-0.138 \\
(0.190)\end{array}$ \\
\hline Imp. water & & & & & & & & $\begin{array}{c}0.728 \\
(0.526)\end{array}$ & & $\begin{array}{c}0.850 \\
(0.802)\end{array}$ \\
\hline Imp. sanitation & & & & & & & & & $\begin{array}{c}0.726 \\
(0.876)\end{array}$ & $\begin{array}{c}-0.578 \\
(0.678)\end{array}$ \\
\hline Observations & 344 & 344 & 344 & 344 & 344 & 332 & 251 & 344 & 344 & 239 \\
\hline R-Squared & 0.760 & 0.756 & 0.759 & 0.758 & 0.761 & 0.770 & 0.734 & 0.757 & 0.756 & 0.768 \\
\hline $\begin{array}{l}\text { Effect Size } \\
(1 \mathrm{SD} \Delta)\end{array}$ & $\begin{array}{c}0.177 \\
(0.127)\end{array}$ & $\begin{array}{c}0.113 \\
(0.116)\end{array}$ & $\begin{array}{c}0.234 \\
(0.190)\end{array}$ & $\begin{array}{c}0.204 \\
(0.180)\end{array}$ & $\begin{array}{l}0.266^{*} \\
(0.156)\end{array}$ & $\begin{array}{c}0.124 \\
(0.187)\end{array}$ & $\begin{array}{c}0.065 \\
(0.130)\end{array}$ & $\begin{array}{c}0.144 \\
(0.104)\end{array}$ & $\begin{array}{c}0.154 \\
(0.185)\end{array}$ & \\
\hline
\end{tabular}

Notes: The dependent variable is an indicator for whether the ITN distribution campagin had begun in the respective region. Each covariate is the fraction of households in a region which report having the respective item or improvement, except for "Urban" which is the fraction of household in the region which are classified as residing in an urban area. Each regression includes country fixed effects. Standard errors clustered at the country level in parentheses. $* * * \mathrm{p}<0.01, * * \mathrm{p}<0.05$, $* \mathrm{p}<0.1$.

Table B.4: Falsification Tests: Other Outcomes

\begin{tabular}{|c|c|c|c|c|}
\hline Dependent Variable & $\begin{array}{c}(1) \\
\text { BCG }\end{array}$ & $\begin{array}{c}(2) \\
\text { DPT }\end{array}$ & $\begin{array}{c}\text { (3) } \\
\text { Either } \\
\text { Vaccine }\end{array}$ & $\begin{array}{c}\text { (4) } \\
\text { Worker's Visit } \\
\text { Last } 12 \text { Months }\end{array}$ \\
\hline ITN & $\begin{array}{c}0.0193 \\
(0.0248)\end{array}$ & $\begin{array}{l}-0.0540 \\
(0.0358)\end{array}$ & $\begin{array}{l}-0.0102 \\
(0.0230)\end{array}$ & $\begin{array}{c}0.0157 \\
(0.0104)\end{array}$ \\
\hline Malaria Prev. in $2000 *$ ITN & $\begin{array}{l}-0.0614 \\
(0.0855)\end{array}$ & $\begin{array}{l}-0.1036 \\
(0.1167)\end{array}$ & $\begin{array}{c}0.0040 \\
(0.0893)\end{array}$ & $\begin{array}{l}-0.0097 \\
(0.0522)\end{array}$ \\
\hline $\begin{array}{l}\text { Observations } \\
\text { R-Squared }\end{array}$ & $\begin{array}{c}524,780 \\
0.2750\end{array}$ & $\begin{array}{c}522,930 \\
0.2896\end{array}$ & $\begin{array}{c}524,862 \\
0.2706\end{array}$ & $\begin{array}{c}978,265 \\
0.0567\end{array}$ \\
\hline
\end{tabular}

Notes: All regressions include year fixed effects, region fixed effects, region time trends, and the same set of individual controls as in the main fertility regressions, as outlined in Section III. Standard errors clustered at the region level in parentheses. $* * * \mathrm{p}<0.01, * * \mathrm{p}<0.05, * \mathrm{p}<0.1$. 
Table B.5: Heterogeneous Effects of Malaria Control on Mortality by Gender

\begin{tabular}{|c|c|c|c|c|c|}
\hline & (1) & (2) & (3) & (4) & (5) \\
\hline & \multicolumn{5}{|c|}{ Months Since Birth } \\
\hline & $0-12$ & $13-24$ & $25-36$ & $37-48$ & $49-60$ \\
\hline \multicolumn{6}{|l|}{ Panel A. Females } \\
\hline Dependent Variable & Death & Death & Death & Death & Death \\
\hline Mean of Dependent Variable & 0.0658 & 0.0218 & 0.0073 & 0.0039 & 0.0027 \\
\hline ITN & $-0.0406 * * *$ & -0.0012 & $0.0062 *$ & 0.0024 & $9.23 \mathrm{e}-05$ \\
\hline & $(0.0111)$ & $(0.0063)$ & $(0.0035)$ & $(0.0029)$ & $(0.0040)$ \\
\hline Malaria Prev. in $2000 *$ ITN & 0.0025 & $-0.0263^{*}$ & -0.0105 & -0.0032 & -0.0023 \\
\hline & $(0.0217)$ & $(0.0137)$ & $(0.0073)$ & $(0.0051)$ & $(0.0070)$ \\
\hline Observations & 566,547 & 507,033 & 431,173 & 366,201 & 303,492 \\
\hline R-Squared & 0.014 & 0.013 & 0.005 & 0.003 & 0.003 \\
\hline Intervention Effect ( $\% \Delta$ from Mean) & $\begin{array}{l}0.775 \\
(6.88) \\
\end{array}$ & $\begin{array}{l}-25.11 * \\
(13.04)\end{array}$ & $\begin{array}{c}-30.06 \\
(20.89)\end{array}$ & $\begin{array}{l}-17.28 \\
(27.00)\end{array}$ & $\begin{array}{c}-17.46 \\
(54.06) \\
\end{array}$ \\
\hline \multicolumn{6}{|l|}{ Panel B. Males } \\
\hline Dependent Variable & Death & Death & Death & Death & Death \\
\hline Mean of Dependent Variable & 0.0768 & 0.0231 & 0.0080 & 0.0043 & 0.0030 \\
\hline \multirow[t]{2}{*}{ ITN } & $-0.0211 *$ & -0.0037 & $0.0133 * * *$ & 0.0020 & -0.0019 \\
\hline & $(0.0116)$ & $(0.0056)$ & $(0.0040)$ & $(0.0027)$ & $(0.0027)$ \\
\hline \multirow[t]{2}{*}{ Malaria Prev. in $2000 *$ ITN } & -0.0340 & $-0.0248 * *$ & $-0.0237 * * *$ & -0.0029 & 0.0001 \\
\hline & $(0.0219)$ & $(0.0115)$ & $(0.0065)$ & $(0.0052)$ & $(0.0049)$ \\
\hline Observations & 580,995 & 514,255 & 436,836 & 370,393 & 307,725 \\
\hline R-Squared & 0.014 & 0.013 & 0.005 & 0.003 & 0.003 \\
\hline Intervention Effect ( $\% \Delta$ from Mean) & $\begin{array}{l}-9.225 \\
(5.927)\end{array}$ & $\begin{array}{c}-22.34 * * \\
(10.35)\end{array}$ & $\begin{array}{c}-61.85^{* * *} \\
(17.08)\end{array}$ & $\begin{array}{l}-13.88 \\
(25.20)\end{array}$ & $\begin{array}{c}0.799 \\
(34.40)\end{array}$ \\
\hline
\end{tabular}

Notes: In both panels, the dependent variable is an indicator for whether a child ever born was alive in a given age range based on the DHS birth histories. All regressions include year fixed effects, region fixed effects, region time trends, and a set of individual controls as outlined in Section III. ITN refers to the fraction of individuals in a region which reported sleeping under an ITN. "Intervention Effect" is the percentage effect from the mean of the dependent variable of an increase in ITNs of 50 percentage points (the average increase between 2000 and 2015 in our data) evaluated at the mean level of malaria prevalence (approximately 40 percent). Standard errors clustered at the region level in parentheses. $* * * \mathrm{p}<0.01, * * \mathrm{p}<0.05, * \mathrm{p}<0.1$. 
Table B.6: Malaria Control and Birth Intervals

\begin{tabular}{|c|c|c|c|c|c|c|}
\hline & $(1)$ & (2) & (3) & (4) & $(5)$ & (6) \\
\hline Woman's Age & All & All & $15-19$ & $20-29$ & $30-39$ & $40-44$ \\
\hline Dependent Variable & Interval & Interval & Interval & Interval & Interval & Interval \\
\hline Mean of Dependent Variable & 34.44 & 34.44 & 25.68 & 32.95 & 37.29 & 41.35 \\
\hline ITN & $\begin{array}{c}2.430 \\
(1.895)\end{array}$ & $\begin{array}{c}1.831 \\
(1.950)\end{array}$ & $\begin{array}{c}6.498 * * \\
(2.705)\end{array}$ & $\begin{array}{c}2.802 \\
(1.874)\end{array}$ & $\begin{array}{c}-0.502 \\
(2.804)\end{array}$ & $\begin{array}{c}0.563 \\
(5.710)\end{array}$ \\
\hline Malaria Prev. in $2000 *$ ITN & $\begin{array}{l}-3.596 \\
(3.659)\end{array}$ & $\begin{array}{l}-1.140 \\
(3.925)\end{array}$ & $\begin{array}{c}-14.28 * * \\
(6.056)\end{array}$ & $\begin{array}{l}-3.761 \\
(3.769)\end{array}$ & $\begin{array}{c}7.038 \\
(5.660)\end{array}$ & $\begin{array}{c}4.722 \\
(11.83)\end{array}$ \\
\hline No Education & & $\begin{array}{c}-1.024 * * * \\
(0.250)\end{array}$ & $\begin{array}{c}1.171 * * * \\
(0.441)\end{array}$ & $\begin{array}{c}-0.171 \\
(0.256)\end{array}$ & $\begin{array}{c}-2.188 * * * \\
(0.385)\end{array}$ & $\begin{array}{r}-2.075^{* *} \\
(1.007)\end{array}$ \\
\hline Malaria Prev. in $2000 *$ No Education & & $\begin{array}{l}-0.276 \\
(0.519)\end{array}$ & $\begin{array}{c}-2.049 * * \\
(0.973)\end{array}$ & $\begin{array}{c}-1.416^{* * * *} \\
(0.529)\end{array}$ & $\begin{array}{c}1.303 \\
(0.823)\end{array}$ & $\begin{array}{c}0.867 \\
(2.220)\end{array}$ \\
\hline ITN * No Education & & $\begin{array}{c}0.996 \\
(1.167)\end{array}$ & $\begin{array}{c}-0.305 \\
(1.528)\end{array}$ & $\begin{array}{c}0.160 \\
(1.261)\end{array}$ & $\begin{array}{c}1.901 \\
(1.763)\end{array}$ & $\begin{array}{l}-4.413 \\
(4.987)\end{array}$ \\
\hline Malaria Prev. in $2000 *$ ITN * No Edu & & $\begin{array}{c}-4.283^{*} \\
(2.276)\end{array}$ & $\begin{array}{c}1.678 \\
(3.282)\end{array}$ & $\begin{array}{l}-1.372 \\
(2.377)\end{array}$ & $\begin{array}{c}-10.07 * * * \\
(3.585)\end{array}$ & $\begin{array}{c}-1.103 \\
(11.00)\end{array}$ \\
\hline Observations & 988,861 & 988,861 & 59,516 & 540,803 & 338,274 & 44,089 \\
\hline R-Squared & 0.110 & 0.110 & 0.056 & 0.081 & 0.100 & 0.112 \\
\hline Intervention Effect ( $\% \Delta$ from Mean) & $\begin{array}{l}-2.193 \\
(2.231)\end{array}$ & & & & & \\
\hline Educated Intervention Effect ( $\% \Delta$ from Mean) & & $\begin{array}{l}-0.695 \\
(2.393)\end{array}$ & $\begin{array}{c}-11.75 * * \\
(4.986)\end{array}$ & $\begin{array}{l}-2.384 \\
(2.390)\end{array}$ & $\begin{array}{c}3.982 \\
(3.203)\end{array}$ & $\begin{array}{c}2.415 \\
(6.047)\end{array}$ \\
\hline Uneducated Intervention Effect ( $\% \Delta$ from Mean) & & $\begin{array}{l}-3.306 \\
(2.260)\end{array}$ & $\begin{array}{c}-10.37 * * \\
(4.542)\end{array}$ & $\begin{array}{l}-3.255 \\
(2.359)\end{array}$ & $\begin{array}{l}-1.715 \\
(2.922)\end{array}$ & $\begin{array}{c}1.851 \\
(4.948)\end{array}$ \\
\hline
\end{tabular}

Notes: The dependent variable is the number of months since the last birth for a given woman-year for each age group. All regressions include year fixed effects, region fixed effects, region time trends, and a set of individual controls as outlined in Section III. ITN refers to the fraction of individuals in a region which reported sleeping under an ITN. "No Educ" or "Uneducated" refers to women who have not completed primary school, while "Educated" refers to women who have. "Intervention Effect" is the percentage effect from the mean of the dependent variable of an increase in ITNs of 50 percentage points (the average increase between 2000 and 2015 in our data) evaluated at the mean level of malaria prevalence (approximately 40 percent). Standard errors clustered at the region level in parentheses. $* * * \mathrm{p}<0.01, * * \mathrm{p}<0.05, * \mathrm{p}<0.1$.

Table B.7: Malaria Control and Gender Ratios

\begin{tabular}{lc}
\hline & $(1)$ \\
\hline Dependent Variable & Male \\
Mean of Dependent Variable & 0.507 \\
& \\
ITN & -0.0098 \\
& $(0.0176)$ \\
Malaria Prev. in 2000 * ITN & 0.0077 \\
& $(0.0348)$ \\
& \\
Observations & $1,331,682$ \\
R-Squared & 0.001 \\
& \\
Intervention Effect $(\% \Delta$ from Mean $)$ & 0.316 \\
& $(1.425)$ \\
\hline
\end{tabular}

Notes: The dependent variable is a dummy for whether the birth was a male. All regressions include year fixed effects, region fixed effects, region time trends, and a set of individual controls as outlined in Section III. ITN refers to the fraction of individuals in a region which reported sleeping under an ITN. "Intervention Effect" is the percentage effect from the mean of the dependent variable of an increase in ITNs of 50 percentage points (the average increase between 2000 and 2015 in our data) evaluated at the mean level of malaria prevalence (approximately 40 percent). Standard errors clustered at the region level in parentheses. *** $\mathrm{p}<0.01, * * \mathrm{p}<0.05, * \mathrm{p}<0.1$. 
Table B.8: Malaria Control and Terminations

\begin{tabular}{|c|c|c|c|c|c|c|}
\hline & $(1)$ & $(2)$ & (3) & (4) & $(5)$ & $(6)$ \\
\hline Woman's Age & All & All & $15-19$ & $20-29$ & $30-39$ & $40-44$ \\
\hline $\begin{array}{l}\text { Dependent Variable } \\
\text { Mean of Dependent Variable }\end{array}$ & $\begin{array}{c}\text { Term. } \\
0.0386\end{array}$ & $\begin{array}{c}\text { Term. } \\
0.0386\end{array}$ & $\begin{array}{c}\text { Term. } \\
0.0362\end{array}$ & $\begin{array}{l}\text { Term. } \\
0.0337\end{array}$ & $\begin{array}{c}\text { Term. } \\
0.0436\end{array}$ & $\begin{array}{l}\text { Term. } \\
0.0787\end{array}$ \\
\hline ITN & $\begin{array}{c}0.0088 \\
(0.0063)\end{array}$ & $\begin{array}{c}0.0113 \\
(0.0070)\end{array}$ & $\begin{array}{l}-0.0150 \\
(0.0115)\end{array}$ & $\begin{array}{c}0.0085 \\
(0.0073)\end{array}$ & $\begin{array}{r}0.0254 * * \\
(0.0115)\end{array}$ & $\begin{array}{c}0.0514 \\
(0.0387)\end{array}$ \\
\hline Malaria Prev. in $2000 *$ ITN & $\begin{array}{c}0.0192 \\
(0.0405)\end{array}$ & $\begin{array}{c}0.0317 \\
(0.0428)\end{array}$ & $\begin{array}{l}-0.0109 \\
(0.0879)\end{array}$ & $\begin{array}{l}0.0742 * \\
(0.0409)\end{array}$ & $\begin{array}{c}0.0246 \\
(0.0647)\end{array}$ & $\begin{array}{l}-0.2707 \\
(0.2048)\end{array}$ \\
\hline No Education & $\begin{array}{c}-0.0099 * * * \\
(0.0009)\end{array}$ & $\begin{array}{c}-0.0088^{* * * *} \\
(0.0013)\end{array}$ & $\begin{array}{c}-0.0052 * * \\
(0.0025)\end{array}$ & $\begin{array}{c}-0.0086^{* * *} \\
(0.0015)\end{array}$ & $\begin{array}{c}-0.0081^{* * *} * \\
(0.0024)\end{array}$ & $\begin{array}{c}-0.0226^{* * * *} \\
(0.0069)\end{array}$ \\
\hline Malaria Prev. in $2000 *$ No Education & & $\begin{array}{c}0.0008 \\
(0.0067)\end{array}$ & $\begin{array}{l}-0.0180 \\
(0.0132)\end{array}$ & $\begin{array}{c}0.0020 \\
(0.0075)\end{array}$ & $\begin{array}{c}0.0074 \\
(0.0114)\end{array}$ & $\begin{array}{l}-0.0038 \\
(0.0316)\end{array}$ \\
\hline ITN * No Education & & $\begin{array}{l}-0.0045 \\
(0.0042)\end{array}$ & $\begin{array}{c}0.0064 \\
(0.0080)\end{array}$ & $\begin{array}{c}0.0003 \\
(0.0051)\end{array}$ & $\begin{array}{c}-0.0206 * * * \\
(0.0079)\end{array}$ & $\begin{array}{l}-0.0219 \\
(0.0247)\end{array}$ \\
\hline Malaria Prev. in $2000 *$ ITN * No Edu & & $\begin{array}{l}-0.0271 \\
(0.0233)\end{array}$ & $\begin{array}{c}0.0657 \\
(0.0485)\end{array}$ & $\begin{array}{l}-0.0465 * \\
(0.0252)\end{array}$ & $\begin{array}{l}-0.0238 \\
(0.0400)\end{array}$ & $\begin{array}{l}-0.0889 \\
(0.1325)\end{array}$ \\
\hline $\begin{array}{l}\text { Observations } \\
\text { R-Squared }\end{array}$ & $\begin{array}{c}605,706 \\
0.0147\end{array}$ & $\begin{array}{c}605,706 \\
0.0147\end{array}$ & $\begin{array}{l}94,789 \\
0.0164\end{array}$ & $\begin{array}{c}318,893 \\
0.0129\end{array}$ & $\begin{array}{c}167,324 \\
0.0158\end{array}$ & $\begin{array}{l}24,700 \\
0.0567\end{array}$ \\
\hline Intervention Effect ( $\% \Delta$ from Mean) & $\begin{array}{c}9.9 \\
(20.9)\end{array}$ & & & & & \\
\hline Educated Intervention Effect ( $\% \Delta$ from Mean) & & $\begin{array}{c}16.4 \\
(22.2)\end{array}$ & $\begin{array}{c}-5.6 \\
(45.5)\end{array}$ & $\begin{array}{l}41.0^{*} \\
(22.6)\end{array}$ & $\begin{array}{c}14.6 \\
(38.4)\end{array}$ & $\begin{array}{l}-124.2 \\
(93.9)\end{array}$ \\
\hline Uneducated Intervention Effect ( $\% \Delta$ from Mean) & & $\begin{array}{c}2.4 \\
(18.4)\end{array}$ & $\begin{array}{c}30.3 \\
(44.2)\end{array}$ & $\begin{array}{c}16.4 \\
(20.1)\end{array}$ & $\begin{array}{c}0.4 \\
(37.9)\end{array}$ & $\begin{array}{l}-91.4 \\
(90.1)\end{array}$ \\
\hline
\end{tabular}

Notes: The dependent variable is an indicator variable for whether the woman's pregnancy ended in termination. All regressions include year fixed effects, region fixed effects, region time trends, and a set of individual controls as outlined in Section III. ITN refers to the fraction of individuals in a region which reported sleeping under an ITN. "No Educ" or "Uneducated" refers to women who have not completed primary school, while "Educated" refers to women who have. "Intervention Effect" is the percentage effect from the mean of the dependent variable of an increase in ITNs of 50 percentage points (the average increase between 2000 and 2015 in our data) evaluated at the mean level of malaria prevalence (approximately 40 percent). Standard errors clustered at the region level in parentheses. $* * * \mathrm{p}<0.01, * * \mathrm{p}<0.05, * \mathrm{p}<0.1$. 
Table B.9: Malaria Control and the Extensive Margin of Sexual Activity

\begin{tabular}{|c|c|c|c|c|c|c|}
\hline & $(1)$ & $(2)$ & $(3)$ & $(4)$ & $(5)$ & (6) \\
\hline Woman's Age & All & All & $15-19$ & $20-29$ & $30-39$ & $40-44$ \\
\hline Dependent Variable & Active & Active & Active & Active & Active & Active \\
\hline Mean of Dependent Variable & 0.433 & 0.433 & 0.189 & 0.459 & 0.538 & 0.520 \\
\hline ITN & $\begin{array}{c}-0.4808 * * * \\
(0.1643)\end{array}$ & $\begin{array}{c}-0.4985 * * * \\
(0.1597)\end{array}$ & $\begin{array}{l}-0.1015 \\
(0.0725)\end{array}$ & $\begin{array}{c}-0.7355^{* * * *} \\
(0.1701)\end{array}$ & $\begin{array}{c}-1.0541 * * * \\
(0.2283)\end{array}$ & $\begin{array}{c}-0.2453 * \\
(0.1473)\end{array}$ \\
\hline Malaria Prev. in $2000 *$ ITN & $\begin{array}{c}0.2265 \\
(0.2113)\end{array}$ & $\begin{array}{c}0.2633 \\
(0.2045)\end{array}$ & $\begin{array}{l}-0.0905 \\
(0.0955)\end{array}$ & $\begin{array}{c}0.3750 * * \\
(0.1894)\end{array}$ & $\begin{array}{c}0.6548^{* *} \\
(0.2667)\end{array}$ & $\begin{array}{c}0.0983 \\
(0.2345)\end{array}$ \\
\hline No Education & $\begin{array}{c}0.0203 * * * \\
(0.0044)\end{array}$ & $\begin{array}{c}0.0561 * * * \\
(0.0122)\end{array}$ & $\begin{array}{c}0.1469 * * * \\
(0.0250)\end{array}$ & $\begin{array}{c}0.0991 * * * \\
(0.0146)\end{array}$ & $\begin{array}{c}0.0156 \\
(0.0139)\end{array}$ & $\begin{array}{l}-0.0241 * \\
(0.0135)\end{array}$ \\
\hline Malaria Prev. in $2000 *$ No Education & & $\begin{array}{c}-0.0923 * * * \\
(0.0257)\end{array}$ & $\begin{array}{l}-0.0223 \\
(0.0485)\end{array}$ & $\begin{array}{c}-0.1501 * * * \\
(0.0326)\end{array}$ & $\begin{array}{c}-0.0962 * * * \\
(0.0296)\end{array}$ & $\begin{array}{c}-0.0241 \\
(0.0303)\end{array}$ \\
\hline ITN * No Education & & $\begin{array}{c}0.0694 \\
(0.0561)\end{array}$ & $\begin{array}{l}-0.0645 \\
(0.0702)\end{array}$ & $\begin{array}{c}0.0370 \\
(0.0620)\end{array}$ & $\begin{array}{c}0.0280 \\
(0.0486)\end{array}$ & $\begin{array}{c}0.0663 \\
(0.0492)\end{array}$ \\
\hline Malaria Prev. in $2000 *$ ITN * No Edu & & $\begin{array}{l}-0.1422 \\
(0.0979)\end{array}$ & $\begin{array}{l}-0.1240 \\
(0.1242)\end{array}$ & $\begin{array}{l}-0.0418 \\
(0.1129)\end{array}$ & $\begin{array}{c}0.0187 \\
(0.0935)\end{array}$ & $\begin{array}{l}-0.1008 \\
(0.1025)\end{array}$ \\
\hline Observations & 895,811 & 895,811 & 185,181 & 336,901 & 232,600 & 141,129 \\
\hline R-Squared & 0.1737 & 0.1741 & 0.1603 & 0.1519 & 0.1402 & 0.0903 \\
\hline Intervention Effect ( $\% \Delta$ from Mean) & $\begin{array}{c}10.27 \\
(11.01)\end{array}$ & & & & & \\
\hline Educated Intervention Effect ( $\% \Delta$ from Mean) & & $\begin{array}{l}11.94 \\
(9.28)\end{array}$ & $\begin{array}{c}-9.48 \\
(10.01)\end{array}$ & $\begin{array}{c}15.98 * * \\
(8.07)\end{array}$ & $\begin{array}{c}23.86^{* * *} \\
(9.72)\end{array}$ & $\begin{array}{c}3.73 \\
(8.90)\end{array}$ \\
\hline Uneducated Intervention Effect ( $\% \Delta$ from Mean) & & $\begin{array}{c}5.50 \\
(10.9)\end{array}$ & $\begin{array}{c}-22.48 \\
(17.4)\end{array}$ & $\begin{array}{l}14.20 \\
(9.68)\end{array}$ & $\begin{array}{c}24.54 * * \\
(9.90)\end{array}$ & $\begin{array}{l}-0.09 \\
(8.95)\end{array}$ \\
\hline
\end{tabular}

Notes: The dependent variable is an indicator variable for whether the woman was sexually active in the four weeks previous to the interview. All regressions include year fixed effects, region fixed effects, region time trends, and a set of individual controls as outlined in Section III. ITN refers to the fraction of individuals in a region which reported sleeping under an ITN. "No Educ" or "Uneducated" refers to women who have not completed primary school, while "Educated" refers to women who have. "Intervention Effect" is the percentage effect from the mean of the dependent variable of an increase in ITNs of 50 percentage points (the average increase between 2000 and 2015 in our data) evaluated at the mean level of malaria prevalence (approximately 40 percent). Standard errors clustered at the region level in parentheses. $* * * \mathrm{p}<0.01$, $* * \mathrm{p}<0.05, * \mathrm{p}<0.1$. 
Table B.10: Malaria Control and Contraceptive Use

\begin{tabular}{|c|c|c|c|c|c|c|}
\hline & $(1)$ & $(2)$ & (3) & (4) & $(5)$ & $(6)$ \\
\hline Woman's Age & All & All & $15-19$ & $20-29$ & $30-39$ & $40-44$ \\
\hline Dependent Variable & Not Using & Not Using & Not Using & Not Using & Not Using & Not Using \\
\hline Mean of Dependent Variable & 0.787 & 0.787 & 0.908 & 0.759 & 0.732 & 0.791 \\
\hline ITN & $\begin{array}{c}0.0927 * * \\
(0.0375)\end{array}$ & $\begin{array}{l}0.0735 * \\
(0.0430)\end{array}$ & $\begin{array}{c}-0.0061 \\
(0.0382)\end{array}$ & $\begin{array}{c}0.0710 \\
(0.0606)\end{array}$ & $\begin{array}{c}0.1527 * * \\
(0.0727)\end{array}$ & $\begin{array}{c}-0.0137 \\
(0.0651)\end{array}$ \\
\hline Malaria Prev. in $2000 *$ ITN & $\begin{array}{c}-0.1934 * * \\
(0.0770)\end{array}$ & $\begin{array}{c}-0.1447 * \\
(0.0843)\end{array}$ & $\begin{array}{l}-0.0405 \\
(0.0770)\end{array}$ & $\begin{array}{l}-0.1234 \\
(0.1217)\end{array}$ & $\begin{array}{c}-0.2652^{* *} \\
(0.1264)\end{array}$ & $\begin{array}{c}-0.0286 \\
(0.1191)\end{array}$ \\
\hline No Education & $\begin{array}{l}1022 * * * \\
(0.0057)\end{array}$ & $\begin{array}{c}0.0706^{* * * *} \\
(0.0094)\end{array}$ & $\begin{array}{c}0.0044 \\
(0.0101)\end{array}$ & $\begin{array}{c}0.0486 * * * \\
(0.0120)\end{array}$ & $\begin{array}{c}0.1136 * * * \\
(0.0131)\end{array}$ & $\begin{array}{c}0.1183^{* * * *} \\
(0.0106)\end{array}$ \\
\hline Malaria Prev. in $2000 *$ No Education & & $\begin{array}{c}0.0794 * * * \\
(0.0201)\end{array}$ & $\begin{array}{c}0.0891 * * * \\
(0.0219)\end{array}$ & $\begin{array}{c}0.1335 * * * \\
(0.0262)\end{array}$ & $\begin{array}{c}0.0081 \\
(0.0305)\end{array}$ & $\begin{array}{c}-0.0436 \\
(0.0267)\end{array}$ \\
\hline ITN $*$ No Education & & $\begin{array}{c}0.0481 \\
(0.0682)\end{array}$ & $\begin{array}{c}-0.0563^{*} \\
(0.0329)\end{array}$ & $\begin{array}{c}0.0854 \\
(0.0869)\end{array}$ & $\begin{array}{c}0.1029 \\
(0.0907)\end{array}$ & $\begin{array}{c}0.1391 \\
(0.0858)\end{array}$ \\
\hline Malaria Prev. in $2000 *$ ITN * No Edu & & $\begin{array}{l}-0.1191 \\
(0.1260)\end{array}$ & $\begin{array}{c}0.1527 * * \\
(0.0729)\end{array}$ & $\begin{array}{l}-0.2175 \\
(0.1619)\end{array}$ & $\begin{array}{l}-0.2538 \\
(0.1676)\end{array}$ & $\begin{array}{c}-0.2691 * \\
(0.1589)\end{array}$ \\
\hline Observations & 762,441 & 762,441 & 150,440 & 283,252 & 201,812 & 126,937 \\
\hline R-Squared & 0.1407 & 0.1408 & 0.1142 & 0.1397 & 0.1557 & 0.1369 \\
\hline Intervention Effect ( $\% \Delta$ from Mean) & $\begin{array}{c}-4.82 * * \\
(1.92)\end{array}$ & & & & & \\
\hline Educated Intervention Effect ( $\% \Delta$ from Mean) & & $\begin{array}{c}-3.61^{*} \\
(2.10)\end{array}$ & $\begin{array}{l}-0.88 \\
(1.68)\end{array}$ & $\begin{array}{l}-3.17 \\
(3.13)\end{array}$ & $\begin{array}{c}-7.09 * * \\
(3.38)\end{array}$ & $\begin{array}{l}-0.71 \\
(2.97)\end{array}$ \\
\hline Uneducated Intervention Effect ( $\% \Delta$ from Mean) & & $\begin{array}{c}-6.58 * * \\
(2.96)\end{array}$ & $\begin{array}{c}2.45 \\
(1.90)\end{array}$ & $\begin{array}{c}-8.76^{* * *} \\
(4.18)\end{array}$ & $\begin{array}{c}-13.88 * * * \\
(4.02)\end{array}$ & $\begin{array}{c}-7.41 * * \\
(2.90)\end{array}$ \\
\hline
\end{tabular}

Notes: The dependent variable is an indicator variable which takes a value of 1 if the woman reports not using contraception, either modern or traditional. All regressions include year fixed effects, region fixed effects, region time trends, and a set of individual controls as outlined in Section III. ITN refers to the fraction of individuals in a region which reported sleeping under an ITN. "No Educ" or "Uneducated" refers to women who have not completed primary school, while "Educated" refers to women who have. "Intervention Effect" is the percentage effect from the mean of the dependent variable of an increase in ITNs of 50 percentage points (the average increase between 2000 and 2015 in our data) evaluated at the mean level of malaria prevalence (approximately 40 percent). Standard errors clustered at the region level in parentheses. $* * * \mathrm{p}<0.01, * * \mathrm{p}<0.05, * \mathrm{p}<0.1$. 
Table B.11: Malaria Control and Fertility Desires: Whether Wants Another Child

\begin{tabular}{|c|c|c|c|c|c|c|}
\hline & $(1)$ & $(2)$ & (3) & (4) & $(5)$ & (6) \\
\hline Woman's Age & All & All & $15-19$ & $20-29$ & $30-39$ & $40-44$ \\
\hline \multirow[t]{2}{*}{ Dependent Variable } & Wants & Wants & Wants & Wants & Wants & Wants \\
\hline & Child & Child & Child & Child & Child & Child \\
\hline Mean of Dependent Variable & 0.553 & 0.553 & 0.673 & 0.683 & 0.485 & 0.199 \\
\hline \multirow[t]{2}{*}{ ITN } & $0.3916 * *$ & $0.3937 * *$ & $0.7661 * *$ & 0.3094 & 0.0100 & 0.0689 \\
\hline & $(0.1876)$ & $(0.1851)$ & $(0.3664)$ & $(0.2594)$ & $(0.1730)$ & $(0.0535)$ \\
\hline \multirow[t]{2}{*}{ Malaria Prev. in $2000 *$ ITN } & $-0.9655^{* * *}$ & $-0.9349 * * *$ & $-1.1436^{* *}$ & $-1.0848 * * *$ & $-0.5674 * * *$ & $-0.1578 *$ \\
\hline & $(0.2375)$ & $(0.2360)$ & $(0.4521)$ & $(0.3069)$ & $(0.2091)$ & $(0.0915)$ \\
\hline \multirow[t]{2}{*}{ No Education } & 0.0036 & 0.0023 & 0.0142 & -0.0081 & 0.0085 & 0.0114 \\
\hline & $(0.0033)$ & $(0.0126)$ & $(0.0170)$ & $(0.0139)$ & $(0.0159)$ & $(0.0134)$ \\
\hline \multirow[t]{2}{*}{ Malaria Prev. in $2000 *$ No Education } & & 0.0242 & 0.0483 & 0.0337 & 0.0180 & 0.0051 \\
\hline & & $(0.0267)$ & $(0.0322)$ & $(0.0282)$ & $(0.0333)$ & $(0.0302)$ \\
\hline \multirow[t]{2}{*}{ ITN $*$ No Education } & & -0.0106 & -0.0293 & 0.0160 & -0.0657 & $-0.0978 *$ \\
\hline & & $(0.0450)$ & $(0.0724)$ & $(0.0496)$ & $(0.0555)$ & $(0.0540)$ \\
\hline \multirow[t]{2}{*}{ Malaria Prev. in $2000 *$ ITN * No Edu } & & -0.0560 & -0.0361 & -0.1215 & 0.0005 & 0.0770 \\
\hline & & $(0.0919)$ & $(0.1320)$ & $(0.1007)$ & $(0.1108)$ & $(0.1082)$ \\
\hline Observations & 895,811 & 895,811 & 185,181 & 336,901 & 232,600 & 141,129 \\
\hline R-Squared & 0.3424 & 0.3424 & 0.4550 & 0.3509 & 0.2214 & 0.1097 \\
\hline Intervention Effect ( $\% \Delta$ from Mean) & $\begin{array}{c}-34.33^{* * *} * \\
(8.44)\end{array}$ & & & & & \\
\hline Educated Intervention Effect ( $\% \Delta$ from Mean) & & $\begin{array}{c}-33.24 * * * \\
(8.39)\end{array}$ & $\begin{array}{c}-33.76^{* *} \\
(13.35)\end{array}$ & $\begin{array}{c}-31.07 * * * \\
(8.79)\end{array}$ & $\begin{array}{c}-22.96 * * * \\
(8.46)\end{array}$ & $\begin{array}{c}-15.67^{*} \\
(9.08)\end{array}$ \\
\hline Uneducated Intervention Effect ( $\% \Delta$ from Mean) & & $\begin{array}{c}-35.23 * * * \\
(8.93)\end{array}$ & $\begin{array}{c}-34.82 * * \\
(13.68)\end{array}$ & $\begin{array}{c}-34.55 * * * \\
(9.55)\end{array}$ & $\begin{array}{c}-22.94 * * \\
(9.63)\end{array}$ & $\begin{array}{l}-8.030 \\
(10.24)\end{array}$ \\
\hline
\end{tabular}

Notes: The dependent variable is an indicator variable which takes a value of 1 if the woman reports wanting another child. All regressions include year fixed effects, region fixed effects, region time trends, and a set of individual controls as outlined in Section III. ITN refers to the fraction of individuals in a region which reported sleeping under an ITN. "No Educ" or "Uneducated" refers to women who have not completed primary school, while "Educated" refers to women who have. "Intervention Effect" is the percentage effect from the mean of the dependent variable of an increase in ITNs of 50 percentage points (the average increase between 2000 and 2015 in our data) evaluated at the mean level of malaria prevalence (approximately 40 percent). Standard errors clustered at the region level in parentheses. $* * * \mathrm{p}<0.01$, $* *$ $\mathrm{p}<0.05, * \mathrm{p}<0.1$. 
Table B.12: Heterogeneous Fertility Effects by Whether a Woman Ever Has a Say in Major Household Decisions

\begin{tabular}{|c|c|c|c|c|c|}
\hline & (1) & (2) & (3) & (4) & (5) \\
\hline Woman's Age & All & $15-19$ & $20-29$ & $30-39$ & $40-44$ \\
\hline Dependent Variable & Birth & Birth & Birth & Birth & Birth \\
\hline Mean of Dependent Variable & 0.218 & 0.199 & 0.266 & 0.198 & 0.0905 \\
\hline ITN & $\begin{array}{c}0.0806 * * * \\
(0.0307)\end{array}$ & $\begin{array}{l}0.0647^{*} \\
(0.0335)\end{array}$ & $\begin{array}{c}0.0052 \\
(0.0442)\end{array}$ & $\begin{array}{l}-0.0162 \\
(0.0344)\end{array}$ & $\begin{array}{l}-0.0292 \\
(0.0319)\end{array}$ \\
\hline Malaria Prev. in $2000 *$ ITN & $\begin{array}{c}0.0483 \\
(0.0604)\end{array}$ & $\begin{array}{c}0.0562 \\
(0.0747)\end{array}$ & $\begin{array}{c}0.0485 \\
(0.0931)\end{array}$ & $\begin{array}{c}0.0350 \\
(0.0700)\end{array}$ & $\begin{array}{c}0.0704 \\
(0.0662)\end{array}$ \\
\hline Ever Say & $\begin{array}{c}0.0317 * * * \\
(0.0074)\end{array}$ & $\begin{array}{c}0.0516 * * * \\
(0.0082)\end{array}$ & $\begin{array}{c}0.0258 * * * \\
(0.0077)\end{array}$ & $\begin{array}{c}-0.0149 * * * \\
(0.0046)\end{array}$ & $\begin{array}{l}-0.0103^{*} \\
(0.0055)\end{array}$ \\
\hline Malaria Prev. in $2000 *$ Ever Say & $\begin{array}{c}-0.0451 * * * \\
(0.0137)\end{array}$ & $\begin{array}{c}-0.0102 \\
(0.0159)\end{array}$ & $\begin{array}{c}-0.0458 * * * \\
(0.0143)\end{array}$ & $\begin{array}{c}0.0001 \\
(0.0083)\end{array}$ & $\begin{array}{c}-0.0081 \\
(0.0115)\end{array}$ \\
\hline ITN * Ever Say & $\begin{array}{c}-0.1059 * * * \\
(0.0230)\end{array}$ & $\begin{array}{c}-0.1272 * * * \\
(0.0324)\end{array}$ & $\begin{array}{c}-0.0912 * * * \\
(0.0247)\end{array}$ & $\begin{array}{c}-0.0274 \\
(0.0185)\end{array}$ & $\begin{array}{l}-0.0226 \\
(0.0202)\end{array}$ \\
\hline Malaria Prev. in $2000 *$ ITN * Ever Say & $\begin{array}{c}0.1050 * * \\
(0.0433)\end{array}$ & $\begin{array}{c}0.0737 \\
(0.0653)\end{array}$ & $\begin{array}{c}0.1437 * * * \\
(0.0482)\end{array}$ & $\begin{array}{c}0.0834 * * \\
(0.0351)\end{array}$ & $\begin{array}{l}0.0696 * \\
(0.0418)\end{array}$ \\
\hline $\begin{array}{l}\text { Observations } \\
\text { R-Squared }\end{array}$ & $\begin{array}{c}3,723,356 \\
0.0380\end{array}$ & $\begin{array}{c}583,334 \\
0.0625\end{array}$ & $\begin{array}{c}1,625,953 \\
0.0176\end{array}$ & $\begin{array}{c}1,180,371 \\
0.0256\end{array}$ & $\begin{array}{c}333,698 \\
0.0251\end{array}$ \\
\hline Never Say Intervention Effect ( $\% \Delta$ from Mean) & $\begin{array}{c}4.64 \\
(5.800)\end{array}$ & $\begin{array}{c}5.935 \\
(7.883)\end{array}$ & $\begin{array}{c}3.823 \\
(7.336)\end{array}$ & $\begin{array}{c}3.704 \\
(7.418)\end{array}$ & $\begin{array}{c}16.08 \\
(15.11)\end{array}$ \\
\hline Ever Say Intervention Effect ( $\% \Delta$ from Mean) & $\begin{array}{c}14.73 * * * \\
(3.848)\end{array}$ & $\begin{array}{c}13.71 \\
(8.819)\end{array}$ & $\begin{array}{c}15.15 * * * \\
(5.875)\end{array}$ & $\begin{array}{l}12.53^{*} \\
(6.587)\end{array}$ & $\begin{array}{c}31.98 * * \\
(12.64)\end{array}$ \\
\hline
\end{tabular}

Notes: The dependent variable is an indicator for whether the woman had a live birth within the last 12 months for a given woman-year by age group. "Ever Say" is an indicator variable which takes the value of one if a woman reported having at least partial say on any of six household decisions. The six decisions are: decisions on her own health care, making large household purchases, making household purchases for daily needs, visits to family or relatives, food to be cooked each day, or what to do with money her husband earns. All regressions include year fixed effects, region fixed effects, region time trends, and a set of individual controls as outlined in Section III. ITN refers to the fraction of individuals in a region which reported sleeping under an ITN. "No Educ" or "Uneducated" refers to women who have not completed primary school, while "Educated" refers to women who have. "Intervention Effect" is the percentage effect from the mean of the dependent variable of an increase in ITNs of 50 percentage points (the average increase between 2000 and 2015 in our data) evaluated at the mean level of malaria prevalence (approximately 40 percent). Standard errors clustered at the region level in parentheses. $* * * \mathrm{p}<0.01, * * \mathrm{p}<0.05, * \mathrm{p}<0.1$. 
Table B.13: Heterogeneous Fertility Effects by Unmet Need

\begin{tabular}{|c|c|c|c|c|c|}
\hline & (1) & (2) & (3) & (4) & (5) \\
\hline Woman's Age & All & $15-19$ & $20-29$ & $30-39$ & $40-44$ \\
\hline Dependent Variable & Birth & Birth & Birth & Birth & Birth \\
\hline Mean of Dependent Variable & 0.185 & 0.128 & 0.236 & 0.184 & 0.0821 \\
\hline ITN & $\begin{array}{l}-0.0277 \\
(0.0192)\end{array}$ & $\begin{array}{c}-0.0405^{* *} \\
(0.0183)\end{array}$ & $\begin{array}{c}-0.0857 * * * \\
(0.0300)\end{array}$ & $\begin{array}{c}-0.0718 * * * \\
(0.0269)\end{array}$ & $\begin{array}{c}-0.0690 * * * \\
(0.0205)\end{array}$ \\
\hline Malaria Prev. in $2000 *$ ITN & $\begin{array}{c}0.1789 * * * \\
(0.0335)\end{array}$ & $\begin{array}{c}0.1287 * * * \\
(0.0380)\end{array}$ & $\begin{array}{c}0.2092 * * * \\
(0.0609)\end{array}$ & $\begin{array}{c}0.1769 * * * \\
(0.0540)\end{array}$ & $\begin{array}{c}0.1736 * * * \\
(0.0442)\end{array}$ \\
\hline No Education & $\begin{array}{c}0.0371 * * * \\
(0.0016)\end{array}$ & $\begin{array}{c}0.0694 * * * \\
(0.0021)\end{array}$ & $\begin{array}{c}0.0377 * * * \\
(0.0018)\end{array}$ & $\begin{array}{c}0.0179 * * * \\
(0.0016)\end{array}$ & $\begin{array}{c}0.0136 * * * \\
(0.0016)\end{array}$ \\
\hline Unmet Need & $\begin{array}{c}0.0671 * * * \\
(0.0046)\end{array}$ & $\begin{array}{c}0.0772 * * * \\
(0.0061)\end{array}$ & $\begin{array}{c}0.0671 * * * \\
(0.0054)\end{array}$ & $\begin{array}{c}0.0591 * * * \\
(0.0040)\end{array}$ & $\begin{array}{c}0.0374 * * * \\
(0.0044)\end{array}$ \\
\hline Malaria Prev. in $2000 *$ Unmet Need & $\begin{array}{c}-0.0250^{* * * *} \\
(0.0092)\end{array}$ & $\begin{array}{l}-0.0056 \\
(0.0124)\end{array}$ & $\begin{array}{c}-0.0254 * * \\
(0.0108)\end{array}$ & $\begin{array}{c}-0.0236^{* * * *} \\
(0.0083)\end{array}$ & $\begin{array}{c}-0.0218 * * \\
(0.0095)\end{array}$ \\
\hline ITN $*$ Unmet Need & $\begin{array}{c}0.0574 * * * \\
(0.0156)\end{array}$ & $\begin{array}{c}0.1010 * * * \\
(0.0292)\end{array}$ & $\begin{array}{c}0.0593 * * * \\
(0.0224)\end{array}$ & $\begin{array}{c}0.0662 * * * \\
(0.0142)\end{array}$ & $\begin{array}{c}0.0169 \\
(0.0150)\end{array}$ \\
\hline Malaria Prev. in $2000 *$ ITN * Unmet Need & $\begin{array}{c}-0.2025 * * * \\
(0.0352)\end{array}$ & $\begin{array}{c}-0.2932 * * * \\
(0.0599)\end{array}$ & $\begin{array}{c}-0.1865^{* * *} * \\
(0.0475)\end{array}$ & $\begin{array}{c}-0.1875 * * * \\
(0.0362)\end{array}$ & $\begin{array}{c}-0.0744 * * \\
(0.0344)\end{array}$ \\
\hline Observations & $4,942,962$ & $1,078,373$ & $2,047,482$ & $1,405,657$ & 411,450 \\
\hline R-Squared & 0.0527 & 0.0899 & 0.0308 & 0.0304 & 0.0269 \\
\hline No Unmet Need Intervention Effect ( $\% \Delta$ from Mean) & $\begin{array}{c}16.70 * * * \\
(3.689)\end{array}$ & $\begin{array}{c}20.37 * * * \\
(6.014)\end{array}$ & $\begin{array}{c}18.02 * * * \\
(5.242)\end{array}$ & $\begin{array}{c}19.68 * * * \\
(6.007)\end{array}$ & $\begin{array}{c}42.59 * * * \\
(10.84)\end{array}$ \\
\hline Unmet Need Intervention Effect ( $\% \Delta$ from Mean) & $\begin{array}{c}-2.21 \\
(4.952)\end{array}$ & $\begin{array}{c}-26.04 * * \\
(10.21)\end{array}$ & $\begin{array}{c}1.953 \\
(6.563)\end{array}$ & $\begin{array}{l}-1.185 \\
(7.528)\end{array}$ & $\begin{array}{c}24.33 * * \\
(12.33)\end{array}$ \\
\hline
\end{tabular}

Notes: The dependent variable is an indicator for whether the woman had a live birth within the last 12 months for a given woman-year by age group. "Unmet Need" is an indicator variable which takes the value of one if a woman reports she is sexually active, not using birth control, and does not want more children. All regressions include year fixed effects, region fixed effects, region time trends, and a set of individual controls as outlined in Section III. ITN refers to the fraction of individuals in a region which reported sleeping under an ITN. "No Educ" or "Uneducated" refers to women who have not completed primary school, while "Educated" refers to women who have. "Intervention Effect" is the percentage effect from the mean of the dependent variable of an increase in ITNs of 50 percentage points (the average increase between 2000 and 2015 in our data) evaluated at the mean level of malaria prevalence (approximately 40 percent). Standard errors clustered at the region level in parentheses. $* * * \mathrm{p}<0.01, * * \mathrm{p}<0.05, * \mathrm{p}<0.1$. 
Table B.14: Heterogeneous Fertility Effects by Anemia Status

\begin{tabular}{|c|c|c|c|c|c|}
\hline & $(1)$ & $(2)$ & (3) & (4) & $(5)$ \\
\hline Woman's Age & All & $15-19$ & $20-29$ & $30-39$ & $40-44$ \\
\hline Dependent Variable & Birth & Birth & Birth & Birth & Birth \\
\hline Mean of Dependent Variable & 0.182 & 0.125 & 0.234 & 0.182 & 0.0822 \\
\hline ITN & $\begin{array}{c}-0.0640 * * \\
(0.0287)\end{array}$ & $\begin{array}{c}-0.0693 * * \\
(0.0281)\end{array}$ & $\begin{array}{c}-0.1535^{* * * *} \\
(0.0490)\end{array}$ & $\begin{array}{c}-0.1454 * * * \\
(0.0441)\end{array}$ & $\begin{array}{c}-0.0851^{* * * *} \\
(0.0306)\end{array}$ \\
\hline Malaria Prev. in $2000 *$ ITN & $\begin{array}{c}0.2583 * * * \\
(0.0470)\end{array}$ & $\begin{array}{c}0.1579 * * * \\
(0.0560)\end{array}$ & $\begin{array}{c}0.3216^{* * *} \\
(0.0908)\end{array}$ & $\begin{array}{c}0.2701 * * * \\
(0.0871)\end{array}$ & $\begin{array}{c}0.1797 * * * \\
(0.0597)\end{array}$ \\
\hline No Education & $\begin{array}{c}0.0370 * * * \\
(0.0017)\end{array}$ & $\begin{array}{c}0.0654 * * * \\
(0.0026)\end{array}$ & $\begin{array}{c}0.0378 * * * \\
(0.0021)\end{array}$ & $\begin{array}{c}0.0184 * * * \\
(0.0018)\end{array}$ & $\begin{array}{c}0.0149 * * * \\
(0.0022)\end{array}$ \\
\hline Anemic & $\begin{array}{c}-0.0188 * * * \\
(0.0028)\end{array}$ & $\begin{array}{l}-0.0036 \\
(0.0045)\end{array}$ & $\begin{array}{c}-0.0282 * * * \\
(0.0042)\end{array}$ & $\begin{array}{c}-0.0187 * * * \\
(0.0045)\end{array}$ & $\begin{array}{c}-0.0114 * * \\
(0.0049)\end{array}$ \\
\hline Malaria Prev. in $2000 *$ Anemic & $\begin{array}{c}0.0289 * * * \\
(0.0060)\end{array}$ & $\begin{array}{l}-0.0062 \\
(0.0095)\end{array}$ & $\begin{array}{c}0.0451 * * * \\
(0.0086)\end{array}$ & $\begin{array}{c}0.0283 * * * \\
(0.0093)\end{array}$ & $\begin{array}{c}0.0244 * * \\
(0.0118)\end{array}$ \\
\hline ITN $*$ Anemic & $\begin{array}{c}0.0620 * * * \\
(0.0168)\end{array}$ & $\begin{array}{c}0.0094 \\
(0.0234)\end{array}$ & $\begin{array}{c}0.0831 * * * \\
(0.0245)\end{array}$ & $\begin{array}{c}0.0617 * * \\
(0.0305)\end{array}$ & $\begin{array}{c}0.0090 \\
(0.0278)\end{array}$ \\
\hline Malaria Prev. in $2000 *$ ITN * Anemic & $\begin{array}{c}-0.1432 * * * \\
(0.0345)\end{array}$ & $\begin{array}{c}0.0090 \\
(0.0473)\end{array}$ & $\begin{array}{c}-0.2256 * * * \\
(0.0508)\end{array}$ & $\begin{array}{c}-0.1675 * * * \\
(0.0614)\end{array}$ & $\begin{array}{l}-0.0724 \\
(0.0559)\end{array}$ \\
\hline Observations & $1,844,190$ & 403,762 & 758,180 & 524,509 & 157,739 \\
\hline R-Squared & 0.0503 & 0.0848 & 0.0295 & 0.0291 & 0.0270 \\
\hline Not Anemic Intervention Effect ( $\% \Delta$ from Mean) & $\begin{array}{c}23.49 * * * \\
(5.107)\end{array}$ & $\begin{array}{c}24.82 * * * \\
(8.794)\end{array}$ & $\begin{array}{c}27.27 * * * \\
(7.702)\end{array}$ & $\begin{array}{c}29.76^{* * * *} \\
(9.592)\end{array}$ & $\begin{array}{c}42.41^{* * * *} \\
(14.09)\end{array}$ \\
\hline Anemic Intervention Effect ( $\% \Delta$ from Mean) & $\begin{array}{l}10.47 * * \\
(5.082)\end{array}$ & $\begin{array}{c}26.23 * * * \\
(10.06)\end{array}$ & $\begin{array}{c}8.144 \\
(7.643)\end{array}$ & $\begin{array}{c}11.31 \\
(10.75)\end{array}$ & $\begin{array}{c}25.33 \\
(17.72)\end{array}$ \\
\hline
\end{tabular}

Notes: The dependent variable is an indicator for whether the woman had a live birth within the last 12 months for a given woman-year by age group. "Anemic" is an indicator variable which takes the value of one if a woman's blood test indicates she is either moderately or severely anemic. All regressions include year fixed effects, region fixed effects, region time trends, and a set of individual controls as outlined in Section III. ITN refers to the fraction of individuals in a region which reported sleeping under an ITN. "No Educ" or "Uneducated" refers to women who have not completed primary school, while "Educated" refers to women who have. "Intervention Effect" is the percentage effect from the mean of the dependent variable of an increase in ITNs of 50 percentage points (the average increase between 2000 and 2015 in our data) evaluated at the mean level of malaria prevalence (approximately 40 percent). Standard errors clustered at the region level in parentheses. $* * *$ $\mathrm{p}<0.01, * * \mathrm{p}<0.05, * \mathrm{p}<0.1$ 
Table B.15: Heterogeneous Fertility Effects by Underweight Status

\begin{tabular}{|c|c|c|c|c|c|}
\hline & (1) & (2) & (3) & (4) & $(5)$ \\
\hline Woman's Age & All & $15-19$ & $20-29$ & $30-39$ & $40-44$ \\
\hline Dependent Variable & Birth & Birth & Birth & Birth & Birth \\
\hline Mean of Dependent Variable & 0.185 & 0.129 & 0.236 & 0.182 & 0.0806 \\
\hline ITN & $\begin{array}{l}-0.0204 \\
(0.0205)\end{array}$ & $\begin{array}{l}-0.0268 \\
(0.0235)\end{array}$ & $\begin{array}{l}-0.0528 \\
(0.0331)\end{array}$ & $\begin{array}{l}-0.0370 \\
(0.0306)\end{array}$ & $\begin{array}{l}-0.0270 \\
(0.0258)\end{array}$ \\
\hline Malaria Prev. in $2000 *$ ITN & $\begin{array}{c}0.0698 * * \\
(0.0325)\end{array}$ & $\begin{array}{c}0.0639 \\
(0.0467)\end{array}$ & $\begin{array}{c}0.0895 \\
(0.0619)\end{array}$ & $\begin{array}{c}0.0510 \\
(0.0616)\end{array}$ & $\begin{array}{c}0.0496 \\
(0.0538)\end{array}$ \\
\hline No Education & $\begin{array}{c}0.0406 * * * \\
(0.0018)\end{array}$ & $\begin{array}{c}0.0768 * * * \\
(0.0028)\end{array}$ & $\begin{array}{c}0.0411 \text { *** } \\
(0.0022)\end{array}$ & $\begin{array}{c}0.0211 * * * \\
(0.0019)\end{array}$ & $\begin{array}{c}0.0151^{* * * *} \\
(0.0020)\end{array}$ \\
\hline Underweight & $\begin{array}{c}0.0015 \\
(0.0032)\end{array}$ & $\begin{array}{l}-0.0035 \\
(0.0032)\end{array}$ & $\begin{array}{c}0.0028 \\
(0.0039)\end{array}$ & $\begin{array}{c}0.0039 \\
(0.0053)\end{array}$ & $\begin{array}{l}-0.0013 \\
(0.0040)\end{array}$ \\
\hline Malaria Prev. in $2000 *$ Underweight & $\begin{array}{c}-0.0260 * * * \\
(0.0063)\end{array}$ & $\begin{array}{c}-0.0329 * * * \\
(0.0071)\end{array}$ & $\begin{array}{c}-0.0224 * * * \\
(0.0085)\end{array}$ & $\begin{array}{l}-0.0206^{*} \\
(0.0107)\end{array}$ & $\begin{array}{l}-0.0150 \\
(0.0094)\end{array}$ \\
\hline ITN * Underweight & $\begin{array}{l}-0.0209 \\
(0.0183)\end{array}$ & $\begin{array}{l}-0.0125 \\
(0.0137)\end{array}$ & $\begin{array}{l}-0.0117 \\
(0.0297)\end{array}$ & $\begin{array}{c}0.0125 \\
(0.0236)\end{array}$ & $\begin{array}{l}-0.0067 \\
(0.0253)\end{array}$ \\
\hline Malaria Prev in $2000 *$ ITN $*$ Underweight & $\begin{array}{c}0.0549 \\
(0.0374)\end{array}$ & $\begin{array}{c}0.0925^{* * * *} \\
(0.0317)\end{array}$ & $\begin{array}{c}0.0640 \\
(0.0620)\end{array}$ & $\begin{array}{c}0.0063 \\
(0.0482)\end{array}$ & $\begin{array}{c}0.0675 \\
(0.0539)\end{array}$ \\
\hline Observations & $3,297,004$ & 713,916 & $1,365,493$ & 939,734 & 277,861 \\
\hline R-Squared & 0.0495 & 0.0853 & 0.0275 & 0.0276 & 0.0258 \\
\hline Not Underweight Intervention Effect ( $\% \Delta$ from Mean) & $\begin{array}{c}6.82 \\
(3.556)\end{array}$ & $\begin{array}{c}9.941 \\
(7.264)\end{array}$ & $\begin{array}{c}7.640 \\
(5.285)\end{array}$ & $\begin{array}{c}5.686 \\
(6.868)\end{array}$ & $\begin{array}{c}12.41 \\
(13.45)\end{array}$ \\
\hline Underweight Intervention Effect ( $\% \Delta$ from Mean) & $\begin{array}{l}12.19 * * \\
(5.656)\end{array}$ & $\begin{array}{c}24.32 * * * \\
(7.511)\end{array}$ & $\begin{array}{c}13.10 \\
(8.136)\end{array}$ & $\begin{array}{c}6.384 \\
(9.080)\end{array}$ & $\begin{array}{c}29.30 \\
(18.81)\end{array}$ \\
\hline
\end{tabular}

Notes: The dependent variable is an indicator for whether the woman had a live birth within the last 12 months for a given woman-year by age group. "Underweight" is an indicator variable which takes the value of one if a woman's measured weight and height yield a BMI of less than 18.5. All regressions include year fixed effects, region fixed effects, region time trends, and a set of individual controls as outlined in Section III. ITN refers to the fraction of individuals in a region which reported sleeping under an ITN. "No Educ" or "Uneducated" refers to women who have not completed primary school, while "Educated" refers to women who have. "Intervention Effect" is the percentage effect from the mean of the dependent variable of an increase in ITNs of 50 percentage points (the average increase between 2000 and 2015 in our data) evaluated at the mean level of malaria prevalence (approximately 40 percent). Standard errors clustered at the region level in parentheses. $* * *$ $\mathrm{p}<0.01, * * \mathrm{p}<0.05, * \mathrm{p}<0.1$. 
Figure B.1: Bed Net Usage by Education Group in the DHS

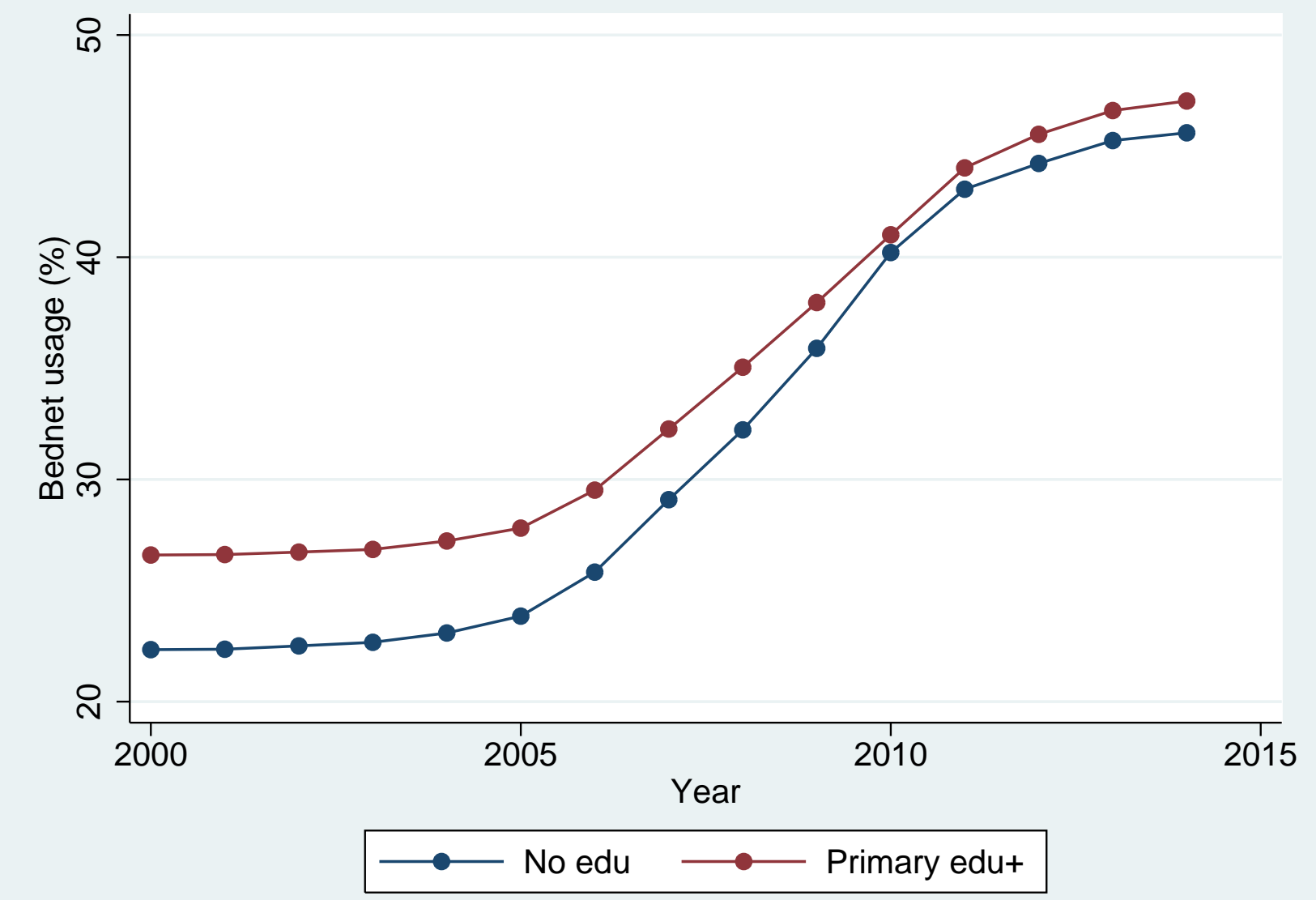

Notes: We plot reported bed net usage rates from the DHS data by education group against time. For years in which there was no DHS survey available, we use geometric interpolation between DHS survey years at the country level. 
Figure B.2: Mortality Autor - 13-24 months

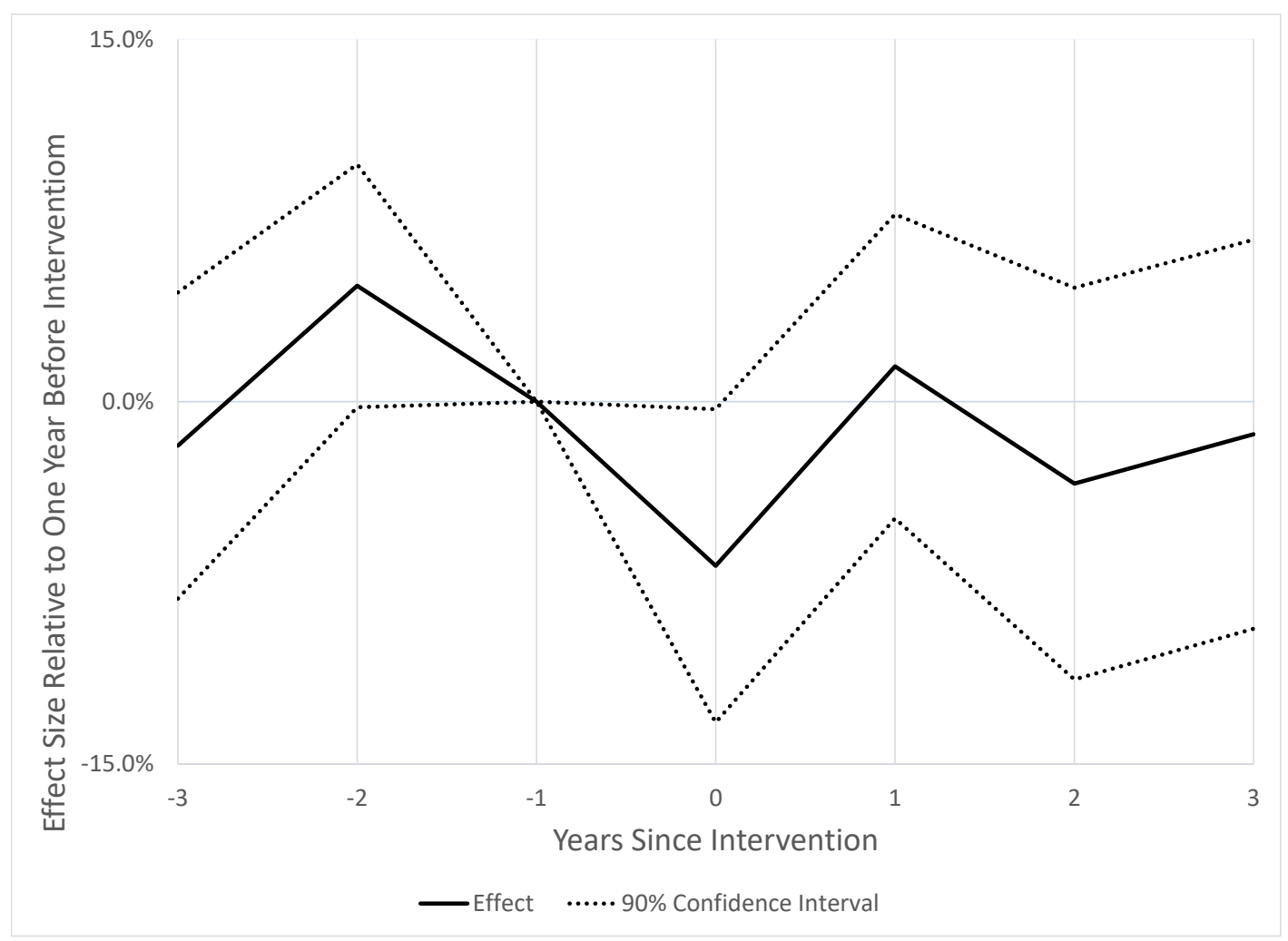

Notes: The figure shows the triple interaction coefficients from a regression which re-estimates the 13-24 month mortality regression reported in Table 3, Panel A, Column 2, but instead of using regional time trends, includes triple interactions with leads and lags of the ITN variable. 
Figure B.3: Mortality Autor - 25-36 months

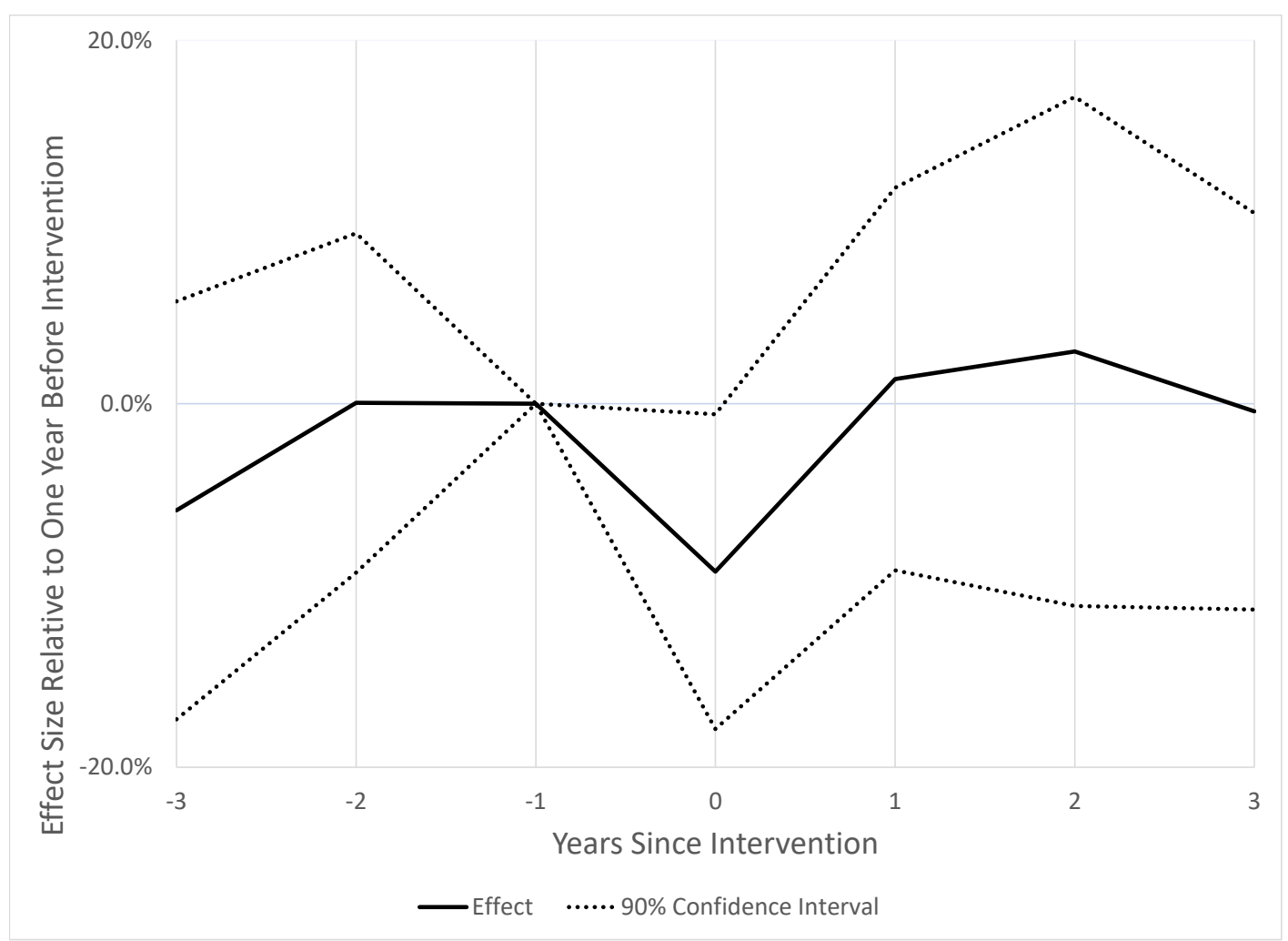

Notes: The figure shows the triple interaction coefficients from a regression which re-estimates the 25-36 month mortality regression reported in Table 3, Panel A, Column 3, but instead of using regional time trends, includes triple interactions with leads and lags of the ITN variable. 
Figure B.4: Fertility Autor - Uneducated

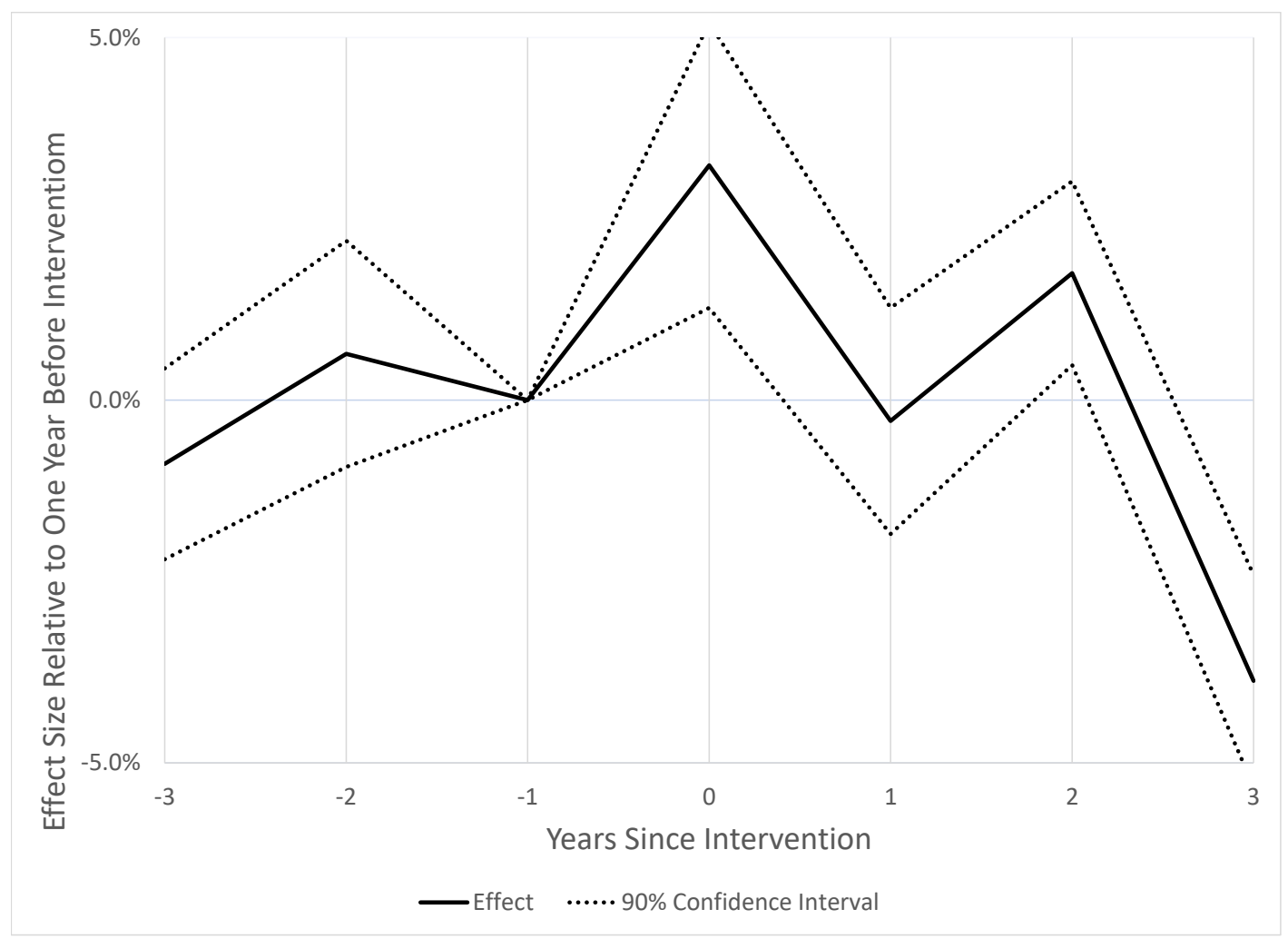

Notes: The figure plots the triple interaction coefficients from a regression which re-estimates the fertility regression reported in Table 3, Panel $\mathrm{B}$, Column 1, but instead of using regional time trends, includes triple interactions with leads and lags of the ITN variable. The regression only includes women who do not have at least a primary education. 